\author{
Aus der Abteilung \\ Zahnerhaltung, Präventive Zahnheilkunde und Parodontologie \\ (Ehem. Leiter: Prof. Dr. med. dent. T. Attin) \\ im Zentrum Zahn-, Mund- und Kieferheilkunde \\ der Medizinischen Fakultät der Universität Göttingen
}

\title{
Fluoridabgabe von verschiedenen Füllungsmaterialien in den an die Restauration angrenzenden Zahnschmelz
}

\author{
INAUGURAL - DISSERTATION \\ zur Erlangung des Doktorgrades \\ für Zahnheilkunde \\ der Medizinischen Fakultät \\ der Georg August Universität zu Göttingen \\ vorgelegt von \\ Tim Schliemann \\ aus \\ Hildesheim
}


Dekan:

I. Berichterstatter:

II. Berichterstatter/in:

III. Berichterstatter/in:

Tag der mündlichen Prüfung:
Prof. Dr. med. C. Frömmel

Prof. Dr. med. dent. T. Attin 


\section{$\underline{\text { Inhaltsverzeichnis }}$}

1 Einleitung 1

2 Literaturübersicht 3

2.1 Direkte und indirekte Restaurationen 3

2.2 Werkstoffkunde plastischer Füllungsmaterialien 3

2.2.1 Komposit 3

2.2.2 Glasionomerzement 5

2.2.3 Kompomer 5

2.3 Überlebensraten von zahnärztlichen Füllungen 6

$\begin{array}{ll}\text { 2.3.1 Überlebensrate von Kompositfüllungen } & 6\end{array}$

$\begin{array}{ll}\text { 2.3.2 Überlebensrate von Kompomerfüllungen } & 7\end{array}$

2.3.3 Überlebensrate von Glasionomerzementfüllungen 8

2.3.4 Vergleich der Verlustgründe untereinander 8

2.4 Haftverbund von Füllungsmaterialien an der Zahnhartsubstanz 9

$\begin{array}{ll}2.5 \text { Fluoridfreisetzung aus Füllungsmaterialien } & 11\end{array}$

2.6 Lokale Interaktionen des Fluorids mit der Zahnhartsubstanz 12

2.7 Ziel der Studie

3 Versuchsplanung $\quad 15$

4 Material und Methoden 17

$\begin{array}{ll}4.1 \text { Probengewinnung } & 17\end{array}$

$\begin{array}{ll}\text { 4.1.1 Probenverteilung } & 17\end{array}$

4.2 Vorbereiten der Proben und Präparieren der Kavität 18

4.2.1 Applikation der Füllungsmaterialien
20

4.3 Bestimmung der Fluoridkonzentration 22

4.3.1 Bestimmung des natürlichen Fluoridgehalts (Basisfluoridgehalt) 24

4.3.2 Fluoridgehaltbestimmung nach Applikation der Füllungsmaterialien $\quad 25$ 
4.3.4 Umrechnung der Fluoridkonzentration bezogen auf das Ausgangsvolumen $\begin{array}{ll}\text { der Säure } & 28\end{array}$

5 Ergebnisse $\quad 30$

$\begin{array}{ll}5.1 \text { Basisfluoridgehalt } & 30\end{array}$

5.2 Fluoridgehalt nach Applikation der Füllmateralien 30

$\begin{array}{ll}\text { 5.2.1 Glasionomerzement } & 30\end{array}$

$\begin{array}{ll}\text { 5.2.2 Komposit } & 30\end{array}$

$\begin{array}{ll}\text { 5.2.3 Kompomer } & 30\end{array}$

5.3 Vergleich zwischen den Füllungsmaterialien 31

5.3.1 Vergleich der Messwerte $24 \mathrm{~h}$ nach Füllungsapplikation 31

5.3.2 Vergleich der Messwerte $48 \mathrm{~h}$ nach Füllungsapplikation 31

5.3.3 Vergleich der Messwerte $72 \mathrm{~h}$ nach Füllungsapplikation 31

5.4 Verteilung der einzelnen Fluoridgehalte in den Gruppen 31

6 Diskussion 33

6.1 Diskussion der Methode 33

6.1.2 Boviner Schmelz 34

$\begin{array}{ll}\text { 6.1.3 Analysemethoden } & 35\end{array}$

6.2 Diskussion der Ergebnisse 36

6.2.1 Fluoridabgabe in Abhängigkeit vom verwendeten Material 36

6.2.2 Fluoridaufnahme in den Schmelz in Abhängigkeit von der Zeit 38

6.2.3 Auswirkungen des aufgenommen Fluorids auf den Schmelz 39

6.3 Schlussfolgerungen 43

7 Zusammenfassung $\quad 44$ 
8 Tabellarischer Anhang $\quad 45$

8.1 Gruppe 1 (Glasionomerzement): Werte aus der Fluoridgehaltbestimmung $\quad 45$

8.2 Gruppe 2 (Komposit): Werte aus der Fluoridgehaltbestimmung 46

8.3 Gruppe 3 (Kompomer): Werte aus der Fluoridgehaltbestimmung 47

$\begin{array}{ll}9 \text { Literaturverzeichnis } & 48\end{array}$

10 Liste der verwendeten Geräte und Materialien 65

10.1 Geräte und Werkzeuge 65

10.2 Chemikalien und Reagenzien 66

10.3 Verbrauchsmaterialien 66 
Abbildungs- und Tabellenverzeichnis

$\begin{array}{cccc}\text { Abbildung } & \text { Seite } & \text { Tabelle } & \text { Seite } \\ 1 & 16 & \text { I } & 30 \\ 2 & 19 & \text { II } & 31 \\ 3 & 19 & \text { III } & 45 \\ 4 & 20 & \text { IV } & 46 \\ 5 & 20 & \text { V } & 47 \\ 6 & 26 & & \\ 7 & 27 & & \\ 8 & 32 & & \end{array}$




\section{Einleitung}

Karies entsteht durch kariogene Mikroorganismen, die in ihrem Umgebungsmilieu (Plaque) durch Zufuhr von Kohlenhydraten organische Säuren produzieren, die die Zahnhartsubstanzen demineralisieren (Miller 1889). Sobald die kariöse Läsion das Dentin betrifft, sollte die Karies entfernt und durch ein Füllungsmaterial ersetzt werden (Klinger und Wiedemann 1985). Dem Zahnarzt stehen zum Füllen von Kavitäten verschiedene zahnfarbene Füllungsmaterialien zur Verfügung: Glasionomerzemente, Kompomere und Komposite. Die applizierten Füllungsmaterialien haben unterschiedliche jährliche Ausfallraten, die für Glasionomerzemente etwa 3,5-14,3\% (Ho et al. 1999, Nicolaisen et al. 2000, Phantumvanit et al. 1996, Pilebro und van Dijken 2001, Smales et al. 1990, Ziraps und Honkala 2002), für Kompomere 1,3-2,25\% (Cehreli und Altay 2000, Demirci 2007, Krämer et al. 2006, van Dijken et al. 1999) und für Komposite 0,33-2,6\% betragen (Collins et al. 1998, Freilich et al. 1992, Pallesen und Qvist 2003, Roulet 1997, Rowe 1989, Smales 1977, Wilder et al. 1999). Sekundärkaries ist einer der Hauptgründe, warum zahnärztliche Restaurationen scheitern (Mjör 2005). Die Entstehung einer Sekundärkaries ist häufig mit einer schlechten marginalen Adaptation des Füllungsrandes an die angrenzenden Zahnhartsubstanzen assoziiert (Roulet 1994). Als Hauptursache dafür wird die Schrumpfung der Füllungsmaterialien während der Aushärtungsreaktion angesehen. Diese setzt den Verbund von Zahn und Füllungsmaterial unter Spannung, welcher sich dann partiell lösen kann. Es entstehen sogenannte „microleakages“ (Brännström et al. 1984, Roulet et al. 1991). Obwohl die Haftmechanismen von Restaurationsmaterialien an der Zahnhartsubstanz durch verschiedene Verfahren wie z. B. Schmelzätztechniken, Dentinkonditionierung oder Schichttechniken verbessert worden sind, können immer noch „microleakages“ beobachtet werden (Buonocore 1955, Deliperi und Bardwell 2002, Galan et al. 1976, Nikolaenko et al. 2004, Powis et al. 1982). In diesen Spalten können sich kariogene Bakterien (Plaque) ansiedeln, die die Demineralisation der Zahnhartsubstanzen und die Bildung von Sekundärkaries begünstigen (Carvalho et al. 1996, Hayashi und Wilson 2003, Krejci und Lutz 1991, Qvist 1993, Roulet 1994, Roulet et al. 1991). Schlechte Mundhygiene, Zahnfehlstellungen und der häufige Konsum vor allem niedermolekularer Kohlenhydrate begünstigen ebenfalls die Plaquebildung und die Demineralisation der Zahnhartsubstanzen (Etty et al. 1994, Kalsbeek und Verrips 1994, Krämer et al. 1996, Mundorff-Shrestha et al. 1994). 
Der kariesprotektive Effekt des Fluorids beruht hauptsächlich darauf, dass die Demineralisation der Zahnhartsubstanzen durch kariogene Säuren vermindert und die Remineralisation gefördert wird (Buchalla et al. 2002, Casals et al. 2007, Feller et al. 1976, Limeback 1994). Die lokale, posteruptive Fluoridierung der Zahnhartsubstanzen, z. B. durch fluoridhaltige Zahnpasten, Lacke oder Gele, hat dabei einen größeren Effekt als die systemische, präeruptive Fluoridverabreichung während der Zahnentwicklung (Burt 1966, Gedalia 1969, Klinkenberg und Bibby 1950, Leverett et al. 1997, Mirth et al. 1985). Ferner kann Fluorid den Stoffwechsel und das Wachstum der kariesassoziierten Bakterien hemmen (Bunick und Kashket 1981, Loesche et al. 1973, Yost und van Demark 1978). Fluoridhaltige Füllungsmaterialien wie Kompomere und Glasionomerzemente haben die Eigenschaft Fluorid abzugeben. Die Abgabe ist für beide Materialien initial hoch und geht dann in eine langsame, langanhaltende Fluoridabgabe über. Bei Glasionomerzementen sind die beide Vorgänge stärker ausgeprägt als bei Kompomeren (de Araujo et al. 1996, Dionysopoulos et al. 2003, Grobler et al. 1998, Karantakis et al. 2000). Von dieser Fluoridabgabe könnte man sich eine positive Beeinflussung auf die Verringerung der Demineralisation der Zahnhartsubstanz während eines kariösen Angriffs und auf die Remineralisation in der Zeit danach erhoffen, die vielleicht in einer niedrigen Sekundärkariesrate resultiert. Klinisch lassen sich diese erhofften Effekte nicht eindeutig nachweisen. So zeigten verschiedene Studien, die die Sekundärkariesraten an Glasionomerzement-, Kompomer- und Kompositfüllungen untersuchten, sehr unterschiedliche und teils widersprüchliche Ergebnisse (Ho et al. 1999, Krämer et al. 2006, Smales et al. 1990, Ziraps und Honkala 2002). Ziel der vorliegenden Studie war es daher zu untersuchen, wie viel Fluorid im unmittelbaren Randbereich aus verschiedenen Füllungsmaterialien aufgenommen und durch Säure herausgelöst werden kann. Diese Bestimmung könnte Rückschlüsse erlauben, wie viel Fluorid im Fall eines kariösen Angriffs zur Verfügung steht. Dabei ist es von besonderem Interesse, wie viel Fluorid in den unmittelbaren Randbereich aufgenommen wird, ohne dass das Fluorid aus der Füllungsoberfläche in Lösung gegangen ist. Diese Ergebnisse könnten Aufschluss darüber geben, ob eine Fluoridaufnahme bei möglichen Randspalten in tieferen Regionen des Füllungsrandes stattgefunden haben könnte. 


\section{Literaturübersicht}

\subsection{Direkte und indirekte Restaurationen}

Unter direkten Restaurationen versteht man Restaurationen aus plastischen Füllungsmaterialien, die vom Zahnarzt direkt in die präparierte Kavität im Zahn appliziert werden und dort aushärten. Dagegen abzugrenzen sind indirekte Restaurationen, die auf einem naturgetreuen Situationsmodell aus Gips, i. R. in einem zahntechnischen Labor, hergestellt werden. Darunter fallen Einlagefüllungen (Inlays), aber auch Teilkronen, Kronen und Brücken aus Metall und/oder Keramik. Für die Herstellung der Restaurationen müssen Abformungen (Abdrücke) der Kavität einschließlich des restlichen Zahnbestands und des Gegenkiefers mit einem zahnärztlichen Abformmaterial genommen werden. Mit diesen Abformungen werden dann Gipsmodelle der Kiefer angefertigt, mit deren Hilfe die Restauration hergestellt wird. Diese wird dann in der Zahnarztpraxis beim Patienten eingepasst und eingesetzt. Moderne CAD-/CAM-Verfahren („Computer Aided Design“/„Computer Aided Manufactoring“) erlauben auch die virtuelle Modellherstellung. Dazu wird mit einer speziellen Kamera ein digitales Foto von der Kavität und den angrenzenden Zähnen gemacht. Ein computergestütztes System stellt davon ein virtuelles, dreidimensionales Modell her. Auf diesem kann die Restauration am Computerbildschirm konstruiert werden. Mithilfe der Datensätze wird die Restauration dann entweder in einem Labor oder in der Zahnarztpraxis von Fräsmaschinen aus industriell vorgefertigten Blöcken (i. R. Keramik) hergestellt (Heidemann et al. 2004, Hellwig et al. 2003).

\subsection{Werkstoffkunde plastischer Füllungsmaterialien}

\subsubsection{Komposit}

Unter Kompositen versteht man plastische Füllungsmaterialen, die nach dem Einbringen in die Zahnkavität entweder chemisch oder unter UV-Lichtbestrahlung aushärten. Ein Komposit besteht aus drei Hauptkomponenten: der organischen Matrix, den anorganischen Füllern und dem Haftvermittler, der die ersten beiden Komponenten nach der Aushärtung verbindet. Die organische Matrix kann aus variablen Monomeren bestehen, die aber alle am Anfang und am Ende des Moleküls je eine Methylacrylatgruppe gemein haben, die eine radikalische Polymerisation an den Doppelbindungen der Methyl-Gruppen ermöglicht. Als Initiator für diese Reaktion dient bei den lichthärtenden Kompositen Kampferchinon und bei 
den chemisch härtenden Kompositen Benzoylperoxid (Miyazaki und Horibe 1988). Das heute am weitesten verbreitete und bekannteste Monomer ist Bisphenol-A-Glycidyl-Methacrylat (Bis-GMA), welches von Bowen (1962) patentiert und in die Zahnheilkunde eingeführt wurde. Der sogenannte Bowen-Kunststoff enthielt schon silanisierte $\mathrm{SiO}_{2}$-Füllkörper (Siliziumdioxid/Quarz) (Bowen 1962). Der anorganische Füllkörperanteil heutiger Komposite besteht in der Regel aus Quarzglas $\left(\mathrm{SiO}_{2}\right)$ oder anderen Gläservarianten (Silikaten) oder auch Keramikanteilen (Zirkonoxid). Durch den Zusatz von Schwermetalloxiden (i. R. Bariumoxide) erreicht man, dass das Material röntgenopak ist (Bowen und Cleek 1972). Die Einteilung der Komposite erfolgt über die Partikelbeschaffenheit des Füllers. Makrofüllerkomposite enthalten 1,5-15 $\mu \mathrm{m}$ große, splitterförmige Partikel, die Mikrofüllerkomposite hingegen kugelförmige, reine Siliziumdioxid Partikel der Größe 0,007-0,04 $\mu \mathrm{m}$. Der Fülleranteil liegt bei den Makrofüllerkompositen bei ca. $75 \%$ und bei den Mikrofüllerkompositen bei 50\%. Der geringere Fülleranteil der Mikrofüllerkomposite ist dadurch bedingt, dass die kleineren Partikel bei gleicher Menge eine sehr viel größere Oberfläche haben als die Makrofüllerpartikel. Dadurch würde sich die Viskosität des Füllungsmaterials so sehr erhöhen, dass eine Verarbeitung schwierig wäre (Hosoda et al. 1990, Khan et al. 1992). Der niedrige Fülleranteil bewirkt allerdings, dass eine daraus gefertigte Füllung gegenüber Abrasion (z. B. beim Zähneputzen) weniger widerstandsfähig ist. Die Resistenz gegenüber Druck und Verformung ist herabgesetzt, die Wasseraufnahme erhöht. Zusätzlich weisen Mikrofüllerkomposite eine höhere Polymerisationsschrumpfung auf als Makrofüller- und Hybridkomposite (Li et al. 1985). Die höhere Wasseraufnahme und die höhere Polymerisationsschrumpfung sind assoziiert mit einem häufigeren Auftreten von „microleakages“ (Crim 1989). Die Vorteile der Mikrofüllerkomposite liegen in der Ästhetik. Aufgrund der kleinen Partikelgröße, des niedrigen Füllergehaltes und der besseren Polierbarkeit ist diese auf lange Sicht besser als bei Makrofüller- oder Hybridkompositen (Dietschi et al. 1994). Als Weiterentwicklung der Makrofüller- und Mikrofüllerkomposite kann man die Hybridkomposite sehen. Diese haben insgesamt einen Fülleranteil von ca. 85\%, welcher zu 85-95\% aus Makropartikeln und zu 10-15\% aus Mikropartikeln besteht (Hosoda et al. 1990, Khan et al. 1992). Hybridkomposite lassen sich besser polieren als Makrofüllerkomposite. Dies reduziert die Oberflächenrauigkeit der Füllung. Die bessere, glattere Oberflächengüte der Mikrofüllerkomposite erreichen sie aber nicht (Barbosa et al. 2005). Je glatter die Oberfläche ist, desto geringer ist die Plaqueakkumulation und die bakterielle Besiedelung. Daher sollte eine gute, glatte Oberflächenqualität mit glatten 
Restaurationsrändern angestrebt werden (Quirynen et al. 1990). Durch den höheren Fülleranteil kann die Härte und somit auch die Resistenz gegenüber Abnutzung im Vergleich zu den Mikrofüllerkompositen deutlich erhöht werden (Suzuki et al. 1996, Wassell et al. 1992). Teilweise sind die Hybridkomposite den Makrofüllerkompositen bezüglich der Härte ebenbürtig (Gladys et al. 1997). Wie bei dem von Bowen entwickelten Kunststoff sind die anorganischen Füllpartikel heutiger Komposite meistens silanisiert. Diese Schicht verbindet sich chemisch mit der organischen Matrix (an den Methylacrylatketten). Dadurch resultiert eine stabile Einbettung der Füller in die Kunststoffphase, wodurch der Verschleiß des Materials verringert wird (Lin et al. 2000).

\subsubsection{Glasionomerzement}

Glasionomerzement wurde durch Wilson und Kent (1972) in die Zahnheilkunde eingeführt. Es ist ein Zweikomponentenmaterial aus Pulver und einer Anmischflüssigkeit. Der Pulveranteil besteht bei konventionellen Glasionomerzementen aus Kalzium-AluminiumSilikat-Gläsern. Zusätzlich enthält das Pulver gefriergetrocknete Polycarbonsäuren, i. R. Polyacrylsäure. Der Flüssigkeitsanteil besteht aus destilliertem Wasser mit oder ohne Weinsäurezusatz. Meistens werden die beiden Komponenten vordosiert in Kapselsystemen verwendet, welche ein optimales Mischungsverhältnis von Flüssigkeit und Pulver gewährleisten. Durch das Mischen der beiden Komponenten wird die Aushärtungsreaktion in Gang gesetzt. Im ersten Schritt werden durch die Säure zuerst überwiegend Kalziumionen $\left(\mathrm{Ca}^{2+}\right)$ und in geringerem Anteil auch Aluminiumionen $\left(\mathrm{Al}^{3+}\right)$ aus den Glaspartikeln herausgelöst (Barry et al. 1979). Im zweiten Schritt entsteht ein Kalziumpolycarboxylatgel, welches im weiteren Verlauf durch die Herauslösung von weiteren $\mathrm{Al}^{3+}$-lonen nach mehreren Stunden nach und nach in stabileres Kalzium-Aluminium-Carboxylatgel umgewandelt wird (Crisp et al. 1974, Zainnuddin et al. 2009). Während dieser Zeit ist die Füllung, d. h. genauer die Kalziumpolycarboxylatphase, äußerst empfindlich gegenüber Austrocknung und Feuchtigkeitszutritt. Nach etwa $3 \mathrm{~h}$ ist der zweite Schritt der Aushärtungsreaktion abgeschlossen. Die gesamte Reaktion bis zur Bildung des stabilen Kalzium-AluminiumCarboxylatgels dauert insgesamt etwa $48 \mathrm{~h}$ (Crisp und Wilson 1974).

\subsubsection{Kompomer}

Kompomere sind polyalkensäuremodifizierte Komposite, d. h. sie sind werkstoffkundlich betrachtet eine Art kombinierte Weiterentwicklung der Komposite und 
Glasionomerzemente. Es handelt sich dabei um Einkomponentenmaterialien, die wie die meisten Komposite durch UV-Licht gehärtet werden. Sie enthalten sowohl eine organische Matrix mit polymerisierbaren Monomeren, Initiatoren und Stabilisatoren wie die Komposite als auch Polyalkensäuren wie die Glasionomerzemente. Der anorganische Füller besteht aus Silikatpartikeln. Diese sind einerseits wie die Füller der Glasionomerzemente fluoridhaltig, andererseits teilweise silanisiert wie die Füller der Komposite. Im Gegensatz zu den Polyalkensäuren der Glasionomerzemente haben die der Kompomere zusätzlich Doppelbindungen. Diese ermöglichen neben der Säure-Basen-Reaktion der Glasionomerzemente auch eine radikalische Polymerisation (Mathis und Ferracane 1989, Young et al. 2004). Kompomerfüllungen nehmen in Kontakt mit Speichel allmählich Wasser auf (Cattani Lorente et al. 1999). Die Säure-Basen-Reaktion findet erst oberflächennah statt, wo Kontakt zum Speichel besteht oder im Kontaktbereich zum Dentin und seinem Liquor. Wenn die Wasseraufnahme in die Füllung durch den ständigen Speichelkontakt voranschreitet, können wahrscheinlich auch in tieferen Bereichen Säure-Basen-Reaktionen stattfinden (Eliades et al. 1998, Small et al. 1998). Bei diesen Säure-Basen-Reaktionen findet eine Fluoridfreisetzung statt (Can-Karabulut et al. 2007, Verbeeck et al. 1998). Verglichen mit den Kompositen und Glasionomerzementen unterliegen Kompomere in der Regel einer höheren Polymerisationsschrumpfung (Attin et al. 1995). Die Härte des Füllungsmaterials steigt mit der Erhöhung des Fülleranteils, der bis zu 84\% der Gesamtmasse ausmacht (Kwon et al. 2002).

\section{3 Überlebensraten von zahnärztlichen Füllungen}

\subsection{1 Überlebensrate von Kompositfüllungen}

Für Klasse-I- und Klasse-II-Kompositfüllungen liegt die jährliche Ausfallrate bei 0,33-2,6\% (Collins et al. 1998, Freilich et al. 1992, Pallesen und Qvist 2003, Roulet 1997, Rowe 1989, Smales 1977, Wilder et al. 1999). Im Vergleich mit Amalgamfüllungen kann man für Kompositfüllungen ähnlich gute Erfolgsraten auch im Seitenzahnbereich erreichen (Mair 1995, Roulet 1997, Rowe 1989). Sekundärkaries war mit einem Anteil 27,7-32\% Hauptgrund für das Scheitern von Klasse-I- und Klasse-II-Kompositrestaurationen. An zweiter Stelle folgte die Fraktur der Füllung in 14-27\% aller Fälle (Collins et al. 1998, Letzel 1989, Wilder et al. 1999). Große Molarenfüllungen scheiterten etwa dreifach häufiger als kleine Prämolarenfüllungen (Pallesen und Qvist 2003). Für Klasse-III- und Klasse-IV- 
Kompositfüllungen wurde eine jährliche Ausfallrate von 1-3.4\% beobachtet. Der Grund für den Austausch der Füllungen war selten Sekundärkaries. Der Grund für einen Austausch war häufig in der schlechter werdenden Ästhetik, z. B. durch marginale Verfärbungen oder alterungsbedingte gravierende Farbabweichungen von Zahn und Füllungsmaterial, begründet (Demirci et al. 2008, Millar et al. 1997, Pieper et al. 1991, Smales und Gerke 1992).

\subsection{2 Überlebensrate von Kompomerfüllungen}

Kompomere werden eher selten für Klasse-I- und Klasse-II-Restaurationen in permanenten Zähnen verwendet. Für Klasse-I- und Klasse-II-Restaurationen werden jährliche Ausfallraten von 1,3-2,25\% beobachtet (Cehreli und Altay 2000, Demirci 2007, Krämer et al. 2006, van Dijken et al. 1999). Klasse-I-Füllungen haben dabei niedrigere jährliche Ausfallraten als Klasse-II-Füllungen und große Füllungen höhere jährliche Ausfallraten als kleine. Der Beobachtungszeitraum der einzelnen Studien lag bei drei bis fünf Jahren. Längere Beobachtungszeiträume können aufgrund fehlender Studien nicht betrachtet werden. Klasse-I- und Klasse-II-Kompomerfüllungen scheitern selten an Sekundärkaries (Cehreli und Altay 2000). Die Hauptgründe für das Scheitern sind unakzeptable Randspaltbildung (55\%), partielle Schmelzabsprengungen (33\%) und Verschleiß des Füllungsmaterials (25\%) (Krämer et al. 2006). Für Klasse-III- und Klasse-IV-Frontzahnfüllungen liegt die jährliche Ausfallrate bei 0-2,1 \% (Demirci et al. 2002, Demirci et al. 2008, Prati et al. 1998, Tyas 2000, van Dijken 1999). Am häufigsten mussten die Füllungen wegen einer unakzeptablen Verfärbung, Fraktur der Füllung oder Sekundärkaries erneuert werden (Demirci et al. 2002, Demirci et al. 2008, van Dijken 1999). Kompomer findet heute häufig Anwendung in der Kinderzahlheilkunde als Restaurationsmaterial für Milchzähne. Die jährliche Ausfallrate von Klasse-I- und Klasse-II-Füllungen beträgt 1,7-2\% (Qvist et al. 2004, Welbury et al. 2000). Bis zum Zahnwechsel wird eine Erfolgsrate von 74-82\% erreicht (Duggal et al. 2002, Marks et al. 1999). Sekundärkaries wird auch hier selten beobachtet (Duggal et al. 2002, Marks et al. 1999, Qvist et al. 2004). Die Füllungen scheitern häufig durch den Verschleiß oder den Verlust des Füllungsmaterials oder wegen endodontischer Komplikationen (Collins et al. 1998, Letzel 1989, Qvist et al. 2004, Welbury et al. 2000, Wilder et al. 1999). 


\subsection{3 Überlebensrate von Glasionomerzementfüllungen}

Die jährlichen Ausfallraten von Klasse-I- und Klasse-II-Glasionomerzementfüllungen liegen bei 3,5-14,3\%. (Ho et al. 1999, Nicolaisen et al. 2000, Phantumvanit et al. 1996, Pilebro und van Dijken 2001, Smales et al. 1990, Ziraps und Honkala 2002). Der Hauptgrund für das Scheitern von 5,1-11,4\% aller Klasse-I- und Klasse-II-Glasionomerzementfüllungen waren Füllungsfrakturen, während 0-3,8\% aller Füllungen wegen Sekundärkaries scheiterten (Ho et al. 1999, Smales et al. 1990, Ziraps und Honkala 2002). Für Klasse-IIIGlasionomerzementfüllungen kann eine jährliche Ausfallrate von 1,8-3,9\% beobachtet werden, die hauptsächlich auf dem Verlust des Füllungsmaterials durch mangelnde Retention an der Zahnhartsubstanz und partiellen Füllungs- oder Zahnfrakturen beruht. Durch Sekundärkaries scheiterte hier keine Füllung (Cefaly et al. 2006, Mount 1986, Ngo et al. 1986, Zanata et al. 2003). Für Glasionomerzementfüllungen in Milchzähnen (Klasse I und II) liegen die Erfolgsraten bis zum Zahnwechsel bei 63-74\%. Von allen applizierten Füllungen scheitern 26-27\% durch Frakturen des Füllungsmaterials und nur ein geringer Teil aufgrund von Sekundärkaries (Espelid et al. 1999, Qvist et al. 1997, Welbury et al. 1991, Welbury et al. 2000).

\subsubsection{Vergleich der Verlustgründe untereinander}

Glasionomerzementfüllungen scheitern im Vergleich mit Komposit- und Kompomerfüllungen häufiger aus mechanischen Gründen, d. h. wegen des Verlusts der Füllung durch Frakturen oder durch den kompletten Retentionsverlust zu den Zahnhartsubstanzen vor allem bei okklusaler Belastung (Hickel et al. 1998, Krämer et al. 1994, Mandari et al. 2003, Mjör und Jokstad 1993, Mjör et al. 1990, Welbury et al. 1991). Die Langzeitprognose von Glasionomerzementfüllungen hängt stark von der korrekten Applikation ab, bei der jeglicher Flüssigkeitszutritt oder Austrocknung der Füllung bis zum vollständigen Abbinden des Materials nach etwa $48 \mathrm{~h}$ vermieden werden muss. Bei Kompomer- und Kompositfüllungen ist diese Isolierung nur solange notwendig, bis die Füllung appliziert und lichtgehärtet ist (Crisp und Wilson 1974, Ferrari und Tay 2003, Smales et al. 1990, Svanberg 1992). Glasionomerzement- und Kompomerfüllungen scheitern in vielen Studien weniger häufig wegen Sekundärkaries als Komposit oder Amalgamfüllungen (Cefaly et al. 2006, Mount 1986, Ngo et al. 1986, Zanata et al. 2003). Bezogen auf Füllungen in Milchzähnen scheitern Glasionomerzementfüllungen im Vergleich mit Kompomerfüllungen häufiger wegen 
Sekundärkaries und haben teilweise auch höhere Ausfallraten (Croll et al. 2001, Welbury et al. 2000).

\subsection{Haftverbund von Füllungsmaterialien an der Zahnhartsubstanz}

Komposite, Kompomere und auch Glasionomerzemente unterliegen einer Polymerisationsschrumpfung während des Aushärtungsprozesses. Für moderne Komposite liegt diese bei ca. 2-6 \% (Kleverlaan und Feilzer 2005). Bei einem neu entwickelten Komposit mit einer neuen Art von Monomer (FiltekTM Silorane) soll diese Volumenschrumpfung auf $1 \%$ reduziert sein (Weinmann et al. 2005). Glasionomerzement schrumpft innerhalb der ersten $24 \mathrm{~h}$ um etwa 4\% (Feilzer et al. 1988). Bei Kompomeren schrumpft das Volumen nach der Polymerisation produktabhängig um 2,6-3,3\% (Latorre-Garcia et al. 2006). Diese Schrumpfung setzt den Haftverbund zwischen Füllungsmaterial und Zahn unter Spannung (Kontraktionsstress) und kann ihn unter Spaltbildung gegebenenfalls sogar auflösen (Brännström et al. 1984). Der Kontraktionsstress ist der Hauptgrund für den (partiellen) Verlust des Verbunds von Zahn und Füllung. Er führt häufig zur Öffnung des marginalen Randbereiches, Bakterienbesiedelung und fördert die Bildung von Sekundärkaries (Carvalho et al. 1996, Hayashi und Wilson 2003, Krejci und Lutz 1991, Qvist 1993, Roulet 1994, Roulet et al. 1991). Ein besonderes Merkmal der Glasionomerzemente ist, dass das Füllungsmaterial mit den anorganischen Bestandteilen der Zahnhartsubstanz chemische Bindungen eingehen kann. Dieser Verbund ist stärker, wenn man die Kavitätenwände vorher mit Polyacrylsäure kurz anätzt und so die beim Präparieren entstandene Schmierschicht entfernt (Powis et al. 1982). Bei Kompositen und Kompomeren kommt erschwerend hinzu, dass diese hydrophob sind und die Zahnhartsubstanzen hingegen hydrophil. Um den Verbund zum Zahn zu verbessern, führte Buonocore (1955) die Schmelzätztechnik mit Phosphorsäure ein. Hierbei wird der Schmelz mit Phosphorsäure angeätzt, sodass ein retentives Ätzmuster entsteht und die Oberfläche besser benetzbar wird (Marshall et al. 1975). Dann wird ein Adhäsiv aufgetragen, das die Verbindung zwischen Füllung und Zahn herstellen soll. Das Adhäsiv ist eine Flüssigkeit, die variable, polymerisierbare Kunststoffmonomere enthält. Meistens ist der Flüssigkeitsanteil auf Basis von Azeton und die Monomere eine Mischung aus verschieden Methakrylaten, die den Monomeren der Komposite und Kompomere ähneln oder gleich sind. Nach der Verdunstung des Azetons werden diese Monomere mit UV-Licht polymerisiert und bilden eine funktionelle Matrix, die als Haftvermittler zwischen Zahn und Füllungsmaterial dient (Gwinnett und Matsui 1967, Swift et al. 1997). Die Verbesserung des 
Haftverbunds zum Schmelz kommt dadurch zustande, dass das applizierte Adhäsiv in die Räume zwischen den freigelegten Schmelzprismen eindringt und dort nach der Lichthärtung sogenannte "tags" aus Kunststoff bildet. Es findet eine Verzahnung statt. An diese Schicht kann dann das eingebrachte Komposit oder Kompomer nahtlos chemisch anbinden (Hannig et al. 2002, Prati et al. 2004). In der Kombination mit einem Adhäsiv wird der Verbund der Zahnhartsubstanzen zum Füllungsmaterial weiter verstärkt, sodass signifikant weniger häufig eine Spaltbildung („microleakage“) zwischen Zahn und Füllungsmaterial entsteht (Galan et al. 1976). Zudem muss zur Lösung des Verbunds mehr Kraft aufgewendet werden (Bowen 1965). Der Haftverbund zum Dentin kann ebenfalls mit Adhäsiven verbessert werden. Die klassische Methode besteht darin, das Dentin etwa $15 \mathrm{~s}$ mit Phosphorsäure zu ätzen und so die Kollagenfasern des Dentins freizulegen. Die Schmierschicht von der vorangegangenen Präparation wird beim Abspülen der Säure entfernt. Anschließend wird ein Adhäsiv aufgetragen, welches die Kollagenfasern des Dentins umgibt und auch in freie Dentintubuli penetrieren kann. Durch die Lichtpolymerisation bildet sich eine sogenannte Hybridschicht aus. An diese Schicht kann das Füllungsmaterial beim Aushärten direkt chemisch anbinden. Verhindert man zusätzlich noch das Austrocknen des Dentins nach dem Ätzen, kann der Haftverbund weiter verstärkt werden (Prati et al. 2004, Tam und Pilliar 1994). Dies liegt daran, dass die Kollagenfasern durch das Trocknen zusammenfallen. Der Vorgang kann durch minimales Anfeuchten des Dentins vor dem Auftragen des Adhäsivs rückgängig gemacht werden. Alternativ kann auch eines wasserhaltiges Adhäsiv verwendet werden (Eliades et al. 1999). Trotzdem dürfen weder das Dentin noch der Schmelz während der Applikation des Adhäsivs oder auch des Füllungsmaterials zu feucht sein. Eine Kontamination mit Feuchtigkeit, z. B. durch Speichel oder Plasma, führt zu einer Verschlechterung des Haftverbundes (Chiba et al. 2004, Xie et al. 1993). Eine weitere Maßnahme, den Verbund von Schmelz und Kompomer-/Kompositfüllungen zu verbessern, stellt das Anschrägen (Winkel $45^{\circ}$ ) der approximalen Schmelzränder der Kavität vor dem Auftragen des Adhäsivs dar. Nach dem Anschrägen der oralen und fazialen Schmelzränder treten dort nach dem Simulieren von Alterungsvorgängen („thermocycling“) bei 5\% der Füllungen „microleakages“ auf. Wird der Schmelz nicht angeschrägt, treten bei 70\% der Füllungen „microleakages“ auf. Durch Anschrägen des Schmelzes zervikalen Schmelzbereich treten dort bei $25 \%$ der Füllungen „microleakages“ auf. Ist der Schmelz dort nicht angeschrägt, so findet bei $85 \%$ der Füllungen eine Spaltbildung im zervikalen Bereich statt (Opdam et al. 1998). Schmidlin et al. (2007) stellten ebenfalls fest, dass die Anschrägung der approximalen Schmelzränder das 
Auftreten von „microleakages" signifikant reduzieren kann. Die dreidimensionale Konfiguration der Kavität, beschrieben durch den C-Faktor („configuration factor“) und die Größe der Kavität bestimmen ebenfalls die Stärke des Polymerisationsstresses und die Ausbildung von „microleakages“. Der C-Faktor ergibt sich aus dem Verhältnis der Größe der an die Zahnhartsubstanz gebundenen Oberfläche der Füllung zu der Größe der freien Oberfläche der Füllung. Ein niedriger C-Faktor, d. h. eine möglichst große freie Füllungsoberfläche und eine möglichst kleine gebundene Oberfläche, resultiert in einem geringeren Polymerisationsstress und weniger „microleakages“ (Feilzer et al. 1987, Nikolaenko et al. 2004, Witzel et al. 2007). Vor allem bei größeren Füllungen mit hohem CFaktor kann die Inkrementtechnik den Polymerisationsstress und die Ausprägung von „microleakages“ verringern. Hierbei wird das Füllungsmaterial in kleinen Portionen in die Kavität eingebracht und einzeln ausgehärtet (Deliperi und Bardwell 2002, Nikolaenko et al. 2004). Wenn man die Politur der Füllung erst 12-24 h nach Applikation durchführt, kann bei Glasionomerzement- und Kompositfüllungen eine bessere marginale Adaptation des Füllungsrandes erreicht werden. Kompomerfüllungen kann man auch sofort nach der Applikation polieren. Die Qualität des Randschlusses wird durch eine verzögerte Politur nicht positiv oder negativ beeinflusst (Irie und Suzuki 2002, Irie et al. 2003). Thermocyclingversuche, die die Alterung von Füllungsmaterialien in einer kurzen Zeit simulieren sollen, haben gezeigt, dass der Verbund zwischen verschiedenen zahnfarbenen Füllungsmaterialien und dem Zahn mit der Zeit trotzdem signifikant nachlässt. Es findet eine Spaltbildung statt (Wahab et al. 2003). Es hat sich gezeigt, dass die Spaltbildung bei schmelzbegrenzten Füllungen geringer ist als bei dentinbegrenzten (Awliya und El-Sahn 2008, Manhart et al. 2001, Silveira de Araújo et al. 2006).

\subsection{Fluoridfreisetzung aus Füllungsmaterialien}

Bei der Herstellung der Füllpartikel der Glasionomerzemente und Kompomere wird der Glasschmelze als Flussmittel Kalziumfluorid $\left(\mathrm{CaF}_{2}\right)$ zugesetzt, welches dann in den Füllpartikeln enthalten ist und aus der späteren Füllung an das Umgebungsmilieu freigesetzt werden kann. Die Fluoridabgabe ist dabei abhängig von der Art des Füllungsmaterials unterschiedlich hoch. Konventioneller Glasionomerzement gibt, gefolgt von den Kompomeren, durchschnittlich am meisten Fluorid an die Umgebung ab. Komposite mit einem Anteil fluoridhaltiger Füller geben im Vergleich mit Glasionomerzementen und Kompomeren die geringste Menge Fluorid an die an die Umgebung ab. (Can-Karabulut et al. 
2007, Mazzaoui et al. 2000, Shaw et al. 1998, Yamauti et al. 2009). In einem sauren Umgebungsmilieu findet eine höhere Fluoridfreisetzung statt als in einem neutralen Milieu. Auch hier ist die Höhe der Fluoridfreisetzung bei den Glasionomerzementfüllungen am höchsten, gefolgt von den Kompomeren und fluoridhaltigen Kompositen (Attin et al. 1996, Attin et al. 1999 a, Carey et al. 2003, Hattab und Amin 2001, Hayacibara et al. 2004, Karantakis et al. 2000, Marks et al. 2000, Nicholson JW und Czarnecka et al. 2004). Es wird vermutet, dass die höhere Fluoridabgabe im sauren Umgebungsmilieu auf der oberflächlichen Zersetzung des Restaurationsmaterials durch die Säure beruht (Attin et al. 1999 a, Carey et al. 2003, Carvalho und Cury 1999, Czarnecka et al. 2002, Karantakis et al. 2000, Nicholson JW und Czarnecka et al. 2004). Dem entgegengesetzt wiesen Attin et al. (1996) für Kompomerfüllungen im sauren Milieu (pH 4,8) eine höhere Fluoridfreisetzung im Vergleich mit Glasionomerzementfüllungen nach. Im neutralen Milieu $(\mathrm{pH} 6,8)$ hingegen wiesen die Kompomere über den Messzeitraum eine geringere Fluoridfreisetzung als die Glasionomerzemente auf. Die Fluoridfreisetzung in das Umgebungsmilieu hängt dabei mehr von der Größe der Oberfläche des Materials ab als von der eigentlichen Masse (Williams et al. 1999).

\subsection{Lokale Interaktionen des Fluorids mit der Zahnhartsubstanz}

Fluorid kann grundsätzlich auf zwei verschiedene Arten zur Kariesprävention eingesetzt werden: posteruptiv, d. h. lokal auf der Zahnhartsubstanz oder präeruptiv, d. h. systemisch über orale Aufnahme während der Zahnentwicklung. Anfangs war man der Ansicht, dass die systemische Wirkung des Fluorids, basierend auf seinem strukturellen Einbau in den Zahnschmelz und der Bildung von Fluorapatit während der Zahnentwicklung, die kariesprotektiven Effekte auf den Schmelz bewirkt (McKay 1952). Heute weiß man, dass die kariesprotektive Wirkung der Fluoride hauptsächlich durch lokale, posteruptive Applikation auf die Zahnhartsubstanz, unter Bildung einer kalziumfluoridhaltigen Schicht und lockere Anlagerung in das interkristalline Wasser der Schmelzprismen, hervorgerufen wird (Higuchi et al. 1974, Klinkenberg und Bibby 1950, Mellberg et al. 1966, Stearns 1971, Wefel und Harless 1981). Die antikariogene Wirkung der Fluoride beruht auf der Verminderung der Säurelöslichkeit, der Hemmung der Demineralisation und der Förderung der Remineralisation der Zahnhartsubstanzen (Buchalla et al. 2002, Casals et al. 2007, Feller et al. 1976). Kalzium hat eine hohe Affinität zum Fluorid. Kommt das Fluorid mit dem Schmelz in Kontakt, so bindet es hauptsächlich an aus dem Schmelz herausgelöste Kalziumionen. Es 
bildet sich ein kalziumfluoridhaltiger Niederschlag (Higuchi et al. 1974, Mellberg et al. 1966, Wefel und Harless 1981). Unter sauren Bedingungen (pH 5), z. B. bei Applikation saurer Fluoridgele, kann eine dickere kalziumfluoridhaltige Schicht entstehen. Durch den niedrigen pH-Wert können mehr Kalziumionen aus dem Schmelz herausgelöst werden und als Reaktionspartner für die Fluoridionen zur Verfügung stehen (Gray et al. 1958). Diese kariesprotektiven Effekte können folgendermaßen erklärt werden: Die kalziumfluoridhaltige Schicht wird im neutralen $\mathrm{pH}-$ Bereich durch Phosphate und Proteine stabilisiert. Beginnt nun der $\mathrm{pH}$-Wert zu sinken, reagieren die Phosphate mit den Protonen und puffern diese ab. Die Kalziumfluoridschicht löst sich auf, es gehen Kalzium- und Fluoridionen in Lösung. Diese wirken dann der Demineralisation des Schmelzes entgegen und fördern die Remineralisation. Daher wird die Kalziumfluoridschicht auch als pH-gesteuertes Fluoridreservoir bezeichnet. Dafür spricht auch, dass nach Entfernen der Kalziumfluoridschicht mit Kalilauge $(\mathrm{KOH})$ der kariostatische Effekt verloren geht (Gerth et al. 2007, Øgaard 2001). Teilweise diffundiert das Fluorid auch in die Hydrathülle der Apatitkristalle des Zahnschmelzes (Stearns 1971). Ein kleiner Teil dieser Fluoridionen reagiert direkt mit dem Schmelz. Die OH-Gruppen des Hydroxylapatits werden dann teilweise durch Fluoridionen ersetzt. Dadurch entsteht Fluorapatit oder Fluorhydroxylapatit (Takagi et al. 2000). Fluorid wird bei lokaler Applikation auch in die Plaque eingelagert (Duckworth et al. 1994, Poureslami et al. 2007, Watson et al. 2005) und kann das Wachstum der kariesassoziierten Bakterien, wie Streptococcus mutans, hemmen (Loesche et al. 1973). Am umfangreichsten ist die Wirkung des Fluorids auf Streptococcus mutans untersucht. Das Fluorid kann bei niedrigen $\mathrm{pH}$-Werten in protonierter Form (Fluorwasserstoff/HF) ins Zellinnere von Streptococcus mutans diffundieren. Dort zerfällt es wieder und der intrazelluläre $\mathrm{pH}$-Wert sinkt. Dadurch kann bis zu einem gewissen Grad weiterer Fluorwasserstoff in die Zelle eindringen, da der Konzentrationsgradient durch den Zerfall des Fluorwasserstoffes erhalten bleibt (Whitford et al. 1977). Sowohl das Fluorid selbst als auch der sinkende $\mathrm{pH}$-Wert stören den Stoffwechsel des Bakteriums über die Hemmung der Enolase, einem zentralen Enzym des Glucosestoffwechsels. Dieses Enzym katalysiert die Reaktion von 2-Phosphoglyzerat zu Phosphoenolpyruvat (Bunick und Kashket 1981). Auf zellulärer Ebene findet außerdem eine Hemmung der Glucoseaufnahme ins Zellinnere des Bakteriums statt (Germaine und Tellefson 1986). So zeigen In-vitro-Versuche, dass die Anwesenheit von Fluorid ein Absinken des pH-Wertes in der bakteriellen Plaque in kritische Bereiche unter 5,5 verhindern kann (Bradshaw et al. 2002). Auch die verwendete 
Fluoridverbindung hat einen Einfluss auf die Stärke der Wachstumshemmung der Bakterien. So hemmt Zinnfluorid das Wachstum von Streptococcus mutans stärker als Natriumfluorid (Yost und van Demark 1978).

\subsection{Ziel der Studie}

Verschiedene In-vitro-Studien haben nachgewiesen, dass fluoridhaltige Füllungsmaterialien in der Lage sind, Fluorid in die Umgebung (Speichel, Plaque, Zahnhartsubstanz) abzugeben. Bislang sind allerdings nur wenige Studien bekannt, die die Fluoridaufnahme des die Restauration umgebenden Schmelzes untersucht haben. Ziel der vorliegenden Studie war es daher, die Fluoridaufnahme des Schmelzes in unmittelbarer Umgebung zu Glasionomerzement-, Kompomer- und Kompositfüllungen zu untersuchen. 


\section{Versuchsplanung}

Für die Versuche werden 90 mittlere, bovine Unterkieferschneidezähne extrahiert und gereinigt. Die Zahnkronen werden parallel zur Zahnachse in zwei gleich große Hälften geteilt, wobei je eine Hälfte zur Bestimmung des Basisfluoridgehalts des Schmelzes dient. Die verbliebenen Zahnhälften werden dann folgendermaßen aufgeteilt:

Gruppe 1: Glasionomerzement $n=30$ Probenhälften

Gruppe 2: Komposit $n=30$ Probenhälften

Gruppe 3: Kompomer n=30 Probenhälften

In der Probe wird eine halbkreisförmige Kavität mit dem Radius $r=2,5 \mathrm{~mm}$ und der Tiefe 2 $\mathrm{mm}$ angelegt. Die Kavitäten werden in der Gruppe 1 mit dem Glasionomerzement Ketac ${ }^{\mathrm{TM}}$ Fil Plus Aplicap ${ }^{\mathrm{TM}}$ (3M ESPE AG Dental Products, Seefeld), in der Gruppe 2 mit dem Komposit Spectrum $^{\circledR}$ (Dentsply De Trey GmbH, Konstanz) und in der Gruppe 3 mit dem Kompomer Dyract $^{\circledR}$ eXtra (Dentsply De Trey $\mathrm{GmbH}$, Konstanz) gefüllt.

Vierundzwanzig Stunden nach der Applikation des Materials erfolgt die Fluoridgehaltbestimmung des Schmelzes am Füllungsrand. Dazu wird Salzsäure (pH 2) auf den Schmelz am Füllungsrand aufgetragen, nach $15 \mathrm{~s}$ Einwirkzeit abgesaugt und mit Natronlauge $(\mathrm{pH}$ 12) neutralisiert. Durch die Zugabe von Tisab III wird die Lösung für die Fluoridgehaltbestimmung aufbereitet. Nach Bestimmen des Fluoridgehalts werden die Zahnhälften im Brutschrank bei $37^{\circ} \mathrm{C}$ und $100 \%$ Luftfeuchte gelagert. Die Messung wird $48 \mathrm{~h}$ und $72 \mathrm{~h}$ nach Füllungsapplikation wiederholt. Der Versuchsaufbau ist in $A b b .1$ grafisch dargestellt. 
Bovine Unterkieferschneidezähne ( $n=90)$

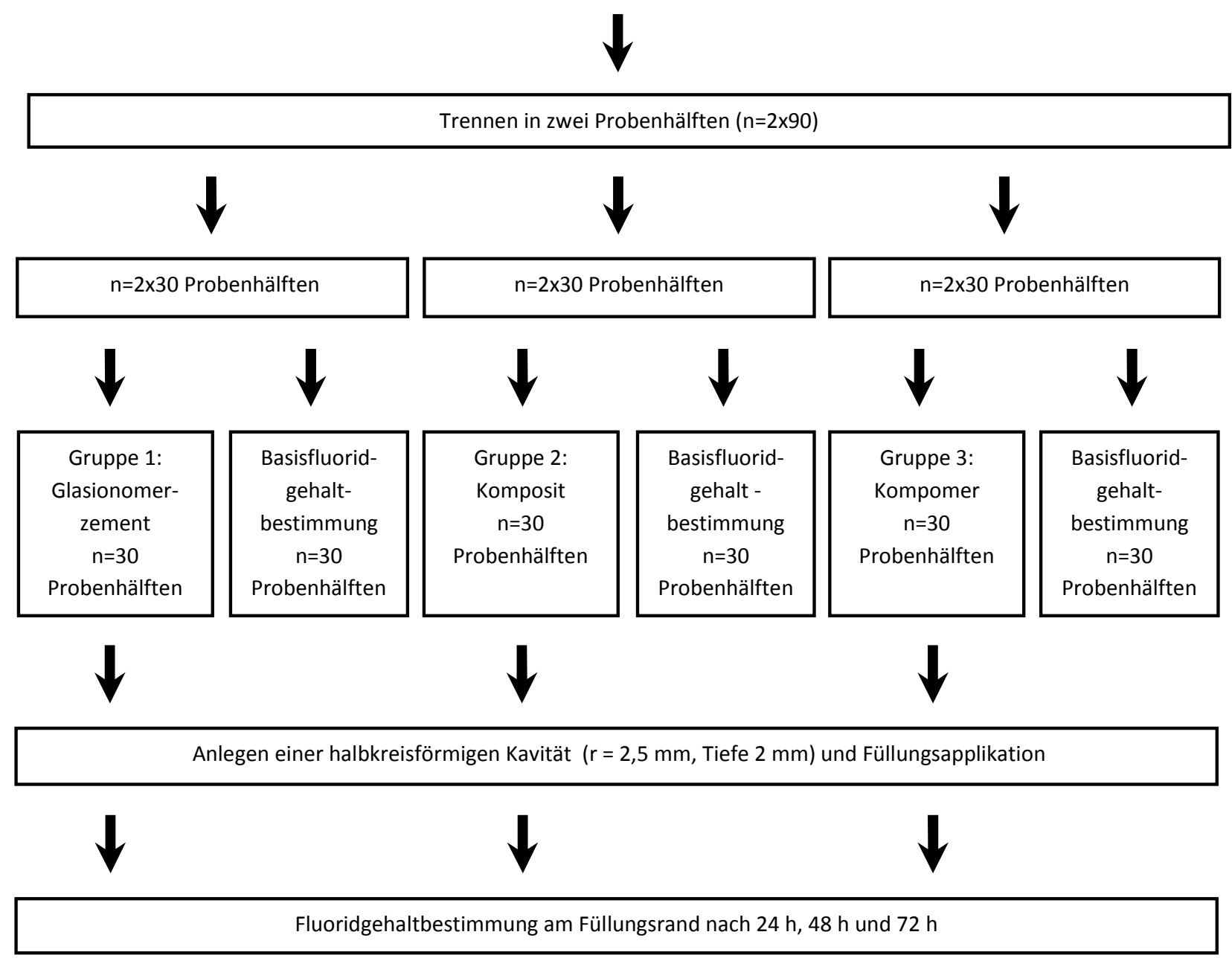

Abb. 1 Grafische Darstellung des Versuchsaufbaus 


\section{Material und Methoden}

\subsection{Probengewinnung}

Für die Studie wurden bovine Unterkieferschneidezähne verwendet. Kariöse, stark abradierte, verfärbte oder beschädigte Zähne wurden aussortiert. Die so gewonnenen 90 Zähne wurden von Geweberesten befreit und bis zur endgültigen Probenherstellung in 0,9\%iger NaCl-Lösung mit 0,1\% Thymolzusatz aufbewahrt. Die Zähne wurden dann entlang der Kronenachse in zwei gleich große Hälften zerteilt. Die Zahnhälften wurden mit einer Suspension aus Schlämmkreide und bidestillierten Wasser gereinigt und anschließend mit bidestilliertem Wasser abgespült. Der Winkel zwischen dem planen Anteil der Labialfläche und der Sägeschnittfläche musste immer $90^{\circ}$ betragen, damit das Volumen der Bohrkavität, und somit auch der späteren Füllung immer gleich war. Gegebenenfalls wurden die Unterschiede von maximal $1-2^{\circ}$ mit 800er Nassschleifpapier (Hermes Schleifmittel GmbH \& Co. KG, Hamburg) ausgeglichen. Von jedem Zahn wurde eine Hälfte für die Versuche zur Fluoridgehaltbestimmung genutzt, die andere Hälfte zur Basisfluoridgehaltbestimmung. Bis zur Probenherstellung wurden die Proben zusammen in 0,9\%iger $\mathrm{NaCl}$-Lösung luftdicht aufbewahrt.

\subsubsection{Probenverteilung}

Neunzig Zahnhälften wurden zur Bestimmung des Basisfluoridgehalts des entsprechenden Zahns verwendet. Die korrespondierenden Zahnhälften wurden folgendermaßen aufgeteilt:

Gruppe 1: $n=30$ Proben

Füllungsmaterial: Ketac ${ }^{\mathrm{TM}}$ Fil Plus Aplicap Glasionomerzement, 3M ESPE AG Dental Products, Seefeld

Gruppe 2: $n=30$ Proben

Füllungsmaterial: Spectrum ${ }^{\circledR}$ Komposit, Dentsply De Trey GmbH, Konstanz

Gruppe 3: $n=30$ Proben

Füllungsmaterial: Dyract ${ }^{\circledR}$ eXtra Kompomer, Dentsply De Trey GmbH, Konstanz 


\subsection{Vorbereiten der Proben und Präparieren der Kavität}

Zunächst wurde ein Gelatinegel hergestellt. Dazu wurde ein Blatt weißer Blattgelatine Typ A von ca. 1,7 g (Gelita Deutschland GmbH, Eberbach) in $20 \mathrm{ml}$ bidestilliertem Wasser über dem Bunsenbrenner unter ständigem Rühren aufgelöst. Mit einem Pinsel wurde eine ca. $1 \mathrm{~mm}$ dicke Schicht dieses Gels deckend und blasenfrei auf die Zahnhälfte aufgetragen. Das offenliegende Pulpakavum wurde dabei vollständig und blasenfrei mit Gelatine aufgefüllt. Die Zahnhälfte wurde dann mit einer 0,6 mm starken Propylen-Tiefziehfolie (Bego Goldschlägerei Wilh. Herbst GmbH \& Co. KG, Bremen) für die Kronenherstellung bedeckt. Bei diesem Verfahren wird die in einen speziellen Halter (Bego Goldschlägerei Wilh. Herbst $\mathrm{GmbH}$ \& Co. KG, Bremen) fixierte Folie über einer Bunsenbrennerflamme gleichmäßig erhitzt, bis sie transparent und somit plastisch verformbar wird. Umgehend wurde die Folie samt Halter auf dem Formgerät positioniert und die Zahnhälfte mit gleichmäßigem Druck senkrecht in die noch plastische Folie und die darunterliegende, weichbleibende Silikonmasse gedrückt. Der Gegendruck der Silikonmasse bewirkt ein dichtes und gleichmäßiges Anlegen der Folie auf der Zahnoberfläche. Folienüberschüsse im Wurzelbereich wurden mit einem erhitzten Skalpell vorsichtig entfernt. Der Gelatineüberzug dient als Haftschicht zwischen Folie und Zahn und umgibt den Zahn als hydrokolloide Schutzschicht. Dann wurde die Probe in der Bohrschablone (Abb. 2) mithilfe thermoplastischer Kerr ${ }^{\circledR}$-Masse (Kerr Italia, Scafati Salerno, Italien) fixiert, sodass die Zahnoberfläche senkrecht zur späteren Bohrung ausgerichtet war (Abb. 3). Der Diamantzylinderbohrer (Hoffmann $\mathrm{GmbH}$, München) wurde standardmäßig auf eine Bohrtiefe von 2,3 mm eingestellt. Beim Ausrichten musste die Folienstärke von etwa 0,3 mm berücksichtigt werden. Dann wurde die Kavität unter Wasserkühlung (0,9\%ige NaCl-Lösung) gebohrt (Durchmesser des zylindrischen Bohrkopfes: $\varnothing 5 \mathrm{~mm}$ ) und die Abmessungen anschließend unter Zuhilfenahme eine Parodontalsonde mit Skalierung allseitig überprüft. Über dieses Verfahren wurde eine allseitig $2 \mathrm{~mm}$ tiefe, halbkreisförmige Kavität mit einem Radius von 2,5 mm in der Probe erstellt. Die Probe wurde aus der Schablone entfernt und mit destilliertem Wasser abgespült, um losen Präparationsabrieb zu entfernen. Durch das Bohren entstandene Fahnen an der Kunststoffoberfläche im Randbereich der Kavität wurden mit einem scharfen Skalpell vorsichtig entfernt. Dann erfolgte die Freilegung der Kavität im seitlichen Bereich (ehemalige Sägekante) circa 1,5 mm parallel zum Kavitätenrand mit einem erhitzten Skalpell, um das Angleichen der späteren Füllung an die Kavitätenränder zu 
erleichtern (Abb. 4). Dann wurde der Übergang von der Folie zum Zahn unter 6-facher Vergrößerung mit einem Auflichtmikroskop (Carl Zeiss Jena $\mathrm{GmbH}$, Jena) auf dichtes Anliegen überprüft. Durch das Überziehen des Zahnschmelzes mit der Kunststofffolie konnte die später applizierte Füllung vollständig mit Schellack isoliert werden und eine Isolierung des Schmelzrandes vermieden werden.

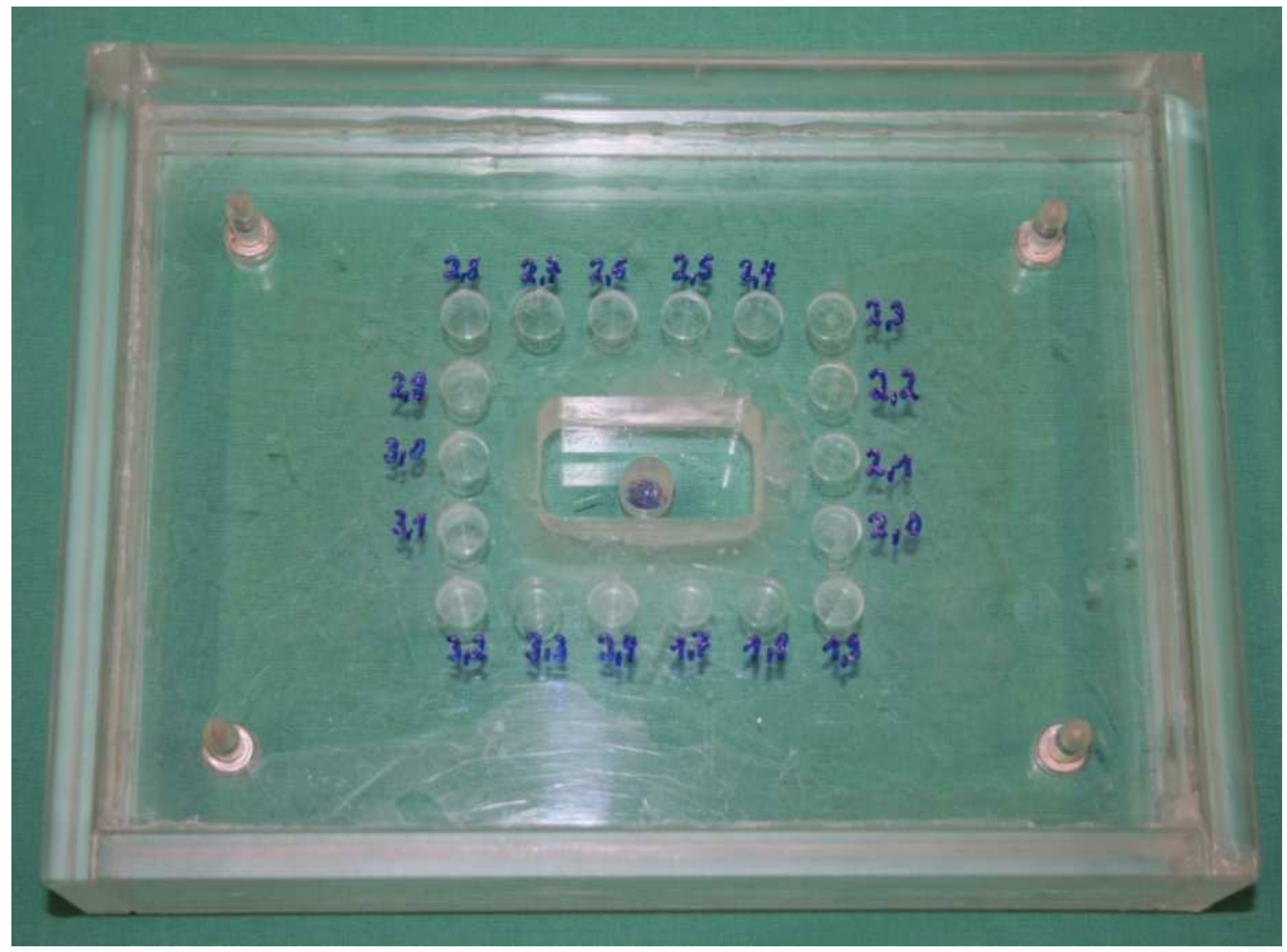

Abb. 2 Selbstkonstruierte Bohrschablone aus PMMA (Polymethylmethacrylat). In der Mitte befindet sich die Aussparung zur Aufnahme der Probe umringt von im parallelen Abstand angeordneten, zylindrischen Vertiefungen $(1,7-3,4 \mathrm{~mm}$ tief, planparalleler Boden) zur präzisen Einstellung der gewünschten Bohrtiefe des Bohrers.

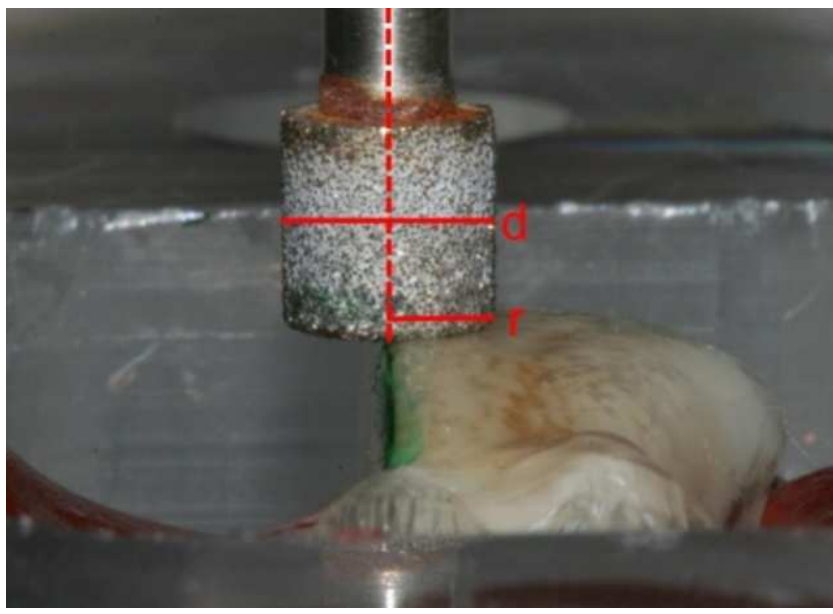

Abb. 3 Korrekte Position des Bohrers auf der Labialfläche $(\mathrm{d}=5 \mathrm{~mm}, \mathrm{r}=2,5$ $\mathrm{mm})$. 


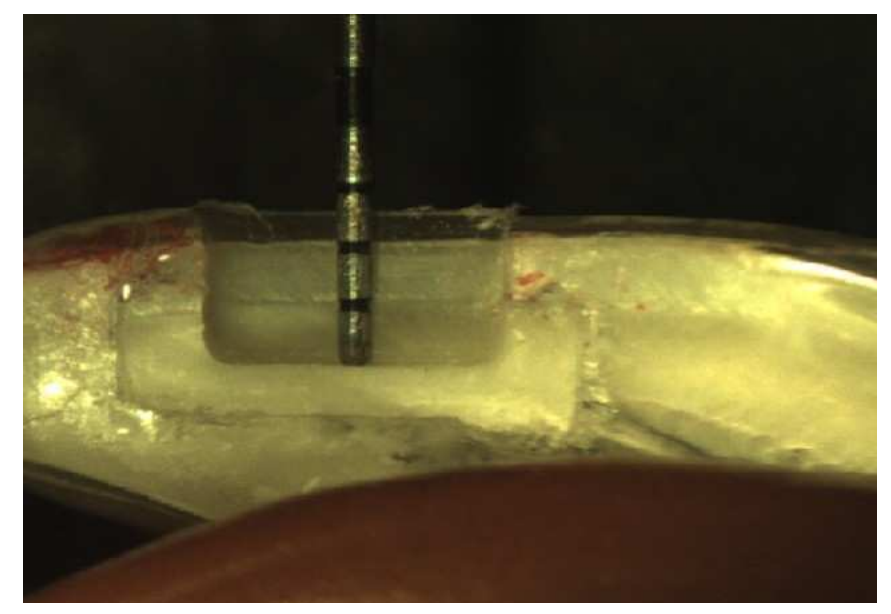

Abb. 4 Kavität mit Parodontalsonde (Markierung $1 \mathrm{~mm}$ ). Die Kavität ist allseitig $2 \mathrm{~mm}$ tief.

\subsubsection{Applikation der Füllungsmaterialien}

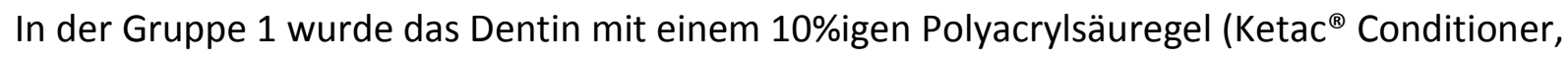
3M ESPE AG Dental Products, Seefeld) angeätzt, um die Schmierschicht von der Präparation zu entfernen. Die Säure wurde nach 10 s Einwirkzeit mit bidestilliertem Wasser mindestens $30 \mathrm{~s}$ abgespült. Außerhalb der Kavität anhaftendes Wasser wurde mit Druckluft entfernt, die Kavität selbst aber mit Wattepellets trocken getupft, um ein zu starkes Austrocknen der Zahnhartsubstanzen zu vermeiden. Die Glasionomerzementkapsel wurde aktiviert und $10 \mathrm{~s}$ im Anmischgerät Silamat (Vivadent - Schaan, Liechtenstein) gerüttelt. Das Füllungsmaterial wurde mit einer Applikationsspritze in die Kavität eingebracht und an die Kavitätenränder (Abb. 5) unter Zuhilfenahme dünn mit Kakaobutter (GC Corporation, Tokyo, Japan) überzogener Instrumente unter dem Auflichtmikroskop (Carl Zeiss Jena GmbH, Jena) angeglichen.

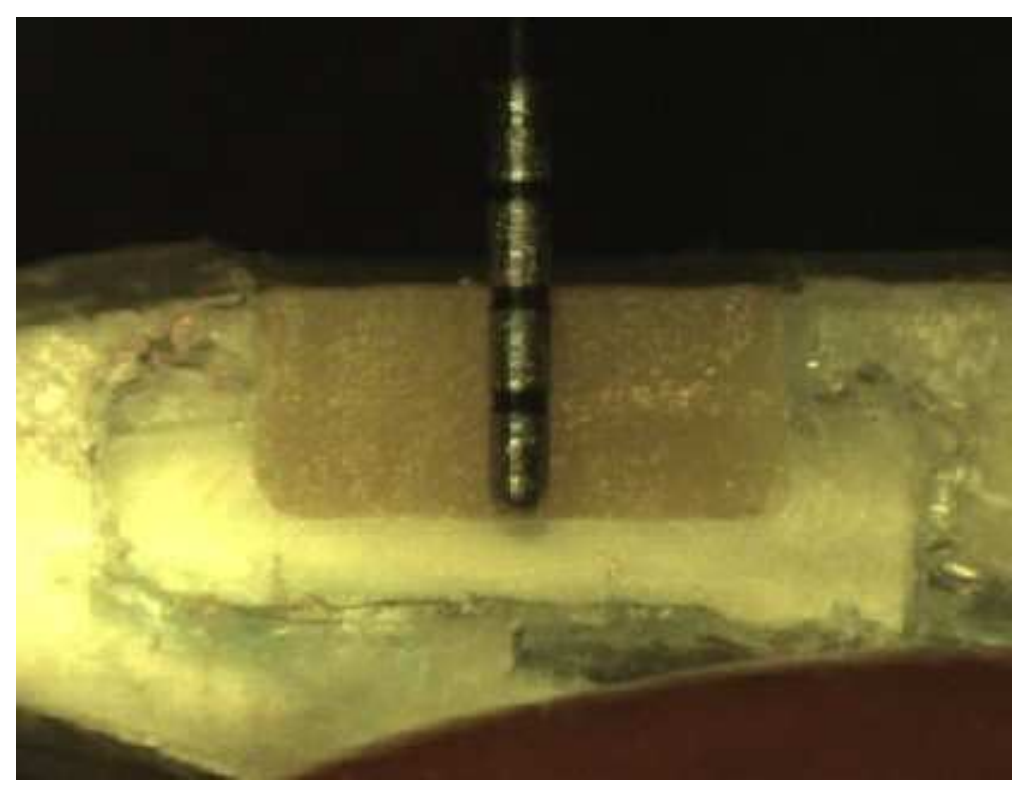

Abb. 5 Mit Glasionomerzement gefüllte Kavität 
In Gruppe 2 und 3 wurde die Zahnhartsubstanz mithilfe von 35\%igem Phosphorsäuregel (Ultra Etch ${ }^{\circledR}$, Ultradent Products Inc., South Jordan, Utah, USA) konditioniert. Hierbei wurde der Schmelz $45 \mathrm{~s}$ und das Dentin $15 \mathrm{~s}$ angeätzt. Anschließend wurde die Probe mindestens 30 s mit bidestilliertem Wasser abgespült. Die Probe wurde mit Druckluft getrocknet, das Wasser innerhalb der Kavität aber mit Wattepellets entfernt, um ein zu starkes Austrocknen der Zahnhartsubstanzen zu verhindern. Dann erfolgte das Auftragen des Adhäsivs Prime\&Bond ${ }^{\circledR}$ NT (Dentsply De Trey $\mathrm{GmbH}$, Konstanz). Dieses wurde $30 \mathrm{~s}$ mit einem EinmalApplikator-Tip (Hager \& Werken GmbH \& Co KG, Duisburg) einmassiert und anschließend mit einer UV-Polymerisationslampe (Dentsply De Trey GmbH, Konstanz) 30 s gehärtet. Dann wurde in der Gruppe 2 das Komposit (Spectrum ${ }^{\circledR}$, Dentsply De Trey GmbH, Konstanz), bzw. in der Gruppe 3 das Kompomer (Dyract ${ }^{\circledR}$ eXtra, Dentsply De Trey GmbH, Konstanz) portionsweise (Inkrementtechnik) in die Kavität eingebracht. Die eingebrachten Teilportionen von ca. 35 mg wurden jeweils 40 s mit der UV-Polymerisationslampe gehärtet. Die Masse von ca. 35 mg stellt einen Orientierungswert dar, der im Vorfeld beispielhaft an typischen Teilportionen mit einer geeichten Waage (Feinwaage „R $160 \mathrm{P}^{\prime}$, Sartorius AG, Göttingen) ermittelt wurde. Die Adaptation im Füllungsrandbereich erfolgte auch hier unter dem Auflichtmikroskop. Nach der Aushärtung wurden die Füllungen allseitig mit Schellack (Eberhard Faber GmbH, Staedler Group, Neumarkt) überzogen. Nach ca. 10 Minuten war der Schellack berührtrocken und es erfolgte das Aufbringen einer zweiten Schellackschicht. Die Proben wurden anschließend für $24 \mathrm{~h}$ gelagert, um ein vollständiges Abbinden des Schellacks zu ermöglichen. Die Schellackschicht verblieb während des gesamten Versuchzeitraums auf der Füllung, um diese bei der Gewinnung der Proben für die Fluoridgehaltbestimmung gegen die aufgetragene Salzsäure zu isolieren und eine Fluoridfreisetzung aus der Oberfläche der Füllung zu verhindern. So wurde bei der Messung nur der Teil des Fluorids erfasst, der direkt durch den Kontakt der Füllungsmaterialien in den angrenzenden Schmelz aufgenommen wurde. Schellack zeigte sich in den Vorversuchen als säurefeste und dichte Diffusionsbarriere. Zusammen mit der Tiefziehfolie und dem Gelatineüberzug bildet der Schellack eine dichte Abdeckung um die Zahnhälfte. Diese soll den Zahn vor Austrocknung schützen. Gelatine ist chemisch-physikalisch betrachtet ein Hydrokolloid und umgibt den Zahnschmelz bis zur ersten Messung wie ein feuchtes Schutzpolster. Nach der Entfernung der Kunststoffhülle findet man die Gelatine als dünne Gelschicht auf dem darunter liegenden, feuchtglänzenden Schmelz vor. 


\subsection{Bestimmung der Fluoridkonzentration}

Der Fluoridgehalt einer wässrigen Lösung kann mithilfe einer speziellen (fluorid-) ionenselektiven Elektrode (ISE) bestimmt werden. Man unterscheidet hier sogenannte Einstabmessketten, bei der die Referenzelektrode/Bezugselektrode und Messelektrode in einen Schaft integriert sind, von Zweistabmessketten, bei der die beiden Elektroden getrennt sind. Zentraler Bestandteil der Messelektrode ist ein schwer löslicher Lathanfluorideinkristall $\left(\mathrm{LaF}_{3}\right)$. Zusätzlich ist dieser mit Europium dotiert, das die Empfindlichkeit der Sonde steigert. Taucht man die Sonde nun in die Probenlösung, so stellt sich ein Gleichgewicht zwischen sich von der Oberfläche ablösenden und anlagernden Fluoridionen ein. Erhöht man jetzt die Fluoridkonzentration in der Probenlösung, so heften sich tendenziell mehr Fluoridionen an die Bindungsstellen an der Kristalloberfläche. Diese bewirken eine Fluoridionenverschiebung über das Kristallgitter ins Innere der Sonde. Hierbei wandert allerdings nicht das lon durch den Kristall durch, sondern außen lagert sich ein Fluoridion an und innen löst sich zum Ausgleich eins aus dem Kristallverbund. Dieser Fluoridionenüberschuss bewirkt an der Ableitung zur Referenzelektrode eine Elektronenfreisetzung und zeigt sich als Spannungsänderung auf dem zwischengeschalteten Spannungsmessgerät. Umgekehrt findet ein stärkeres Abwandern von Fluoridionen von der Kristalloberfläche in die Lösung statt, wenn die Fluoridkonzentration in der Probenlösung gesenkt wird. Der Elektronenüberschuss verringert sich, die Spannung ändert sich wieder in die entgegengesetzte Richtung, bis wieder ein Gleichgewicht eingestellt ist.

Das Messprinzip ist die Potenziometrie. Die beiden Elektroden sind über ein Spannungsmessgerät miteinander verbunden. Das Potenzial der Referenzelektrode ist konstant. Wenn man die Messelektrode in die Probenlösungen taucht, ändert sich dort das Potenzial und man kann die Potenzialdifferenz zwischen beiden Elektroden messen.

Die Potenziale $E$ werden für beide Elektroden durch die Nernst-Gleichung ausgedrückt:

$$
\begin{aligned}
E & =E_{0}+\frac{R \cdot T}{z \cdot F} \cdot \ln \frac{[O x]}{[\text { Red }]} \\
& =E_{0}+\frac{R \cdot T}{z \cdot F} \cdot \ln \left[a_{I o n}\right]
\end{aligned}
$$


$\underline{\text { Die Potenzialdifferenz } \Delta E \text { ergibt sich aus der Differenz der Potenziale beider Elektroden: }}$

$$
\begin{aligned}
\Delta E & =E_{\text {Referenzelektrode }}-E_{\text {Messelektrode }} \\
& =\left(E_{0 \text { Ref }}+\frac{R \cdot T}{z \cdot F} \cdot \ln \left[a_{\text {Ref }}\right]\right)-\left(E_{0 \text { Mess }}+\frac{R \cdot T}{z \cdot F} \cdot \ln \left[a_{\text {Mess }}\right]\right)
\end{aligned}
$$

\section{Erläuterung der Abkürzungen:}

E Entspricht dem Potenzial der Elektrode

$E_{0} \quad$ Standardpotenzial, Ref $=$ Referenzelektrode, Mess $=$ Messelektrode

$\Delta E \quad$ Potenzialdifferenz

$\frac{[O x]}{[\text { Red }]}=\left[\mathrm{a}_{\text {Ion }}\right]$ Aktivität der lonen, d. h. entspricht der Konzentration der lonen, die frei in der Lösung vorliegen. So werden theoretisch auch gebundene lonen, die nicht zum Potenzial beitragen können, in der Rechnung berücksichtigt.

[a $\mathrm{a}_{\text {Mess }}$ Entspricht hier der Konzentration der ungebundenen $\mathrm{F}^{-}$, die das Potenzial an der Messelektrode erzeugen

$\left[a_{\text {Ref }}\right]$ Entspricht der Aktivität der freien lonen im Elektrolyt der Bezugselektrode, die dort das Potenzial bestimmen.

R Allgemeine Gaskonstante

F $\quad$ Faradaykonstante

T Absolute Temperatur in Kelvin

Anzahl der übertragenen Elektronen bei der Redoxreaktion, entspricht der Ladung des entsprechenden lons mit Vorzeichen

Die Messungen wurden bei einer konstanten Temperatur von $20^{\circ} \mathrm{C}$ durchgeführt, da die Potenziale temperaturabhängig sind. Ebenso musste ein pH-Wert von 5 bis 5,5 eingestellt werden. In diesem Bereich liegt das Fluorid als ungebundenes lon in der Lösung vor und kann vollständig von der Messelektrode erfasst werden. Liegt ein pH Wert von unter 5 vor, bilden die überschüssigen Protonen zusammen mit Fluoridionen teilweise Fluorwasserstoff 
(HF), welches bei der Messung nicht registriert wird, da es gebunden ist. Bei einem pH-Wert über 5,5 liegen zunehmend mehr $\mathrm{OH}^{-}$-lonen vor. Diese können als sogenannte Interferenzoder Störionen an die Sonde binden. Dort haben die $\mathrm{OH}^{-}$-lonen denselben Effekt wie die Fluoridionen und täuschen dadurch einen höheren Fluoridgehalt in der Probenlösung vor. Bis auf diese kontrollierbare Ausnahme ist die Sonde aber sehr selektiv für Fluoridionen. Es muss außerdem ein Chelator zugesetzt werden. Dieser bindet eventuell vorhandene $\mathrm{Ca}^{2+}$ Ionen, die sonst mit Fluoridionen schwer lösliches Kalziumfluorid $\left(\mathrm{CaF}_{2}\right)$ bilden würden, welches ebenfalls nicht bei der Potenzialmessung registriert werden würde. Durch Zugabe von TISAB-III-Pufferlösung (Total Ionic Strength Adjustment Buffer), die Essigsäure/AcetatPuffer, Ammoniumchlorid und als Chelator Titriplex IV enthält, wurde ein pH-Wert von 5,4 eingestellt. Vorher muss die Probe neutralisiert werden. In den Versuchen wurde die eingesetzte Salzsäure $(\mathrm{pH} 2)$ mit einer äquimolaren Menge Natronlauge $(\mathrm{pH} 12)$ neutralisiert. Der Aktivitätskoeffizient der Nernst-Gleichung ist nicht allein von den Fluoridionen in der Probe oder Eichlösung abhängig, sondern auch von der Gesamtionenkonzentration (lonenstärke). Wenn man einen konstanten Aktivitätskoeffizienten des zu messenden Fluorids erhalten will und somit genaue Ergebnisse, muss diese lonenstärke in den Proben und Eichlösungen ausreichend hoch und konstant sein. TISAB III kompensiert und relativiert hier leichte Unterschiede der lonenstärke der verschiedenen Proben und Eichlösungen durch eine eigene, um ein Vielfaches höhere lonenstärke.

\subsubsection{Bestimmung des natürlichen Fluoridgehalts (Basisfluoridgehalt)}

Je eine Hälfte des Zahnes wurde zur Bestimmung des Basisfluoridgehalts herangezogen. Aus einen Tesa ${ }^{\circledR}$-Filmstreifen (Tesa AG, Hamburg) wurde mit einer entsprechend zugeschnittenen Rasierklinge ein 1,5x1 mm großes Rechteck ausgestanzt und dann der gefensterte Tesa ${ }^{\circledR}$-Filmstreifen auf die Schmelzoberfläche geklebt. Auf die abgeklebte 1,5 $\mathrm{mm}^{2}$ große Schmelzfläche wurden $11,5 \mu \mathrm{l}$ Salzsäure $(\mathrm{pH} 2)$ aufgetragen. Nach einer Einwirkzeit von $15 \mathrm{~s}$ wurde die Säure vollständig mit einer Mikroliterpipette (Gilson SAS, Villiers-le-Bel, Frankreich) aufgesaugt und in ein PCR-Softtube-Reaktionsgefäß (Biozym Scientific $\mathrm{GmbH}$, Hess. Oldendorf) pipettiert. Um einen neutralen $\mathrm{pH}$-Wert von $7 \mathrm{zu}$ erreichen, wurde zum vom Schmelz abpipettierten Säurevolumen ein äquivalentes Volumen Natronlauge $(\mathrm{pH}$ 12) pipettiert. Dann wurde auf zehn Volumenteile Probenlösung ein Volumenteil TISAB III (Merck AG, Darmstadt) zugefügt. Dadurch wurden eventuelle Interferenzionen komplexiert, der für die Fluoridbestimmung erforderliche $\mathrm{pH}$-Wert 5,4 und 
die richtige Ionenstärke eingestellt. Die Probenlösung wurde dann lichtgeschützt und luftdicht verschlossen bis zur Fluoridgehaltbestimmung aufbewahrt.

\subsubsection{Fluoridgehaltbestimmung nach Applikation der Füllungsmaterialien}

Nach $24 \mathrm{~h}$ konnte die Schutzfolie mit einem erhitzten Skalpell zerteilt und in Fragmenten vorsichtig entfernt werden. Auf dem Zahn haftende Reste des Gelatinegels wurden mit einem mit bidestilliertem Wasser getränkten Tuch entfernt. Die Füllung und der angrenzende Schmelz wurde bis auf den ersten Halbkreisausschnitt von 0 bis $60^{\circ}$ mit Tesa $^{\circledR}$ Film abgeklebt. Dann wurde mit einem genormten Henkellocheisen (Schneider + Klein Metallwaren $\mathrm{GmbH} \&$ Co. $\mathrm{KG}$, Stuttgart) in ein etwa $1 \times 1 \mathrm{~cm}$ großes Stück einer weichen Polyethylen-Klebefolie ein Kreis mit dem Durchmesser $6 \mathrm{~mm}$ gestanzt und entfernt. Auf den Rand wurde im Kreisausschnitt von etwa 0 bis $180^{\circ}$ ein Wall aus weichem Periphery Wachs (Heraeus Kulzer $\mathrm{GmbH}$, Hanau) von circa $3 \times 3 \mathrm{~mm}$ auf der nicht klebenden Seite aufgebaut. Mit einer Sonde wurde der Rand innen abgefahren, sodass von der Klebefolie in Richtung Loch überstehendes Wachs entfernt wurde und ein dichter Übergang im $90^{\circ}$-Winkel zur Folienoberfläche entsteht. Dann wurde diese Folie so auf den Zahn geklebt, dass der Stanzrand mit dem Wachswall genau 0,5 mm parallel zum Füllungsrand liegt. Seitlich am ehemaligen Sägerand wurde der Wachswall mit Wachs so erweitert, dass die Sägekante nach obenhin verlängert wurde. Dadurch wurde erreicht, dass die Säure dort später nicht herunterläuft und auf dem freiliegenden Schmelz bleibt. Das feste, spaltfreie Anliegen der Folie auf dem Schmelz, bzw. außerhalb des ersten Kreisausschnittes auf dem Tesa ${ }^{\circledR}$-Film, wurde unter dem Auflichtmikroskop (Carl Zeiss Jena $\mathrm{GmbH}$, Jena) überprüft. Gegebenenfalls fand eine Korrektur statt. Dadurch wurde gewährleistet, dass der Schmelzrand eingegrenzt von dem Wachswall im Bereich des ersten Halbkreisausschnitts von 0 bis $60^{\circ}(\alpha)$ genau 0,5 $\mathrm{mm}$ freiliegt. Dies entspricht einer Fläche von 1,44 $\mathrm{mm}^{2}$ (Abb. 6). 


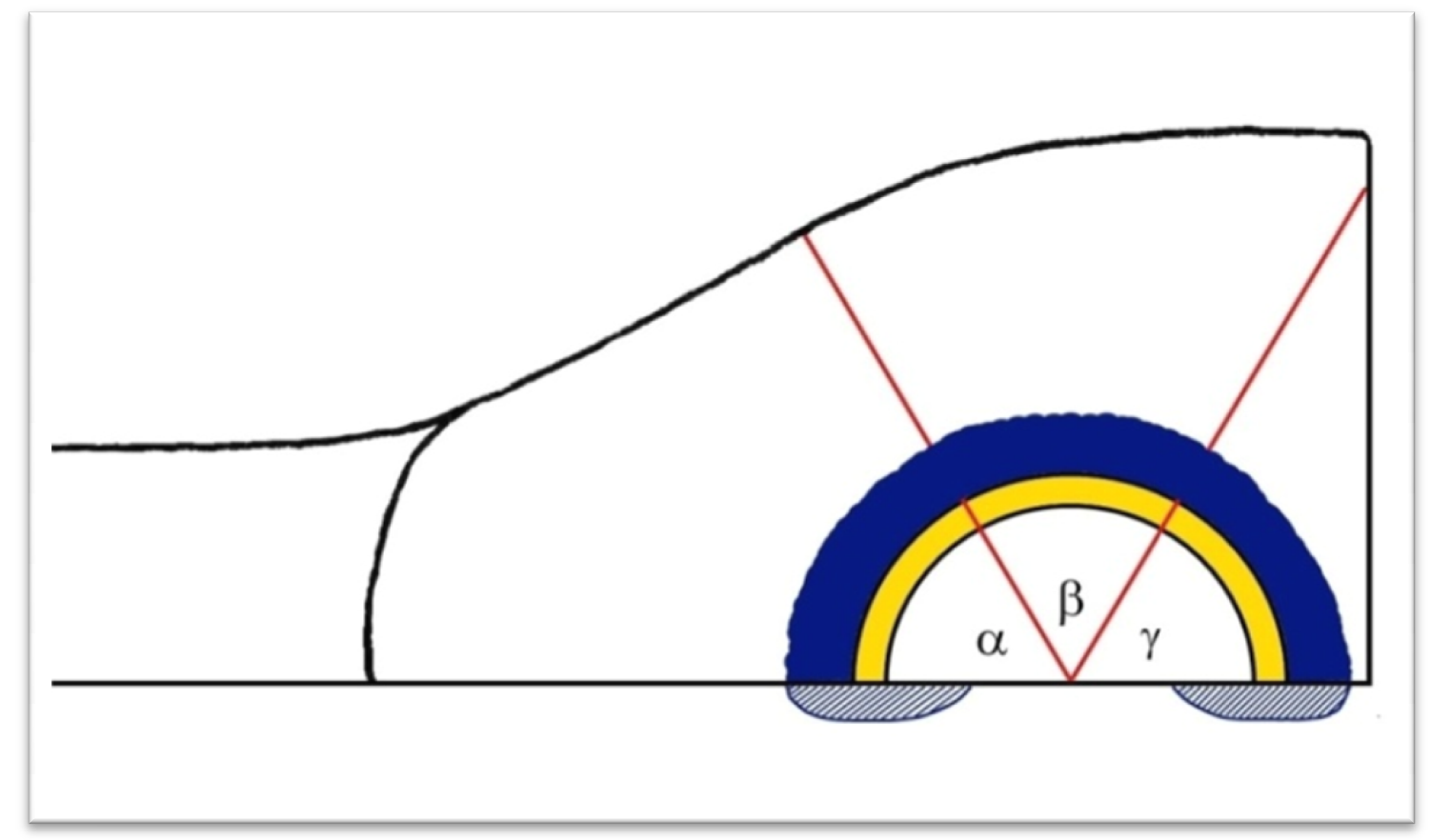

Abb. 6 Schematische Darstellung einer Zahnhälfte vor dem Säureauftrag. Die drei gelben Kreisringausschnitte kennzeichnen den Schmelzbereich 0,5 $\mathrm{mm}$ um die Füllung (weißer Halbkreis), auf den die Säure zu den Zeitpunkten 24 h, 48 h und 72 h nach Füllungsapplikation aufgetragen wurde. Der Wachswall ist blau gekennzeichnet. Die blau schraffierten Anteile stellen jeweils die Erweiterungen des Wachswalls bei den Messungen im Bereich $\alpha$ (24 h nach Füllungsapplikation) und $\gamma$ (72 h nach Füllungapplikation) dar. Je nach Messzeitpunkt wurden die Bereiche entlang der roten Linien mit Tesa ${ }^{\circledR}$-Film abgeklebt.

Auf diesen Bereich wurden mit einer Mikroliterpipette $11 \mu \mathrm{HCl}(\mathrm{pH} 2)$ aufgetragen und nach $15 \mathrm{~s}$ möglichst vollständig mit der Pipette wieder aufgesaugt und in ein PCR-Softtube pipettiert. Die Folie, das Wachs und der Tesa ${ }^{\circledR}$-Film wurden vollständig entfernt, nachdem der Zahn gründlich mit destilliertem Wasser abgespült wurde. Zu dem abpipettierten Volumen Salzsäure $(\mathrm{HCl})$ wurde eine äquivalente Menge Natronlauge $(\mathrm{NaOH})$ mit pH 12 zugefügt, um die Säure zu neutralisieren. Auf zehn Volumenteile dieser Probenlösung wurde dann noch ein Volumenteil TISAB III zugefügt. Dann wurde die Probe im Brutschrank (Fa. Medcenter Einrichtungen MMM Group, Gräfelfing) bei $37^{\circ} \mathrm{C}$ in luftdichten Kunststoffröhrchen (Greiner Bio-One $\mathrm{GmbH}$, Frickenhausen) bei 100\% Luftfeuchtigkeit aufbewahrt. Nach 24 h (48 h nach Füllungsapplikation) erfolgte, wie bereits beschrieben, die zweite Messung im nächsten Halbkreisausschnitt von 60 bis $120^{\circ}(\beta)$ (Abb. 6). Der Tesa ${ }^{\circledR}$-Film deckte den Bereich von 0 bis $60^{\circ}(\alpha)$ und von 120 bis $180^{\circ}(\gamma)$ ab. Danach kam die Probe wieder in den Brutschrank bei $37^{\circ} \mathrm{C}$ und $100 \%$ Luftfeuchte. Nach weiteren $24 \mathrm{~h}$ (72 h nach 
Füllungsapplikation) wurde die dritte Messung im letzten Halbkreisausschnitt von 120 bis $180^{\circ}(\gamma)$ vorgenommen, wobei diesmal folglich die ersten beiden Halbkreisausschnitte von 0 bis $120^{\circ}$ mit Tesa ${ }^{\circledR}$-Film bedeckt waren.

\subsubsection{Fluoridgehaltbestimmung der Proben}

Der Fluoridgehalt der Proben wurde über den Abgleich mit Eichkurven ermittelt. Dafür wurde vor jeder Messreihe mit einer Fluoridstandardlösung (Fa. WTW, Weilheim) eine Fluoridverdünnungsreihe mit den Fluoridkonzentrationen $0,1,2,4,8,16,32,64$ und 128 $\mu \mathrm{mol} / \mathrm{I}$ hergestellt, die ebenfalls TISAB III (Merck AG, Darmstadt) im Verhältnis ein Volumenteil (VT) auf zehn Volumenteile enthielt. Diese wurden dann mit der Fluoridelektrode (Fa. Mettler Toledo, Schweiz) (Abb. 7) angefangen bei der Lösung mit der niedrigsten Fluoridkonzentration $(0 \mu \mathrm{mol} / \mathrm{l})$ aufsteigend bis zur Lösung mit der höchsten Fluoridkonzentration (128 $\mu \mathrm{mol} / \mathrm{l})$ gemessen und aus den Werten anschließend eine Eichkurve erstellt. Dann wurden die gewonnenen Proben ebenfalls mit Fluoridelektrode gemessen und durch das Abgleichen mit den Eichkurvenwerten der Fluoridgehalt ermittelt.

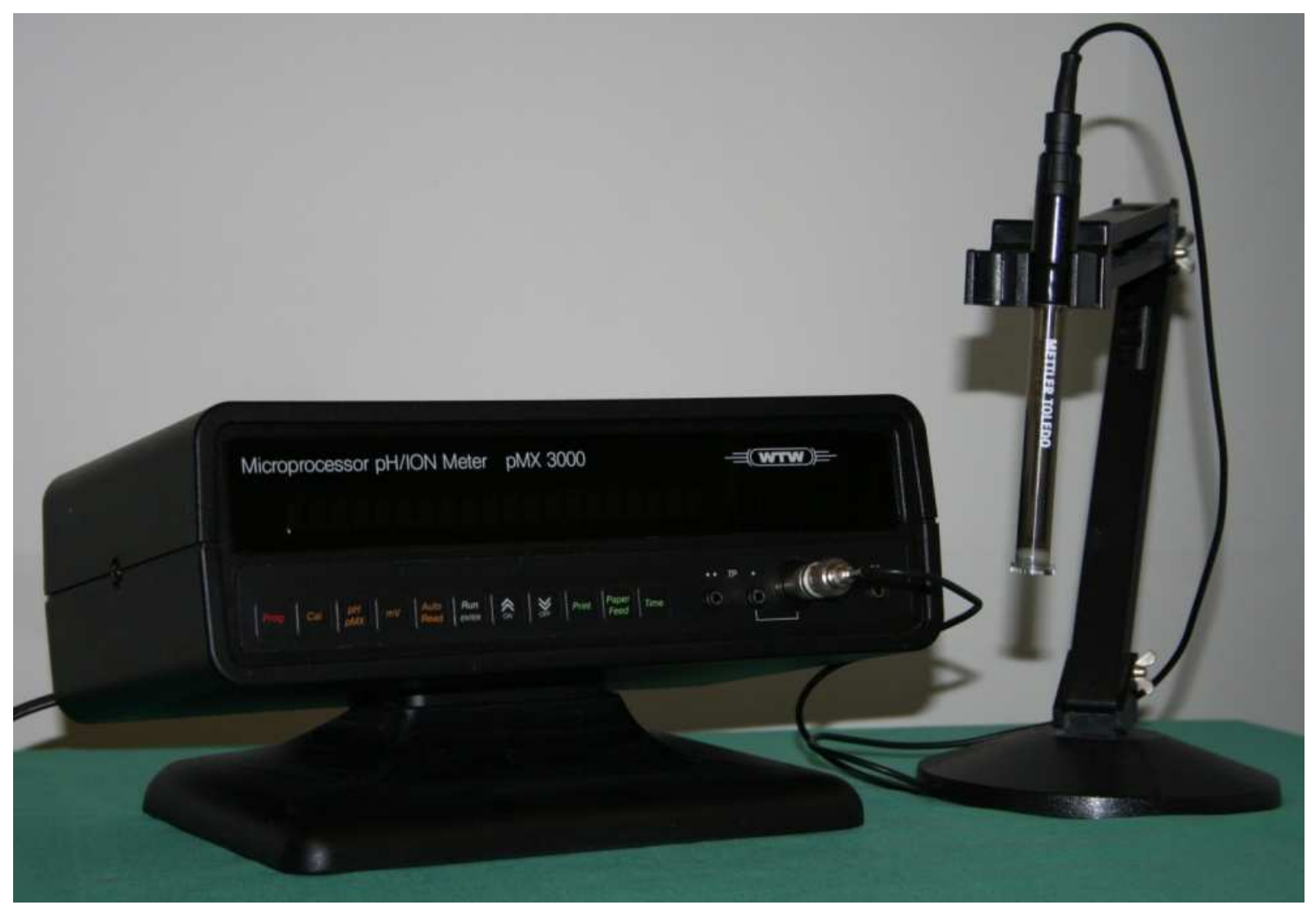

Abb. 7 Messplatz mit Fluoridmesselektrode und angeschlossenem Spannungsmessgerät. 


\subsubsection{Umrechnung der Fluoridkonzentration bezogen auf das Ausgangsvolumen der Säure}

Die ermittelte Fluoridkonzentration der Proben bezieht sich auf das Gesamtprobenvolumen $\left(V_{\text {Gesamt }}\right)$ mit zugesetzter Natronlauge $\left(V T_{\mathrm{NaOH}}\right)$ und TISAB III $\left(V T_{\text {TISAB III }}\right)$ und nicht auf das Ursprungsvolumen der Salzsäure $\left(V T_{H C l}\right)$. Daher musste bei jedem Wert eine Umrechnung nach folgendem Rechenschema stattfinden:

$$
V_{\text {Gesamt }}=1 V T_{H C l}+1 V T_{N a O H}+0,2 V_{T I S A B I I I} \quad[\mu l]
$$

Aus der Verdünnung ergibt sich ein Umrechnungsfaktor von 2,2 bezogen auf die Gesamtprobenkonzentration $\left(\left[c_{F^{-}}\right]_{\text {in } V_{\text {gesamt }}}\right)$, um die Konzentration des Fluorids $\left(\left[c_{F^{-}}\right]_{\text {in } V_{H C l}}\right)$ auf das ursprüngliche Volumen der Salzsäure $(\mathrm{HCl})$ umzurechnen:

$$
\left[c_{F^{-}}\right]_{\text {in } V_{H C l}}=2,2 \cdot\left[c_{F^{-}}\right]_{\text {in }} V_{\text {gesamt }} \quad[\mu \mathrm{mol} / \mathrm{l}]
$$

Dann erfolgte die Umrechnung der Fluoridkonzentration $\left(\left[c_{F^{-}}\right]\right)$von $[\mu \mathrm{mol} / l]$ in $[\mu \mathrm{g} / \mathrm{l}]$ über die Molmasse des Fluorids $\left(M_{m}=19 \mu \mathrm{g} / \mu \mathrm{mol}\right)$ :

$$
M_{m} \cdot\left[c_{F^{-}}\right]_{\text {in } V_{H C l}}=19 \cdot\left[c_{F^{-}}\right]_{i n V_{H C l}} \quad[\mu g / l]
$$

Dann erfolgte die Bestimmung der Masse des Fluorids $\left(m_{F^{-}}\right)$in $\mu \mathrm{g}$ bezogen auf die $11 \mu \mathrm{l}$ Ausgangsvolumen $\mathrm{HCl}$, die auf die Schmelzfläche von 1,44 $\mathrm{mm}^{2} 15$ s einwirkten:

$f \ddot{u} r 1 \mu l:$

$$
m_{F^{-}}=\left[c_{F^{-}}\right]_{\text {in } V_{H C l}} \cdot M_{m} \cdot 10^{-6}
$$

für $11 \mu l$ :

$$
m_{F^{-}}=11 \cdot\left(\left[c_{F^{-}}\right]_{\text {in } V_{H C l}} \cdot M_{m} \cdot 10^{-6}\right)
$$

Die Fläche von 1,44 $\mathrm{mm}^{2}$ ergibt sich folgendermaßen: Der Flächeninhalt des Kreises mit dem Durchmesser $5 \mathrm{~mm}$ (= Innenkreis, entspricht der doppelten halbkreisförmigen Oberfläche der Füllung) muss von dem Flächeninhalt $(A)$ des Kreises mit dem Durchmesser $6 \mathrm{~mm}$ (Außenkreis) subtrahiert werden. So erhält man den Flächeninhalt des kreisförmigen Bereiches 0,5 mm um den Füllungsrand herum (Kreisring). Da eine Messung genau $60^{\circ}$ des Kreisringes einnimmt und der gesamte Kreisring aber $360^{\circ}$ misst, muss die Fläche noch mit dem Faktor $\frac{1}{6}$ multipliziert werden. Es ergibt sich also:

$$
\frac{1}{6} A_{(\text {Außenring })}=\frac{1}{6} A_{(\text {Außenkreis }=A K)}-\frac{1}{6} A_{(\text {Innenkreis }=I K)} \quad\left[\mathrm{mm}^{2}\right]
$$




$$
\begin{array}{ll}
=\frac{1}{6} \pi \cdot r_{(A K)}^{2}-\frac{1}{6} \pi \cdot r_{(I K)}^{2} & {\left[\mathrm{~mm}^{2}\right]} \\
=\frac{1}{6} 3,14 \cdot 3^{2}-\frac{1}{6} 3,14 \cdot 2,5^{2} & {\left[\mathrm{~mm}^{2}\right]} \\
=1,44 \mathrm{~mm}^{2} &
\end{array}
$$

Daher ergibt sich für die Menge des Fluorids in $\mu \mathrm{g}$, das pro $\mathrm{s}$ und $\mathrm{mm}^{2}$ aus dem Schmelz, bezogen auf die Ausgangsmenge von $11 \mu \mathrm{l} \mathrm{HCl}$, herausgelöst wurde, folgende Formel:

$$
\frac{m_{F^{-}}}{t \cdot A}=\frac{11 \cdot\left[c_{F^{-}}\right]_{i n V_{H C l}} \cdot M_{m} \cdot 10^{-6}}{15 \cdot 1,44} \quad\left[\frac{\mu g}{S \cdot m^{2}}\right]
$$




\section{Ergebnisse}

\subsection{Basisfluoridgehalt}

Vor der Applikation der verschiedenen Füllungsmaterialien wurde für jede Zahnprobe $(n=90)$ der natürliche Fluoridgehalt (Basisfluoridgehalt) bestimmt. Alle Messwerte lagen unterhalb der Messgrenze $\left(0,6386 \mathrm{ng} \mathrm{F}^{-} / \mathrm{mm}^{2}\right)$. Für die statistische Auswertung wurde der Basisfluoridgehalt daher gleich Null gesetzt.

\subsection{Fluoridgehalt nach Applikation der Füllungsmateralien}

\subsubsection{Glasionomerzement}

Nach der Applikation des Glasionomerzements wurde nach 24 h, 48 h und 72 h der Fluoridgehalt bestimmt. Alle ermittelten Werte lagen oberhalb der Messgrenze (Tab. I). Die zu den einzelnen Zeitpunkten gemessenen Fluoridgehalte unterschieden sich signifikant vom Basisfluoridgehalt $(p<0,0001)$. Der durchschnittliche Fluoridgehalt unterschied sich zu allen Zeitpunkten signifikant voneinander.

\begin{tabular}{|c|c|c|}
\hline Messzeitpunkt & Mittelwert & SD \\
\hline 24 h nach Füllungsapplikation & 3,19 & 1,72 \\
\hline 48 h nach Füllungsapplikation & 4,78 & 2,8 \\
\hline 72 h nach Füllungsapplikation & 6,94 & 4,07 \\
\hline
\end{tabular}

Tab. I: Mittelwert und Standardabweichung (SD) der Fluoridfreisetzung [ng/mm²] 24, 48 und $72 \mathrm{~h}$ nach Applikation des Glasionomerzements

\subsubsection{Komposit}

Die Fluoridfreisetzung lag zu allen Zeitpunkten ( 24 h, 48 h, 72 h) unterhalb der Messgrenze $\left(0,6386 \mathrm{ng} \mathrm{F}^{-} / \mathrm{mm}^{2}\right)$.

\subsubsection{Kompomer}

Die Fluoridfreisetzung lag zu allen Messzeitpunkten oberhalb der Messgrenze $(0,6386 \mathrm{ng}$ $\mathrm{F}^{-} / \mathrm{mm}^{2}$ ) (Tab. II). Die durchschnittliche Fluoridfreisetzung nach $24 \mathrm{~h}, 48 \mathrm{~h}$ und $72 \mathrm{~h}$ unterschied sich signifikant vom Basisfluoridgehalt $(p<0,0001)$. 


\begin{tabular}{|c|c|c|}
\hline Messzeitpunkt & Mittelwert & SD \\
\hline 24 h nach Füllungsapplikation & 1,82 & 1,1 \\
\hline 48 h nach Füllungsapplikation & 2,61 & 1,92 \\
\hline 72 h nach Füllungsapplikation & 3,61 & 2,6 \\
\hline
\end{tabular}

Tab. II: Mittelwert und Standardabweichung (SD) der Fluoridfreisetzung [ng/mm²] 24, 48 und $72 \mathrm{~h}$ nach Applikation des Kompomers

\subsection{Vergleiche zwischen den Füllungsmaterialien}

\subsubsection{Vergleich der Messwerte $24 \mathrm{~h}$ nach Füllungsapplikation}

Zum Zeitpunkt $24 \mathrm{~h}$ nach Füllungsapplikation war ein signifikanter Unterschied in der durchschnittlichen Fluoridfreisetzung zwischen allen drei Gruppen (Glasionomerzement: $3,19 \mathrm{ng} / \mathrm{mm}^{2}$, Komposit: $0 \mathrm{ng} / \mathrm{mm}^{2}$, Kompomer: 1,82 ng/mm²) feststellbar $(\mathrm{p}<0,0001)$.

\subsubsection{Vergleich der Messwerte $48 \mathrm{~h}$ nach Füllungsapplikation}

Zum Zeitpunkt $48 \mathrm{~h}$ nach Füllungsapplikation gab es einen signifikanten Unterschied in der durchschnittlichen Fluoridfreisetzung zwischen allen drei Gruppen (Glasionomerzement: $3,19 \mathrm{ng} / \mathrm{mm}^{2}$, Komposit: $0 \mathrm{ng} / \mathrm{mm}^{2}$, Kompomer: 2,61 ng/mm²) $(\mathrm{p}<0,0001)$.

\subsubsection{Vergleich der Messwerte 72 h nach Füllungsapplikation}

Zum Zeitpunkt $72 \mathrm{~h}$ nach Füllungsapplikation unterschieden sich alle drei Gruppen signifikant in der durchschnittlichen Fluoridfreisetzung (Glasionomerzement: 6,94 ng/mm², Komposit: 0 $\mathrm{ng} / \mathrm{mm}^{2}$, Kompomer: $\left.3,61 \mathrm{ng} / \mathrm{mm}^{2}\right)(\mathrm{p}<0,0001)$.

\subsection{Verteilung der einzelnen Fluoridgehalte in den Gruppen}

Die ermittelten medianen Werte der Fluoridfreisetzung zeigen für die beiden fluoridhaltigen Füllungsmaterialien einen Anstieg der Fluoridaufnahme über den Messzeitraum (Abb. 8). 


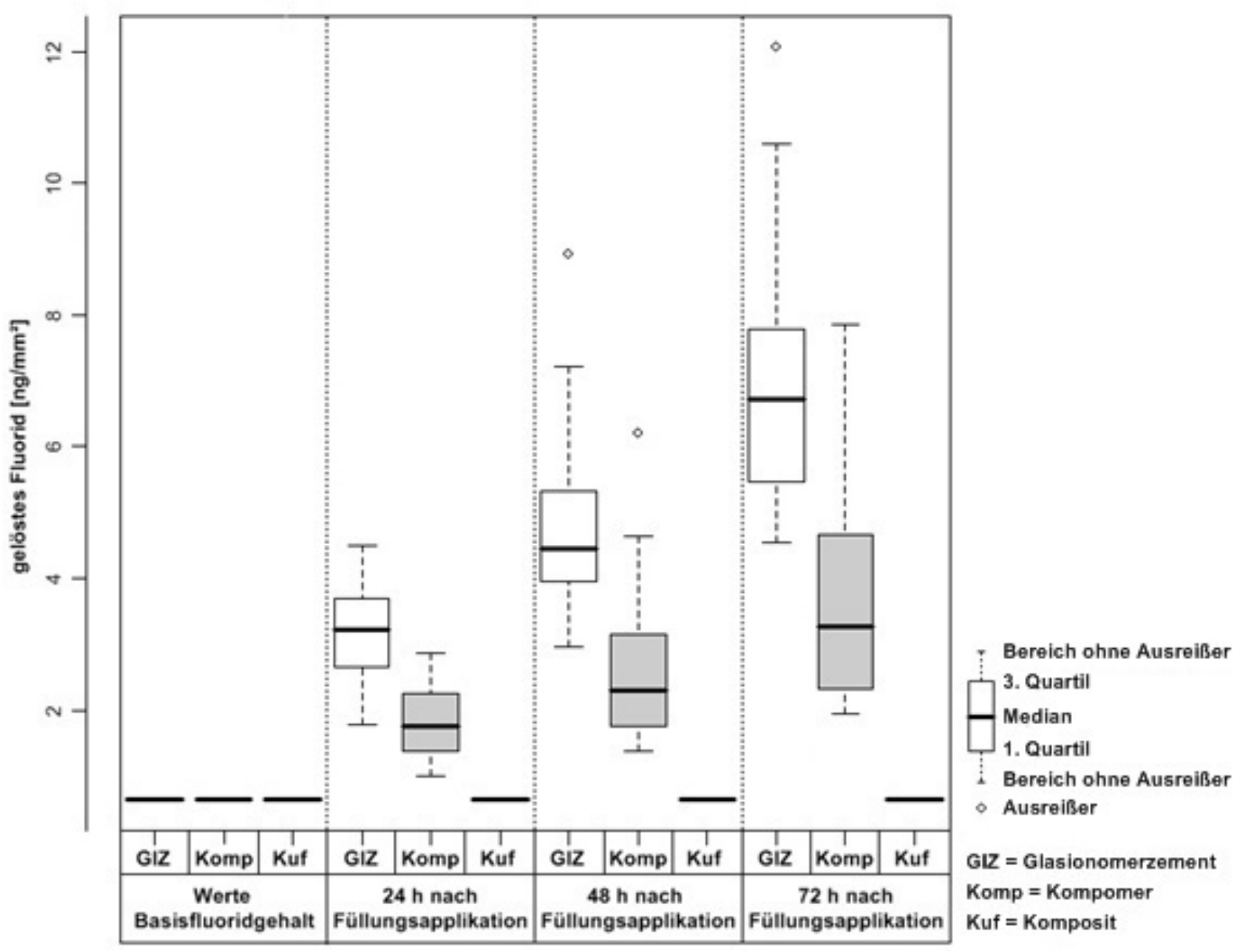

Abb. 8 Grafische Darstellung (Boxplots) der Verteilung der herausgelösten Fluoridmengen [ng/mm²] für die Gruppen Glasionomerzement (GIZ), Kompomer (Komp) und Komposit (Kuf) zu den Zeitpunkten Null (Basisfluoridgehalt), 24 h, 48 h und 72 h nach Füllungsapplikation. 


\section{Diskussion}

\subsection{Diskussion der Methode}

In dieser Studie wurde nicht die genaue Fluoridaufnahme des Schmelzes pro $\mathrm{mm}^{3}$ durch die Füllungsmaterialien im Füllungsrandbereich ermittelt, sondern wie viel bei einer simulierten Säureattacke pro $\mathrm{mm}^{2}$ und Zeiteinheit in Lösung geht. Für die Ermittlung der genauen Fluoridaufnahme hätte man den Schmelz durch Schleifen definiert abtragen müssen und dann den Fluoridgehalt des abgetragenen Volumens bestimmen müssen. Dieser definierte Abtrag, ohne Füllungsanteile dabei zu tangieren, ist wegen des direkten Übergangs des Schmelzes zum Füllungsmaterial in dieser Präzision nicht zu realisieren und eine Verfälschung der Fluoridgehalte wahrscheinlich. Der Fluoridgehalt des Schmelzes ist bei der Demineralisierung der Zahnhartsubstanzen und der Kariesentstehung nicht per se entscheidend. Entscheidend ist, wie viel Fluorid bei einem Säureangriff aus dem interprismatischen Raum des Schmelzes in Lösung geht und zum Schutz der Zahnhartsubstanz gegen Demineralisation und zur späteren Förderung der Remineralisation zur Verfügung steht (Ten Cate 1990). Es sollte außerdem ermittelt werden, wie viel Fluorid allein durch den Kontakt des Füllungsmaterials in die angrenzende Zahnhartsubstanz aufgenommen wird, ohne dass das Fluorid vorher in Lösung gegangen ist. Zu diesem Zweck wurde die freie Füllungsoberfläche mit Schellack isoliert, der über den gesamten Testzeitraum auf der Füllung verblieb. Die Sekundärkaries weist einen zweiteiligen Aufbau auf. Direkt am Rand der Restauration befindet sich die äußere Läsion („outer lesion“). An die äußere Läsion schließt sich, entlang des Füllungsrandes in die Tiefe gehend, die Kavitätenwandläsion („wall lesion“) an (Grossman und Matejka 1999, Hals und Nernaes 1971, Kidd 1976, Kidd et al. 1992, Kidd et al. 1995). Die Ausmaße der äußeren Läsion, marginale Randverfärbungen oder Randimperfektionen lassen nicht immer eindeutige Rückschlüsse auf das Vorhandensein kariöser Läsionen in den tieferen Bereichen des Füllungsrands zu (Foster 1994, Kidd 1991). Der marginale Füllungsrand kann intakt erscheinen und trotzdem kann in der Tiefe an der Kavitätenwand bereits eine behandlungsbedürftige kariöse Läsion entstanden sein. In der Praxis ist es daher teilweise schwierig, richtig einzuschätzen, wie weit eine Sekundärkariesläsion schon entlang des Füllungsrandes vorangeschritten ist und ob eine invasive Maßnahme, sprich ein Austausch oder Reparatur der Restauration, notwendig ist (Ando et al. 2004, Kidd und O‘Hara 1990, Kidd et al. 1992). Daher ist es von besonderem Interesse, die Fluoridaufnahme, die allein 
durch den Kontakt der angrenzenden Füllungsmaterialien in den Schmelz stattfindet, zu ermitteln. Diese lässt Rückschlüsse zu, ob vielleicht auch in tieferen Bereichen des Füllungsrands eine Fluoridaufnahme stattfindet, die dort eventuell der Demineralisation der Zahnhartsubstanz und dem Entstehen und der Progression kariöser Kavitätenwandläsionen entgegenwirken könnte.

\subsubsection{Boviner Schmelz}

Unversehrte und gesunde bovine Schneidezähne können in beliebiger Höhe und ohne großen Aufwand beschafft werden. Das Erscheinungsbild der Schneidezähne entspricht dem vergrößerter humaner Schneidezähne (Komori und Ishikawa 1999). Die Zusammensetzung der Zähne der Menschen variiert sehr viel stärker als dies bei unterschiedlichen Rindern der Fall ist (Mellberg 1992). Für wissenschaftliche Arbeiten und deren Reproduzierbarkeit ist es notwendig, alle Bedingungen und Materialien möglichst zu standardisieren. Die chemische Zusammensetzung und die physikalischen Eigenschaften von bovinen und humanen Zähnen sind vergleichbar. So ist beispielsweise der Gehalt an Kalzium, Phosphor und Magnesium ähnlich (Davidson et al. 1973, Esser et al. 1998, Fincham 1980, Fincham et al. 1982). Mellberg und Loertscher (1974) verglichen den natürlichen Fluoridgehalt humanen Schmelzes von Personen aus einer Region mit einem moderaten Trinkwasserfluoridgehalt (0,5-1 ppm) mit den Fluoridgehalt bovinen Schmelzes. Sie fanden heraus, dass der Fluoridgehalt bovinen Schmelzes weniger stark schwankt als der humanen Schmelzes. Im Durchschnitt ist der Fluoridgehalt bovinen Schmelzes insgesamt deutlich geringer (200 ppm) als der Fluoridgehalt humanen Schmelzes (1350 ppm). Dies birgt den Vorteil, dass boviner Schmelz bezüglich des Fluoridgehalts uniformer ist und ein standardisierteres Material für wissenschaftliche Versuche darstellt als humaner Schmelz. Andere Arbeiten zeigten, dass das Elastizitätsmodul und der thermische Ausdehnungskoeffizient sehr ähnlich sind (Gente et al. 1985, Lees 1968). Die durchschnittliche Dichte von humanem Schmelz beträgt $2,95 \pm 0,05$ $\mathrm{g} / \mathrm{cm}^{3}$ (Weidmann et al. 1967). Esser et al. (1998) gaben für bovinen Schmelz eine ähnliche Dichte von durchschnittlich $2,90 \mathrm{~g} / \mathrm{cm}^{3}$ an. Vergleicht man die Haftkräfte von verschiedenen Komposit- und Glasionomerzementfüllungen an menschlichem und bovinem Schmelz, so resultieren ähnliche Werte. Die Haftkräfte dieser Füllungsmaterialien am bovinem und menschlichem Dentin sind ebenfalls ähnlich hoch (Nakamichi et al. 1983). Bovine Zähne werden in vielen Studien, die sich mit der Fluoridaufnahme der Zahnhartsubstanz beschäftigen, verwendet und in manchen Studien auch explizit als Ersatzmaterial für 
humane Zähne empfohlen, weil sie den menschlichen strukturell sehr ähnlich sind und bezogen auf den Fluoridgehalt weniger stark variieren (Camargo et al. 2007, Lammers et al. 1991, Mellberg und Loertscher 1974, Oesterle et al. 1998, Pearce 1983, Yamazaki und Margolis 2008).

\subsubsection{Analysemethoden}

Zur Bestimmung des Fluorids wurde eine definierte Menge Salzsäure $(\mathrm{HCl})$ mit einer Mikroliterpipette auf den Schmelz im Füllungsrandbereich aufgetragen. Um zu verhindern, dass die Säure auch aus dem Füllungsmaterial selbst Fluorid löst, wurde dies vorher versiegelt. Im Vorfeld wurden diverse Lacke dafür getestet. Von diesen konnte nur Schellack alle notwendigen Anforderungen erfüllen. Er ist säurebeständig und lässt über den Testzeitraum von $72 \mathrm{~h}$ kein Fluorid passieren. Aufgrund der guten Stabilität gegenüber der Salzsäure des Magens findet Schellack breite Verwendung in der pharmazeutischen Industrie, um z. B. säureempfindliche Medikamente während der Passage durch den Magen zu schützen (Pearnchop et al. 2004, Sheorey et al. 1991). Die Bestimmung des Fluoridgehalts der erhaltenen Probenvolumina erfolgte mit einer Fluoridkombinationselektrode (ISE). Hierbei wurde das am weitesten verbreitete Verfahren nach Frant und Ross (1968) angewendet. Den gewonnenen Probelösungen wird vor der Fluoridgehaltbestimmung TISAB (Total Ionic Strength Adjustment Buffer) zugefügt und der Fluoridgehalt durch Vergleich der ermittelten Messwerte mit Kalibrationskurven bekannter Fluoridionenkonzentrationen bestimmt. Venkateswarlu (1990) sieht beim Vergleich diverser Methoden der Fluoridbestimmung den Vorteil dieser Methode gegenüber anderen in der einfachen und schnellen Anwendung. Sie ist für den Nachweis von anorganischem Fluorid sehr gut geeignet. Zudem sind für die Untersuchung keine teuren Geräte (wie z. B. bei der Messung mit einem Massenspektrometer) notwendig. Eine Fluoridkombinationselektrode und ein konventionelles Spannungsmessgerät genügen. Die Messabweichung der ermittelten Werte liegt mit ca. $\pm 5 \%$ in einem tolerablen Bereich (Frant und Ross 1968). Nicholson CR und Mellberg (1969) stellten fest, dass die Höhe der Fluoridaufnahme in den Schmelz vom natürlichen Basisfluoridgehalt beeinflusst wird. Da jedoch der Basisfluoridgehalt aller verwendeten Zähne unterhalb der Nachweisgrenze liegt, kann man davon ausgehen, dass er bei allen Zähnen sehr niedrig und ähnlich hoch ist. 


\subsection{Diskussion der Ergebnisse}

\subsubsection{Fluoridabgabe in Abhängigkeit vom verwendeten Material}

Es kann festgestellt werden, dass die Fluoridaufnahme in den an die Füllung angrenzenden Schmelz innerhalb von 72 h signifikant ansteigt. Glasionomerzement führt zur höchsten Fluoridanreicherung im umgebenden Zahnschmelz. Das Kompomer gibt in diesem Zeitraum durchschnittlich 92\% weniger Fluorid in den Zahnschmelz ab als der Glasionomerzement. Bei den mit Komposit gefüllten Proben lässt sich keine Fluoridabgabe in den angrenzenden Zahnschmelz nachweisen. Für diese Versuche werden zwei fluoridhaltige Füllungsmaterialien (Kompomer/Glasionomerzement) und ein fluoridfreies Füllmaterial (Komposit) verwendet. Das Kompomer enthält laut Herstellerangaben 72 Gew.-\% fluoridhaltige Gläser, entsprechend etwa 10 Gew.-\% Fluorid. Der angemischte Glasionomerzement enthält dagegen etwa 76,16 Gew.-\% fluoridhaltige Gläser. Dies zeigt, dass allein der Fluoridgehalt des Füllungsmaterials, der beim Glasionomerzement nur etwas höher ist als beim Kompomer, anscheinend nicht entscheidend für die Fluoridaufnahme des angrenzenden Schmelzes ist. Der Stoffaustausch im Schmelz selbst findet durch Diffusion über interprismatisch an die Kristallstruktur gebundenes Wasser statt. Diese porenartige Struktur des Schmelzes erlaubt den Austausch von Ionen und niedermolekularen Stoffen und so auch von Fluoridionen (Darling et al. 1961, Featherstone et al. 1979, Moreno und Zahradnik 1973). Es könnte möglich sein, dass das vor Applikation des Kompomers aufgetragene und ausgehärtete Adhäsiv diese Diffusion in den Schmelz einschränkt. Beim Glasionomerzement wird kein Adhäsiv aufgetragen. Das Füllmaterial hat direkt Kontakt zum Schmelz. Möglicherweise ist dies neben dem geringeren Fluoridgehalt der Kompomere der Grund, warum die direkte Aufnahme von Fluorid in den Schmelz nach der Applikation von Glasionomerzement sehr viel höher ist als beim Kompomer. Mazzaoui et al. (2000) stellten fest, dass mit Adhäsiv überzogene Probenkörper aus fluoridhaltigen Füllungsmaterialien signifikant weniger Fluorid in die Umgebungslösung abgaben als unbehandelte Probenkörper. Eine Behinderung der Fluoridabgabe durch das Adhäsiv war sowohl bei den Probenkörpern aus Glasionomerzement als auch bei denen aus Kompomer zu beobachten. Dabei gaben Glasionomerzemente in beiden Testreihen mehr Fluorid ab als Kompomere. Daraus ergibt sich der Hinweis, dass Adhäsive die Fluoridabgabe unabhängig von der Art des Füllungsmaterials behindern können. Ahiropoulos et al. (2008) testeten verschiedene fluoridhaltige Füllungsmaterialien in vitro auf ihre Fähigkeit, Fluorid in den angrenzenden 
bovinen Schmelz abzugeben. Der lichthärtende Glasionomerzement gab am ersten Tag am meisten Fluorid an den Schmelz ab. Danach folgten die konventionellen Glasionomerzemente, die sich produktabhängig nur wenig in der Menge des abgegebenen Fluorids unterschieden. Danach folgten die Kompomere, die sehr viel weniger Fluorid abgaben als die Glasionomerzemente. Nach 64 Tagen zeigten der lichthärtende Glasionomerzement und alle verwendeten konventionellen Glasionomerzemente die höchste Fluoridabgabe an den Schmelz. Die Kompomere gaben bis zum 64. Tag am wenigsten Fluorid an den Schmelz ab. Tam et al. (1997) stellten in vitro ebenfalls fest, dass Glasionomerzementfüllungen die höchste Fluoridaufnahme in die angrenzende Zahnhartsubstanz bewirkten. Die Kompomerfüllungen gaben dabei weniger Fluorid in die Zahnhartsubstanz ab als die Glasionomerzemente. In einer anderen Studie wurde in vivo die Fluoridaufnahme aus verschiedenen, applizierten Füllungsmaterialien in die angrenzende Zahnhartsubstanz gemessen. Die Fluoridaufnahme in den angrenzenden Schmelz und Dentin war in dieser Studie nach einem Monat beim konventionellen Glasionomerzement und beim Kompomer etwa gleich. Der geringste Fluoridgehalt wurde bei der Kontrolle, dem fluoridfreien Komposit, gemessen (Yamamoto et al. 2000). Benelli et al. (1993) konnten in vitro 28 Tage nach Applikation von Glasionomerzementfüllungen einen Fluoridgehalt von durchschnittlich 2500 ppm im angrenzenden Schmelz nachweisen. Der Fluoridgehalt im angrenzenden Schmelz von fluoridfreien Kompositfüllungen betrug nach 28 Tagen durchschnittlich 1300 ppm und war auf den Basisfluoridgehalt des Schmelzes zurückzuführen. Kawai et al. (1998) wiesen in vitro eine Fluoridaufnahme durch verschiedene, fluoridhaltige Komposite von durchschnittlich 312 bis 801 ppm in einer Tiefe von $10 \mu \mathrm{m}$ im angrenzenden Schmelz nach einer Woche nach. In einer Tiefe von $30 \mu \mathrm{m}$ sank die Menge des aus den Füllungsmaterialien aufgenommenen Fluorids auf durchschnittlich 176 bis 406 ppm. Temin et al. (1989) untersuchten ebenfalls in vitro die Fluoridaufnahme aus einem fluoridhaltigen Komposit in den angrenzenden Schmelz. Nach $24 \mathrm{~h}$ wiesen sie in einer Tiefe von $10 \mu \mathrm{m}$ im angrenzenden Schmelz eine sehr viel höhere Fluoridmenge von durchschnittlich 5400 ppm nach. In einer Tiefe von $30 \mu \mathrm{m}$ betrug die Fluoridaufnahme 1300 ppm. In tieferen Bereichen des Füllungsrandes ist die Fluoridaufnahme in die angrenzende Zahnhartsubstanz höher als in den oberflächlichen Bereichen des Schmelzes. Auch hier zeigt sich, dass mit steigendem Fluoridgehalt der Füllungsmaterialien eine höhere Abgabe von Fluorid in die Zahnhartsubstanz stattfindet (Yamamoto et al. 2000, Yamamoto et al. 2001). Hotta et al. (2001) wiesen in tieferen Bereichen an der seitlichen Kavitätenwand eine 
Fluoridaufnahme in die Zahnhartsubstanz aus Glasionomerzementen bis in eine Tiefe von durchschnittlich 21,3 $\mu \mathrm{m}$ nach. Bei den Kompomerfüllungen betrug die Penetrationstiefe des Fluorids nach dem 30-tägigen Studienzeitraum durchschnittlich 5,5 $\mu \mathrm{m}$.

\subsubsection{Fluoridaufnahme in den Schmelz in Abhängigkeit von der Zeit}

Die Fluoridabgabe von Glasionomerzementen kann in zwei Phasen eingeteilt werden: In den ersten 24-72 h lässt sich eine hohe intiale Fluoridfreisetzung („initial burst release“) nachweisen. Diese hohe Fluoridfreisetzung wird auf die Reaktion der fluoridhaltigen Glaspartikel mit den Polycarbonsäuren direkt nach dem Anmischen des Füllungsmaterials zurückgeführt. Dabei findet auch direkt an der Oberfläche der Füllung eine massive Fluoridfreisetzung statt. Diese hohe Menge Fluorid kann direkt an die Umgebung abgegeben werden (Dhondt et al. 2001, Lee et al. 2000, Tay und Braden 1988, Verbeeck et al. 1998, Williams et al. 2001). Kompomere zeigen in den ersten $24 \mathrm{~h}$ ebenfalls wie die Glasionomerzemente eine hohe initiale Fluoridfreisetzung an die Umgebung. Sie ist aber sehr viel geringer als bei den Glasionomerzementen (Attar und Turgut 2003, de Araujo et al. 1996, Grobler et al. 1998, Karantakis et al. 2000). Es wird vermutet, dass dies am Kunststoffanteil der Kompomerfüllungen liegen könnte, denn mit steigendem Kunststoffanteil sinkt die Fluoridabgabe (Momoi und McCabe 1993). Mathis und Ferracane (1989) vermuteten, dass während der Polymerisation des Kompomers die Fluoridionen von der Kunststoffmatrix gebunden werden und die Fluoridabgabe daher geringer ausfällt als bei Glasionomerzementen. Auch die chemische Zusammensetzung der Füllpartikel scheint die Fluoridabgabe der Kompomere $\mathrm{zu}$ beeinflussen. Kompomere mit einem Anteil Ytterbiumtrifluoridfüllern setzen eine höhere Menge Fluorid frei als Kompomere, die Strontiumfluoridfüller enthalten (Abu-Bakr et al. 2000, Attar und Önen 2002, Attin et al. 1996, Attin et al. 1999 b, Sales et al. 2003, Vercruysse et al. 2001). Nach dieser initial hohen Fluoridfreisetzung sinkt die Fluoridabgabe der Glasionomerzemente im Lauf der Zeit rapide (Dionysopoulos et al. 2003, Karantakis et al. 2000). Die zweite Phase der Fluoridfreisetzung besteht in einer langanhaltenden, kontinuierlichen Freisetzung kleiner Mengen Fluorids über Jahre. Es wird angenommen, dass dieser Prozess auf der langsamen Diffusion von Fluorid aus der Füllungsmasse beruht (Dhondt et al. 2001, Lee et al. 2000, Tay und Braden 1988, Verbeeck et al. 1998, Williams et al. 2001). In der zweiten Phase geben auch die Kompomere kleine Mengen Fluorid in die Umgebung ab. Diese Fluoridabgabe ist nicht so langanhaltend wie bei den Glasionomerzementen (Grobler et al. 1998, Karantakis et al. 2000, Preston et al. 
1999, Williams et al. 2001). Yamamoto et al. (2000) wiesen in vivo eine Fluoridaufnahme aus Glasionomerzementfüllungen in den angrenzenden Schmelz bis in eine Tiefe von durchschnittlich $12 \mu \mathrm{m}$ nach einem Monat nach. Für das an die Glasionomerzementfüllungen grenzende Dentin wurde abhängig vom Ort der Messung eine Fluoridaufnahme bis in eine durchschnittliche Tiefe 23 bis $44 \mu \mathrm{m}$ nachgewiesen. Auch hier nahm die Konzentration des aufgenommenen Fluorids im Schmelz und Dentin mit steigender Entfernung vom Füllungsrand schnell ab. Die Menge des durchschnittlich aufgenommenen Fluorids betrug für den Schmelz mit 3,9 x $10^{3} \mathrm{ppm}$ und für das Dentin 5,7 $\mathrm{x}$ $10^{3} \mathrm{ppm}$. Die durchschnittliche Penetrationstiefe des Fluorids betrug bei den mit Kompomer gefüllten Zähnen für den Schmelz $13 \mu \mathrm{m}$ und für das Dentin ortsbezogen 38 bis $45 \mu \mathrm{m}$. Die durchschnittliche Menge aufgenommenen Fluorids betrug für den Schmelz 3,8 x $10^{3} \mathrm{ppm}$ und 6,3 $\times 10^{3} \mathrm{ppm}$ für das Dentin. Die Autoren vermuten, dass die offenen Dentintubuli eine bessere Diffusion des Fluorids ins Dentin ermöglichen könnten. Im Gegensatz dazu könnte im Schmelz die Diffusion des Fluorids durch dessen kompakte und dichte Struktur behindert werden.

\subsubsection{Auswirkungen des aufgenommen Fluorids auf den Schmelz}

$\emptyset$ gaard et al. (1988) setzten Haifischzähne, die zu annähernd 100\% aus Fluorapatit bestehen, kariösen Bedingungen aus. Obwohl der Fluoridgehalt dieser Zähne so hoch ist, zeigten menschliche Zähne mit einem etwa 32-fach niedrigeren Fluoridgehalt unter gleichen kariösen Bedingungen ähnlich stark ausgeprägte Kariesläsionen. Wenn allerdings zusätzlich Fluorid niedrig konzentriert in die Umgebungslösung zugefügt wurde, nahm die Demineralisation stark ab. Zu dem Schluss, dass der Fluoridgehalt im Umgebungsmilieu entscheidend für die Kariesreduktion ist, kamen auch andere Studien (Arends und Christoffersen 1990, Boorsboom et al. 1985, White und Nancollas 1990). Es gibt es viele Studien, die sich mit einer Fluoridaufnahme in die Zahnhartsubstanzen durch fluoridhaltige Füllungsmaterialien und den damit verbundenen Effekten, wie Sekundärkariesreduktion, beschäftigen. Die Ergebnisse der einzelnen Studien sind dabei sehr unterschiedlich: Mayer et al. (1996) setzten in einer In-vitro-Studie mit unterschiedlichen fluoridhaltigen Füllungsmaterialien gefüllte humane Zähne einem demineralisierenden, sauren Milieu aus. Nach 20 Tagen wurde die Tiefe der Demineralisationen direkt am Füllungsrand ermittelt. Die Läsionen waren am Rand der Kompositfüllungen am größten. Am Rand der Glasionomerzementfüllungen waren geringfügig tiefere Läsionen entstanden als am Rand 
der Kompomerfüllungen. Der höhere Fluoridgehalt des Glasionomerzements verglichen mit dem Kompomer resultierte nicht in kleineren Läsionen. Tam et al. (1997) fanden bei ähnlichen Versuchen im Schmelz am Füllungsrandbereich von Kompomerfüllungen produktabhängig sowohl größere als auch kleinere Läsionen als bei den applizierten Glasionomerzementfüllungen. Die Läsionen im Schmelz waren bei einem Kompomer sogar tiefer als bei dem als Kontrolle applizierten fluoridfreien Komposit. Yaman et al. (2004) erzeugten im Füllungsrandbereich von mit verschiedenen fluoridhaltigen Füllungsmaterialien gefüllten Zähnen ebenfalls künstliche Schmelzkariesläsionen. Als Kontrolle dienten mit zwei verschiedenen fluoridfreien Kompositen gefüllte Zähne. Hier wurden die kleinsten Kariesläsionen am Füllungsrand der mit Glasionomerzement gefüllten Zähne gefunden. Am Rand der Kompositfüllungen wurden die größten Läsionen gefunden. Die Läsionen im Füllungsrandbereich der Kompomerfüllungen lagen bezüglich der Größe zwischen denen am Füllungsrand der Komposit- und Kompomerfüllungen. Pereira et al. (1998 a) erzeugten ebenfalls im Füllungsrandbereich von mit Glasionomer und Kompomer gefüllten Zahnproben künstliche Kariesläsionen. Hierbei fand sich in der Zahnhartsubstanz direkt um die fluoridhaltige Füllung herum eine Inhibitionszone, wo die Demineralisation sehr viel geringer ausgeprägt war als in den daran angrenzenden Bereichen. Die Zahnhartsubstanz der Inhibitionszone war beim Glasionomerzement härter, also weniger stark demineralisiert, als bei den beiden verwendeten Kompomeren. Dijkmann und Arends (1992) konnten einen Zusammenhang zwischen dem Fluoridgehalt des Füllungsmaterials und dem Potenzial Demineralisierungen des Schmelzes im Füllungsrandbereich zu verringern nachweisen. Je höher der Fluoridgehalt des Füllungsmaterials war, desto geringer war die Demineralisation des angrenzenden Schmelzes unter kariösen Bedingungen. Im Gegensatz dazu konnten Samuel und Rubinstein (2001) keine Verringerung der Demineralisation des Schmelzes am Füllungsrand durch fluoridhaltige Füllungsmaterialien unter kariösen Bedingungen nachweisen. In den tieferen Bereichen des Füllungsrandes konnte in verschiedenen Studien ein kariesprotektiver Effekt durch fluoridabgebende Füllungen nachgewiesen werden. Die Ausprägung dieser Kavitätenwandläsionen („wall lesions“) war in vitro bei Glasionomerzementfüllungen im Durchschnitt nur etwa halb tief und bezogen auf die räumliche Ausdehnung sehr viel kleiner als bei Kompomerfüllungen. Die Kavitätenrandläsionen an fluoridfreien Kompositfüllungen waren im Vergleich mit denen an Glasionomerzement- und Kompomerfüllungen bis zu 4-mal größer (Yaman et al. 2004). Dunne et al. (1996) konnten geringe Kariesläsionen direkt am Füllungsrand von Kompomer- 
und Glasionomerzementfüllungen nach in vitro simulierten kariogenen Bedingungen nachweisen. Kavitätenwandläsionen in tieferen Bereichen des Füllungsrands traten hingegen nicht auf. Pereira et al. (1998 b) konnten ebenfalls in vitro nachweisen, dass in tieferen Bereichen des Füllungsrandes von Glasionomerzement- und Kompomerfüllungen die Progression der Kavitätenrandläsion gestoppt werden konnte. Die Zahnhartsubstanz wies hier im unmittelbaren Grenzbereich zwischen Zahn und Füllung eine Inhibitionszone auf, die keine Anzeichen von Demineralisationen aufwies. Die Ausdehnung dieser Inhibitionszone war bei den applizierten Glasionomerzementfüllungen größer als bei den applizierten Kompomerfüllungen. Ten Cate und van Duinen (1995) konnten in situ nachweisen, dass künstlich erzeugte Kariesläsionen an der Kavitätenwand nach der Applikation einer Glasionomerzementfüllung in die Kavität auch bei starker Plaqueanlagerung wieder remineralisierten. Diese Remineralisation war höher als die normale Mineralisation der gesunden, restlichen Zahnhartsubstanz. Es fand eine Hypermineralisation statt. Wurde statt Glasionomerzement eine fluoridfreie Füllung (Amalgam/Komposit) appliziert, so schritt die künstlich erzeugte Kariesläsion in situ weiter voran und eine Remineralisation fand nicht statt. Andere Autoren konnten in ähnlichen Versuchen ebenfalls betätigen, dass fluoridhaltige Füllungsmaterialien im Gegensatz zu fluoridfreien Füllungsmaterialien die Progression der Sekundärkaries in die Tiefe des Füllungsrands verhindern und eine Remineralisation der angrenzenden Zahnhartsubstanzen bewirken können (Creanor et al. 1998, Gama-Teixeira et al. 2007, Wesenberg und Hals 1980). Die karieshemmenden Eigenschaften des aus dem Füllungsmaterial abgegebenen Fluorids sind im Bereich der Kavitätenwandläsionen stärker ausgeprägt als im Bereich der äußeren Läsion (Tam et al. 1997). Besteht in der Tiefe des Füllungsrandes ein mit dem äußeren Milieu kommunizierender Randspalt, so sind die karieshemmenden Eigenschaften von fluoridhaltigen Füllungen reduziert (Papagiannoulis et al. 2002). In einer klinischen Studie konnten Maltz et al. (2007) nachweisen, dass Glasionomerzementfüllungen in der Lage sind, in der Kavität belassene Dentinkariesläsionen zum Stillstand zu bringen. Nach 40 Monaten konnte mithilfe von regelmäßigen Röntgenkontrollen während der anschließenden engmaschigen Recallphase nachgewiesen werden, dass die kariösen Läsionen zunehmend remineralisierten und schließlich ausheilten. Grundsätzlich muss eine Karies immer vollständig exkaviert werden. In dieser Studie wurde dies nicht gemacht, da sonst aufgrund der Nähe der Karies zur Pulpa des Zahnes eine endodontische Behandlung unumgänglich gewesen wäre. 
In vitro konnten Benelli et al. (1993) nachweisen, dass auf mit Glasionomerzement gefüllten Zähnen eine deutlich geringere Besiedelung mit Streptococcus mutans stattfand als auf mit Komposit gefüllten Zähnen. Meiers und Miller (1996) wiesen in vitro sowohl für Glasionomerzemente als auch Kompomere eine antibakterielle Wirkung auf diverse orale Streptokokkenstämme nach. Die Glasionomerzemente hatten dabei bessere antibakterielle Eigenschaften als die Kompomere. In einer anderen Studie konnte die antibakterielle Wirkung der Glasionomerzemente auf kariogene Mikroorganismen betätigt werden, während Kompomere keinerlei Auswirkung auf das Wachstum dieser Bakterien hatten (Herrera et al. 2000). Svanberg et al. (1990) konnten in klinischen Studien ebenfalls bestätigen, dass die Plaque am Füllungsrand von Glasionomerzementfüllungen deutlich weniger Streptococcus mutans enthielt als die Plaque am Rand fluoridfreier Amalgam- und Kompositrestaurationen. Die klinische Bedeutung dieser Wachstumshemmung auf die Sekundärkariesentstehung ist unklar (Van Loveren 1990). Man könnte allerdings vermuten, dass die Fluoridfreisetzung aus fluoridhaltigen Füllungsmaterialien eventuell auch über die Hemmung der Vermehrung von Streptococcus mutans in der Plaque die Demineralisation der Zahnhartsubstanzen verringern und so eventuell zur Senkung der Sekundärkariesrate beitragen könnte.

Der kariesprotektive Effekt fluoridhaltiger Füllungsmaterialien erstreckt sich nicht nur auf den unmittelbaren Füllungsrandbereich, sondern lässt sich auch an Nachbarzähnen beobachten, die in Kontakt mit einer fluoridhaltigen Füllung stehen. So untersuchten Lennon et al. (2007) den Effekt von Füllungsmaterialien auf bovinen Schmelz unter kariesfördernden Bedingungen in der menschlichen Mundhöhle. Dazu wurden ein fluoridhaltiges Kompomer und ein fluoridfreies Komposit mit dem Schmelz in Kontakt gebracht. Es wurden kariesfördernde Bedingungen durch mehrmaliges, tägliches Einlegen der Proben in eine zuckerhaltige Lösung simuliert. Der Schmelz, der Kontakt mit dem Kompomer hatte, entwickelte weniger Karies als der Schmelz, der Kontakt mit dem fluoridfreien Komposit hatte. Zu gleichen Ergebnissen kamen auch Donly et al. (1999) in einer ähnlich aufgebauten Studie. Hier wurde neben einem Kompomer und einem Komposit zusätzlich ein Glasionomerzement getestet. Der Glasionomerzement wies, gefolgt von den Kompomeren, die besten kariesprotektiven Eigenschaften auf. In Kombination mit einer fluoridhaltigen Zahnpasta konnte die Progression der Schmelzkariesläsionen an den Nachbarzähnen in jeder Versuchsgruppe noch stärker gehemmt werden und eine höhere Remineralisation der 
Läsionen erreicht werden. Kotsanos (2001) stellte fest, je weiter der Schmelz von dem fluoridhaltigen Füllungsmaterial entfernt war, desto stärker verringerte sich die Härte des Schmelzes im Bereich der Läsion. In einer klinischen Studie von Svanberg (1992) konnte die kariesprotektive Wirkung fluoridhaltiger Füllungsmaterialien auf die Zahnhartsubstanz der Nachbarzähne bestätigt werden. Am Kontaktbereich von Glasionomerzementfüllungen zum Nachbarzahn traten signifikant weniger häufig neue kariöse Läsionen auf als bei den fluoridfreien Amalgamfüllungen.

In dieser Studie wurde eine Verringerung der Sekundärkariesrate durch eine erhöhte Fluoridaufnahme in den Zahnschmelz nicht untersucht. Trotzdem lassen die Ergebnisse anderer Studien zu diesem Thema die Vermutung zu, dass eventuell die Sekundärkariesrate durch eine erhöhte Aufnahme von Fluorid am Rand fluoridhaltiger Füllungen positiv beeinflusst wird.

\subsection{Schlussfolgerungen}

1). Das Verwenden fluoridhaltiger Füllungsmaterialien bewirkt in vitro eine signifikante Aufnahme von Fluorid in den angrenzenden Zahnschmelz am Füllungsrand, in der Menge abhängig vom verwendeten Füllungsmaterial und der Kontaktdauer zum Zahnschmelz.

2). Die direkte Fluoridabgabe in den angrenzenden Schmelz ist bei GlasionomerzementFüllungen signifikant höher als bei Kompomer- und Kompositfüllungen. 


\section{Zusammenfassung}

Ziel der Studie war es, die Fluoridaufnahme in den Zahnschmelz nach der Applikation verschiedener Füllungsmaterialien über einen Zeitraum von $72 \mathrm{~h}$ zu vergleichen.

Material und Methoden: Es wurden 90 mittlere, bovine Schneidezähne entlang der Kronenachse in zwei gleich große Hälften zerteilt. An je einer Hälfte wurde der Basisfluoridgehalt des Schmelzes bestimmt. Die übrigen Hälften wurden zu gleichen Teilen auf drei Gruppen verteilt. Nach dem Anlegen einer halbkreisförmigen Kavität (Radius 2,5 $\mathrm{mm}$, Tiefe $2 \mathrm{~mm}$ ) in den Zahnhälften wurden die Zähne in der Gruppe 1 mit Glasionomerzement Ketac ${ }^{\text {TM }}$ Fil Plus Aplicap ${ }^{\text {TM }}$ (3M ESPE AG Dental Products, Seefeld), in der Gruppe 2 mit Komposit Spectrum ${ }^{\circledR}$ (Dentsply De Trey GmbH, Konstanz) und in der Gruppe 3 mit Kompomer Dyract ${ }^{\circledR}$ eXtra (Dentsply De Trey GmbH, Konstanz) gefüllt. Vierundzwanzig Stunden nach der Applikation des Füllungsmaterials wurde der Fluoridgehalt am Füllungsrand bestimmt. Dazu wurde Salzsäure $(\mathrm{pH} 2)$ auf den Schmelz am Füllungsrand aufgetragen, nach $15 \mathrm{~s}$ Einwirkzeit wieder abgesaugt und mit Natronlauge (pH 12) neutralisiert. Die Aufbereitung der Lösung für die Fluoridgehaltbestimmung erfolgte durch Zugabe von TISAB III. Zwischen den Messungen wurden die Zahnhälften im Brutschrank bei $37^{\circ} \mathrm{C}$ und $100 \%$ Luftfeuchte aufbewahrt. Die Messung wurde $48 \mathrm{~h}$ und $72 \mathrm{~h}$ nach der Applikation des Füllmaterials wiederholt.

Ergebnisse: Der Schmelz im Füllungsrandbereich der Zahnhälften, die mit den fluoridhaltigen Füllungsmaterialien Glasionomerzement und Kompomer gefüllt wurden, reicherte über den Messzeitraum durchschnittlich zunehmend mehr Fluorid an. Glasionomerzement führte zur höchsten Fluoridanreicherung gefolgt von Kompomer und Komposit. Bei den mit fluoridfreiem Komposit gefüllten Zahnhälften ließ sich keine Fluoridaufnahme in den Schmelz nachweisen. Die Messwerte für Komposit lagen, wie auch die Basisfluoridgehalte

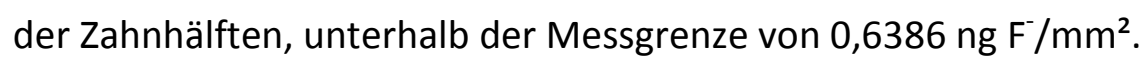

Schlussfolgerung: Die Verwendung fluoridhaltiger Füllungsmaterialien führt zu einer mit der Zeit steigenden Fluoridanreicherung im angrenzenden Schmelz. Die durchschnittliche Fluoridaufnahme in den Schmelz ist bei Glasionomerzementfüllungen über den Messzeitraum signifikant höher als bei Kompomer- und Kompositfüllungen. 


\section{Tabellarischer Anhang}

\subsection{Gruppe 1 (Glasionomerzement): Werte aus der Fluoridgehaltbestimmung}

\begin{tabular}{|c|c|c|c|c|}
\hline \multirow[b]{2}{*}{$\begin{array}{l}\text { Proben- } \\
\text { nummer }\end{array}$} & \multicolumn{4}{|c|}{ Herausgelöstes Fluorid [ng/mm²] } \\
\hline & $\begin{array}{l}\text { Basisfluoridgehalt } \\
\text { vor } \\
\text { Füllungsapplikation }\end{array}$ & $\begin{array}{c}24 \mathrm{~h} \text { nach } \\
\text { Füllungsapplikation }\end{array}$ & $\begin{array}{l}48 \mathrm{~h} \text { nach } \\
\text { Füllungsapplikation }\end{array}$ & $\begin{array}{l}72 \mathrm{~h} \text { nach } \\
\text { Füllungsapplikation }\end{array}$ \\
\hline 1 & $\leq 0,63861$ & 3,42 & 4,60 & 7,19 \\
\hline 2 & $\leq 0,63861$ & 2,46 & 3,51 & 5,75 \\
\hline 3 & $\leq 0,63861$ & 2,65 & 4,18 & 6,45 \\
\hline 4 & $\leq 0,63861$ & 4,15 & 5,33 & 7,57 \\
\hline 5 & $\leq 0,63861$ & 1,88 & 3,16 & 4,66 \\
\hline 6 & $\leq 0,63861$ & 4,12 & 6,23 & 9,07 \\
\hline 7 & $\leq 0,63861$ & 2,88 & 4,38 & 6,39 \\
\hline 8 & $\leq 0,63861$ & 3,19 & 4,57 & 7,06 \\
\hline 9 & $\leq 0,63861$ & 2,33 & 4,02 & 5,14 \\
\hline 10 & $\leq 0,63861$ & 3,26 & 4,28 & 4,63 \\
\hline 11 & $\leq 0,63861$ & 4,50 & 8,91 & 12,07 \\
\hline 12 & $\leq 0,63861$ & 3,00 & 3,86 & 4,53 \\
\hline 13 & $\leq 0,63861$ & 3,83 & 3,93 & 7,79 \\
\hline 14 & $\leq 0,63861$ & 4,34 & 4,69 & 6,71 \\
\hline 15 & $\leq 0,63861$ & 3,61 & 5,52 & 9,01 \\
\hline 16 & $\leq 0,63861$ & 2,68 & 3,96 & 5,30 \\
\hline 17 & $\leq 0,63861$ & 3,35 & 5,84 & 6,74 \\
\hline 18 & $\leq 0,63861$ & 3,70 & 4,15 & 7,47 \\
\hline 19 & $\leq 0,63861$ & 2,40 & 3,61 & 9,93 \\
\hline 20 & $\leq 0,63861$ & 2,94 & 6,42 & 7,92 \\
\hline 21 & $\leq 0,63861$ & 2,94 & 7,22 & 10,60 \\
\hline 22 & $\leq 0,63861$ & 3,58 & 5,24 & 5,68 \\
\hline 23 & $\leq 0,63861$ & 1,78 & 3,10 & 5,08 \\
\hline 24 & $\leq 0,63861$ & 3,10 & 4,31 & 5,46 \\
\hline 25 & $\leq 0,63861$ & 3,83 & 5,14 & 5,59 \\
\hline 26 & $\leq 0,63861$ & 3,35 & 4,28 & 7,35 \\
\hline 27 & $\leq 0,63861$ & 3,83 & 6,58 & 9,33 \\
\hline 28 & $\leq 0,63861$ & 2,49 & 4,53 & 5,81 \\
\hline 29 & $\leq 0,63861$ & 3,54 & 4,82 & 5,14 \\
\hline 30 & $\leq 0,63861$ & 2,65 & 2,97 & 6,93 \\
\hline
\end{tabular}

Tab. III: In der Gruppe 1 (Glasionomerzement) gemessene Fluoridgehalte der einzelnen Proben 1-30 zu den Zeitpunkten $24 \mathrm{~h}, 48 \mathrm{~h}$ und $72 \mathrm{~h}$ nach Füllungsapplikation, sowie der dazugehörige Basisfluoridgehalt des Schmelzes. 
8.2 Gruppe 2 (Komposit): Werte aus der Fluoridgehaltbestimmung

\begin{tabular}{|c|c|c|c|c|}
\hline \multirow[b]{2}{*}{$\begin{array}{l}\text { Proben- } \\
\text { nummer }\end{array}$} & \multicolumn{4}{|c|}{ Herausgelöstes Fluorid [ng/mm²] } \\
\hline & $\begin{array}{c}\begin{array}{c}\text { Basisfluoridgehalt } \\
\text { vor }\end{array} \\
\text { Füllungsapplikation }\end{array}$ & $\begin{array}{c}24 \mathrm{~h} \text { nach } \\
\text { Füllungsapplikation }\end{array}$ & $\begin{array}{c}48 \mathrm{~h} \text { nach } \\
\text { Füllungsapplikation }\end{array}$ & $\begin{array}{c}72 \mathrm{~h} \text { nach } \\
\text { Füllungsapplikation }\end{array}$ \\
\hline 31 & $\leq 0,63861$ & $\leq 0,63861$ & $\leq 0,63861$ & $\leq 0,63861$ \\
\hline 32 & $\leq 0,63861$ & $\leq 0,63861$ & $\leq 0,63861$ & $\leq 0,63861$ \\
\hline 33 & $\leq 0,63861$ & $\leq 0,63861$ & $\leq 0,63861$ & $\leq 0,63861$ \\
\hline 34 & $\leq 0,63861$ & $\leq 0,63861$ & $\leq 0,63861$ & $\leq 0,63861$ \\
\hline 35 & $\leq 0,63861$ & $\leq 0,63861$ & $\leq 0,63861$ & $\leq 0,63861$ \\
\hline 36 & $\leq 0,63861$ & $\leq 0,63861$ & $\leq 0,63861$ & $\leq 0,63861$ \\
\hline 37 & $\leq 0,63861$ & $\leq 0,63861$ & $\leq 0,63861$ & $\leq 0,63861$ \\
\hline 38 & $\leq 0,63861$ & $\leq 0,63861$ & $\leq 0,63861$ & $\leq 0,63861$ \\
\hline 39 & $\leq 0,63861$ & $\leq 0,63861$ & $\leq 0,63861$ & $\leq 0,63861$ \\
\hline 40 & $\leq 0,63861$ & $\leq 0,63861$ & $\leq 0,63861$ & $\leq 0,63861$ \\
\hline 41 & $\leq 0,63861$ & $\leq 0,63861$ & $\leq 0,63861$ & $\leq 0,63861$ \\
\hline 42 & $\leq 0,63861$ & $\leq 0,63861$ & $\leq 0,63861$ & $\leq 0,63861$ \\
\hline 43 & $\leq 0,63861$ & $\leq 0,63861$ & $\leq 0,63861$ & $\leq 0,63861$ \\
\hline 44 & $\leq 0,63861$ & $\leq 0,63861$ & $\leq 0,63861$ & $\leq 0,63861$ \\
\hline 45 & $\leq 0,63861$ & $\leq 0,63861$ & $\leq 0,63861$ & $\leq 0,63861$ \\
\hline 46 & $\leq 0,63861$ & $\leq 0,63861$ & $\leq 0,63861$ & $\leq 0,63861$ \\
\hline 47 & $\leq 0,63861$ & $\leq 0,63861$ & $\leq 0,63861$ & $\leq 0,63861$ \\
\hline 48 & $\leq 0,63861$ & $\leq 0,63861$ & $\leq 0,63861$ & $\leq 0,63861$ \\
\hline 49 & $\leq 0,63861$ & $\leq 0,63861$ & $\leq 0,63861$ & $\leq 0,63861$ \\
\hline 50 & $\leq 0,63861$ & $\leq 0,63861$ & $\leq 0,63861$ & $\leq 0,63861$ \\
\hline 51 & $\leq 0,63861$ & $\leq 0,63861$ & $\leq 0,63861$ & $\leq 0,63861$ \\
\hline 52 & $\leq 0,63861$ & $\leq 0,63861$ & $\leq 0,63861$ & $\leq 0,63861$ \\
\hline 53 & $\leq 0,63861$ & $\leq 0,63861$ & $\leq 0,63861$ & $\leq 0,63861$ \\
\hline 54 & $\leq 0,63861$ & $\leq 0,63861$ & $\leq 0,63861$ & $\leq 0,63861$ \\
\hline 55 & $\leq 0,63861$ & $\leq 0,63861$ & $\leq 0,63861$ & $\leq 0,63861$ \\
\hline 56 & $\leq 0,63861$ & $\leq 0,63861$ & $\leq 0,63861$ & $\leq 0,63861$ \\
\hline 57 & $\leq 0,63861$ & $\leq 0,63861$ & $\leq 0,63861$ & $\leq 0,63861$ \\
\hline 58 & $\leq 0,63861$ & $\leq 0,63861$ & $\leq 0,63861$ & $\leq 0,63861$ \\
\hline 59 & $\leq 0,63861$ & $\leq 0,63861$ & $\leq 0,63861$ & $\leq 0,63861$ \\
\hline 60 & $\leq 0,63861$ & $\leq 0,63861$ & $\leq 0,63861$ & $\leq 0,63861$ \\
\hline
\end{tabular}

Tab. IV: In der Gruppe 2 (Komposit) gemessene Fluoridgehalte der einzelnen Proben 31$60 \mathrm{zu}$ den Zeitpunkten $24 \mathrm{~h}, 48 \mathrm{~h}$ und $72 \mathrm{~h}$ nach Füllungsapplikation, sowie der dazugehörige Basisfluoridgehalt des Schmelzes. 


\subsection{Gruppe 3 (Kompomer): Werte aus der Fluoridgehaltbestimmung}

\begin{tabular}{|c|c|c|c|c|}
\hline \multirow[b]{2}{*}{$\begin{array}{l}\text { Proben- } \\
\text { nummer }\end{array}$} & \multicolumn{4}{|c|}{ Herausgelöstes Fluorid $\left[\mathrm{ng} / \mathrm{mm}^{2}\right]$} \\
\hline & $\begin{array}{c}\text { Basisfluoridgehalt } \\
\text { vor } \\
\text { Füllungsapplikation }\end{array}$ & $\begin{array}{c}24 \mathrm{~h} \text { nach } \\
\text { Füllungsapplikation }\end{array}$ & $\begin{array}{c}48 \mathrm{~h} \text { nach } \\
\text { Füllungsapplikation }\end{array}$ & $\begin{array}{c}72 \mathrm{~h} \text { nach } \\
\text { Füllungsapplikation }\end{array}$ \\
\hline 61 & $\leq 0,63861$ & 1,34 & 1,72 & 2,84 \\
\hline 62 & $\leq 0,63861$ & 1,69 & 2,26 & 4,66 \\
\hline 63 & $\leq 0,63861$ & 1,94 & 3,93 & 5,14 \\
\hline 64 & $\leq 0,63861$ & 2,08 & 2,65 & 3,90 \\
\hline 65 & $\leq 0,63861$ & 1,15 & 1,69 & 2,36 \\
\hline 66 & $\leq 0,63861$ & 2,58 & 4,63 & 5,30 \\
\hline 67 & $\leq 0,63861$ & 1,60 & 2,14 & 2,74 \\
\hline 68 & $\leq 0,63861$ & 2,42 & 3,19 & 3,48 \\
\hline 69 & $\leq 0,63861$ & 2,74 & 3,00 & 4,22 \\
\hline 70 & $\leq 0,63861$ & 2,58 & 3,16 & 5,94 \\
\hline 71 & $\leq 0,63861$ & 2,26 & 3,42 & 5,78 \\
\hline 72 & $\leq 0,63861$ & 2,40 & 2,78 & 4,69 \\
\hline 73 & $\leq 0,63861$ & 1,94 & 2,94 & 4,25 \\
\hline 74 & $\leq 0,63861$ & 1,12 & 1,76 & 4,22 \\
\hline 75 & $\leq 0,63861$ & 1,47 & 2,24 & 3,16 \\
\hline 76 & $\leq 0,63861$ & 2,88 & 3,58 & 3,74 \\
\hline 77 & $\leq 0,63861$ & 1,28 & 2,62 & 3,29 \\
\hline 78 & $\leq 0,63861$ & 2,42 & 4,18 & 4,82 \\
\hline 79 & $\leq 0,63861$ & 1,44 & 1,56 & 2,10 \\
\hline 80 & $\leq 0,63861$ & 1,38 & 1,60 & 1,94 \\
\hline 81 & $\leq 0,63861$ & 1,92 & 6,19 & 7,85 \\
\hline 82 & $\leq 0,63861$ & 1,15 & 1,50 & 2,24 \\
\hline 83 & $\leq 0,63861$ & 1,66 & 1,94 & 2,20 \\
\hline 84 & $\leq 0,63861$ & 1,38 & 1,44 & 1,98 \\
\hline 85 & $\leq 0,63861$ & 1,50 & 2,33 & 3,10 \\
\hline 86 & $\leq 0,63861$ & 1,82 & 1,88 & 2,08 \\
\hline 87 & $\leq 0,63861$ & 1,56 & 2,14 & 2,84 \\
\hline 88 & $\leq 0,63861$ & 0,99 & 1,38 & 1,98 \\
\hline 89 & $\leq 0,63861$ & 2,04 & 2,08 & 2,33 \\
\hline 90 & $\leq 0,63861$ & 1,98 & 2,33 & 3,26 \\
\hline
\end{tabular}

Tab. V: In der Gruppe 3 (Kompomer) gemessene Fluoridgehalte der einzelnen Proben 61$90 \mathrm{zu}$ den Zeitpunkten $24 \mathrm{~h}, 48 \mathrm{~h}$ und $72 \mathrm{~h}$ nach Füllungsapplikation, sowie der dazugehörige Basisfluoridgehalt des Schmelzes. 


\section{Literaturverzeichnis}

Abu-Bakr NH, Han L, Okamoto A, Iwaku M (2000): Effect of alcoholic and low-pH soft drinks on fluoride release from compomer. J Esthet Dent 12(2), 97-104

Ahiropoulos V, Helvatjoglu-Antoniades M, Papadogiannis Y (2008): In vitro fluoride uptake by bovine enamel from aesthetic restorative materials. Int J Paediatr Dent 18(4), 291-299

Ando M, González-Cabezas C, Isaacs RL, Eckert GJ, Stookey GK (2004): Evaluation of several techniques for the detection of secondary caries adjacent to amalgam restorations. Caries Res 38(4), 350-356

Arends J, Christoffersen J (1990): Nature and role of loosely bound fluoride in dental caries. J Dent Res $\underline{69}$, Spec Iss, 601-605

Attar N, Önen A (2002): Fluoride release and uptake characteristics of aesthetic restorative materials. J Oral Rehabil 29(8), 791-798

Attar N, Turgut MD (2003): Fluoride release and uptake capacities of fluoride-releasing restorative materials. Oper Dent $\underline{28(4)}$, 395-402

Attin T, Buchalla W, Kielbassa AM, Hellwig E (1995): Curing shrinkage and volumetric changes of resin-modified glass ionomer restorative materials. Dent Mater $\underline{11(6)}, 359-362$

Attin T, Kielbassa AM, Plogmann S, Hellwig E (1996): Fluoridfreisetzung aus Kompomeren im sauren und neutralen Milieu. Dtsch Zahnärztl Z 51(11), 675-678

Attin T, Buchalla W, Siewert C, Hellwig E (1999 a): Fluoride release/uptake of polyacidmodified resin composites (compomers) in neutral and acidic buffer solutions. J Oral Rehabil $\underline{26(5)}, 388-393$

Attin T, Buchalla W, Ameling K, Hellwig E (1999 b): Effect of toothbrushing on fluoride release of polyacid-modified composite resins. Clin Oral Investig 3(3), 150-154

Awliya WY, El-Sahn AM (2008): Leakage pathway of Class V cavities restored with different flowable resin composite restorations. Oper Dent 33(1), 31-36

Barbosa SH, Zanata RL, Navarro MF, Nunes OB (2005): Effect of different finishing and polishing techniques on the surface roughness of microfilled, hybrid and packable composite resins. Braz Dent J 16(1), 39-44

Barry TI, Clinton DJ, Wilson AD (1979): The structure of a glass-ionomer cement and its relationship to the setting process. J Dent Res $\underline{58(3)}$, 1072-1079

Benelli EM, Serra MC, Rodrigues AL Jr, Cury JA (1993): In situ anticariogenic potential of glass ionomer cement. Caries Res 27(4), 280-284 
Borsboom PC, van der Mei HC, Arends J (1985): Enamel lesion formation with and without 0.12 ppm F in solution. Caries Res 19(5), 396-402

Bowen RL (1962): Dental filling material comprising vinyl silane treated fused silica and a binder consisting of the reaction product of bis phenol and glycidyl acrylate. US Pat Off No. 3 (066), 112

Bowen RL (1965): Adhesive bonding of various materials to hard tooth tissues. II. Bonding to dentin promoted by a surface-active comonomer. J Dent Res $44(5), 895-902$

Bowen RL, Cleek GW (1972): A new series of X-ray-opaque reinforcing fillers for composite materials. J Dent Res 48(1), 79-82

Bradshaw DJ, Marsh PD, Hodgson RJ, Visser JM (2002): Effects of glucose and fluoride on competition and metabolism within in vitro dental bacterial communities and biofilms. Caries Res 36(2), 81-86

Brännström M, Torstenson B, Nordenvall KJ (1984): The initial gap around large composite restorations in vitro: the effect of etching enamel walls. J Dent Res $\underline{63(5)}, 681-684$

Buchalla W, Attin T, Schulte-Mönting J, Hellwig E (2002): Fluoride uptake, retention, and remineralization efficacy of a highly concentrated fluoride solution on enamel lesions in situ. J Dent Res 81(5), 329-333

Bunick FJ, Kashket S (1981): Enolases from fluoride-sensitive and fluoride-resistant streptococci. Infect Immun 34(3), 856-863

Buonocore MG (1955): A simple method of increasing the adhesion of acrylic filling materials to enamel surfaces. J Dent Res $\underline{34(6)}, 849-853$

Burt BA (1966): Dietary fluoride; the effect of maternal ingestion on offspring. J Public Health Dent 26(2), 234-245

Camargo MA, Marques MM, de Cara AA (2007): Morphological analysis of human and bovine dentine by scanning electron microscope investigation. Arch Oral Biol 53(2), 105-108

Can-Karabulut DC, Batmaz I, Solak H, Taştekin M (2007): Linear regression modeling to compare fluoride release profiles of various restorative materials. Dent Mater 23(9), 10571067

Carey CM, Spencer M, Gove RJ, Eichmiller FC (2003): Fluoride release from a resin-modified glass-ionomer cement in a continuous-flow system. Effect of pH. J Dent Res 82(10), 829-832

Carvalho AS, Cury JA (1999): Fluoride release from some dental materials in different solutions. Oper Dent 24(1), 14-19

Carvalho RM, Pereira JC, Yoshiyama M, Pashley DH (1996): A review of polymerization contraction: the influence of stress development versus stress relief. Oper Dent 21(1), 17-24 
Casals E, Boukpessi T, McQueen CM, Eversole SL, Faller RV (2007): Anticaries potential of commercial dentifrices as determined by fluoridation and remineralization efficiency. $J$ Contemp Dent Pract 8(7), 1-10

Cattani-Lorente MA, Dupuis V, Payan J, Moya F, Meyer JM (1999): Effect of water on the physical properties of resin-modified glass ionomer cements. Dent Mater 15(1), 71-80

Cefaly DF, Tapety CM, Mondelli RF, Lauris JR, Phantumvanit P, Navarro MF (2006): Threeyear evaluation of the ART approach in Class III and $\mathrm{V}$ restorations in permanent anterior teeth. Caries Res 40(5), 389-392

Cehreli ZC, Altay N (2000): Three-year clinical evaluation of a polyacid-modified resin composite in minimally invasive occlusal cavities. J Dent 28(2), 117-122

Chiba Y, Miyazaki M, Rikuta A, Moore BK (2004): Influence of environmental conditions on dentin bond strengths of one-application adhesive systems. Oper Dent 29(5), 554.559

Collins CJ, Bryant RW, Hodge KL (1998): A clinical evaluation of posterior composite resin restorations: 8-year findings. J Dent 26(4), 311-317

Creanor SL, Awawdeh LA, Saunders WP, Foye RH, Gilmour WH (1998): The effect of a resinmodified glass ionomer restorative material on artificially demineralised dentine caries in vitro. J Dent 26(5-6), 527-531

Crim GA (1989): Influence of bonding agents and composites on microleakage. J Prosthet Dent $\underline{61(5)}, 571-574$

Crisp S, Wilson AD (1974): Reactions in glass ionomer cements: III. The precipitation reaction. J Dent Res $\underline{53(6)}, 1420-1424$

Crisp S, Pringuer MA, Wardleworth D, Wilson AD (1974): Reactions in glass ionomer cements: II. An infrared spectroscopic study. J Dent Res 53(6), 1414-1419

Croll TP, Bar-Zion Y, Segura A, Donly KJ (2001): Clinical performance of resin-modified glass ionomer cement restorations in primary teeth. A retrospective evaluation. J Am Dent Assoc $\underline{132(8)}, 1110-1116$

Czarnecka B, Limanowska-Shaw H, Nicholson JW (2002): Buffering and ion-release by a glassionomer cement under near-neutral and acidic conditions. Biomaterials 23(13), 27832788

Darling Al, Mortimer KV, Poole DF, Ollis WD (1961): Molecular sieve behaviour of normal and carious human dental enamel. Arch Oral Biol 5(3-4), 251-273

Davidson CL, Boom G, Arends J (1973): Calcium distribution in human and bovine surface enamel. Caries Res 7(4), 349-359

De Araujo FB, García-Godoy F, Cury JA, Conceição EN (1996): Fluoride release from fluoridecontaining materials. Oper Dent 21(5), 185-190 
Deliperi S, Bardwell DN (2002): An alternative method to reduce polymerization shrinkage in direct posterior composite restorations. J Am Dent Assoc 133(10), 1387-1398

Demirci M (2007): Clinical evaluation of a polyacid-modified resin composite (Dyract AP) in class I cavities: 5-year results. J Adhes Dent 9(6), 547-553

Demirci M, Ersev H, Uçok M (2002): Clinical evaluation of a polyacid-modified resin composite (Dyract) in class III cavities: three-year results. Oper Dent 27(3), 223-230

Demirci M, Yildiz E, Uysal O (2008): Comparative clinical evaluation of different treatment approaches using a microfilled resin composite and a compomer in Class III cavities: twoyear results. Oper Dent 33(1), 7-14

Dhondt CL, De Maeyer EA, Verbeeck RM (2001): Fluoride release from glass ionomer activated with fluoride solutions. J Dent Res $\underline{80(5)}, 1402-1406$

Dietschi D, Campanile G, Holz J, Meyer JM (1994): Comparison of the color stability of ten new-generation composites: an in vitro study. Dent Mater 10(6), 353-362

Dijkman GE, Arends J (1992): Secondary caries in situ around fluoride-releasing light-curing composites: a quantitative model investigation on four materials with a fluoride content between 0 and 26 vol\%. Caries Res 26(5), 351-357

Dionysopoulos P, Kotsanos N, Pataridou A (2003): Fluoride release and uptake by four new fluoride releasing restorative materials. J Oral Rehabil 30(9), 866-872

Donly KJ, Segura A, Wefel JS, Hogan MM (1999): Evaluating the effects of fluoride-releasing dental materials on adjacent interproximal caries. J Am Dent Assoc 130(6), 817-825

Duckworth RM, Jones Y, Nicholson J, Jacobson AP, Chestnutt IG (1994): Studies on plaque fluoride after use of F-containing dentifrices. Adv Dent Res 8(2), 202-207

Duggal MS, Toumba KJ, Sharma NK (2002): Clinical performance of a compomer and amalgam for the interproximal restoration of primary molars: a 24-month evaluation. $\mathrm{Br}$ Dent J 193(6), 339-342

Dunne SM, Goolnik JS, Millar BJ, Seddon RP (1996): Caries inhibition by a resin-modified and a conventional glass ionomer cement, in vitro. J Dent 24(1-2), 91-94

Eliades G, Kakaboura A, Palaghias G (1998): Acid-base reaction and fluoride release profiles in visible light-cured polyacid-modified composite restoratives (compomers). Dent Mater 14(1), 57-63

Eliades G, Vougiouklakis G, Palaghias G (1999): Effect of dentin primers on the morphology, molecular composition and collagen conformation of acid-demineralized dentin in situ. Dent Mater 15(5), 310-317 
Espelid I, Tveit AB, Tornes KH, Alvheim H (1999): Clinical behaviour of glass ionomer restorations in primary teeth. J Dent $\underline{27(6)}, 437-442$

Esser M, Tinschert J, Marx R (1998): Materialkennwerte der Zahnhartsubstanz des Rindes im Vergleich zur humanen Zahnhartsubstanz. Dtsch Zahnärztl Z 53(10), 713 -717

Etty EJ, Henneberke M, Gruythuysen RJ, Wöltgens JH (1994): Influence of oral hygiene on early enamel caries. Caries Res 28(2), 132-136

Featherstone JD, Duncan JF, Cutress TW (1979): A mechanism for dental caries based on chemical processes and diffusion phenomena during in-vitro caries simulation on human tooth enamel. Arch Oral Biol 24(4), 101-112

Feilzer AJ, De Gee AJ, Davidson CL (1987): Setting stress in composite resin in relation to configuration of the restoration. J Dent Res 66(11), 1636-1639

Feilzer AJ, De Gee AJ, Davidson CL (1988): Curing contraction of composites and glassionomer cements. J Prosthet Dent 59(3), 297-300

Feller RP, Shannon IL, Matranga LF, Osborne HW, Perez RS (1976): Reduction of enamel solubility by sodium monophosphate. J Dent Res 55(3), 510-514

Ferrari M, Tay FR (2003): Technique sensitivity in bonding to vital, acid-etched dentin. Oper Dent 28(1), 3-8

Fincham AG (1980): Changing amino acid profiles of developing dental enamel in individual human teeth and the comparison of the protein matrix of developing human and bovine enamel. Arch Oral Biol 25(10), 669-674

Fincham AG, Belcourt AB, Lyaruu DM, Termine JD (1982): Comparative protein biochemistry of developing dental enamel matrix from five mammalian species. Calcif Tissue Int $\underline{34(2)}$, 182-199

Foster LV (1994): Validity of clinical judgements for the presence of secondary caries associated with defective amalgam restorations. Br Dent J 177(3), 89-93

Frant MS, Ross JW Jr. (1968): Use of a total ionic strength adjustment buffer for electrode determination of fluoride in water supplies. Anal Chem 40(7), 1169-1171

Freilich MA, Goldberg AJ, Gilpatrick RO, Simonsen RJ (1992): Direct and indirect evaluation of posterior composite restorations at three years. Dent Mater $\underline{8(1)}, 60-64$

Galan J Jr, Mondelli J, Coradazzi JL (1976): Marginal leakage of two composite restorative systems. J Dent Res 55(1), 74-76

Gama-Teixeira A, Simionato MR, Elian SN, Sobral MA, Luz MA (2007): Streptococcus mutansinduced secondary caries adjacent to glass ionomer cement, composite resin and amalgam restorations in vitro. Braz Oral Res 21(4), 368-374 
Gedalia I (1969): The composition of the developing deciduous dentition in relation to fluoride in tissue fluids. J Dent Res $\underline{48(5)}$, 761-765

Gente M, Sondermann U, Lehmann KM (1985): Linearer thermischer Ausdehnungskoeffizient von Rinderschmelz und Rinderdentin. Dtsch Zahnärztl Z 40(5), 488-490

Germaine GR, Tellefson LM. (1986): Role of the cell membrane in pH-dependent fluoride inhibition of glucose uptake by Streptococcus mutans. Antimicrob Agents Chemother 29(1), 58-61

Gerth HU, Dammaschke T, Schäfer E, Züchner H (2007): A three layer structure model of fluoridated enamel containing $\mathrm{CaF}_{2}, \mathrm{Ca}(\mathrm{OH})_{2}$ and FAp. Dent Mater 23(12), 1521-1528

Gladys S, Van Meerbeek B, Braem M, Lambrechts P, Vanherle G (1997): Comparative physico-mechanical characterization of new hybrid restorative materials with conventional glass-ionomer and resin composite restorative materials. J Dent Res 76(4), 883-894

Gray JA, Schweizer HC, Rosevear FB, Broge RW (1958): Electron microscopic observations of the differences in the effects of stannous fluoride and sodium fluoride on dental enamel. J Dent Res 37(4), 683-648

Grobler SR, Rossouw RJ, Van Wyk Kotze TJ (1998): A comparison of fluoride release from various dental materials. J Dent 26(3), 259-265

Grossman ES, Matejka JM (1999): Histological features of artificial secondary caries adjacent to amalgam restorations. J Oral Rehabil 26(9), 737-744

Gwinnett AJ, Matsui A (1967): A study of enamel adhesives. The physical relationship between enamel and adhesive. Arch Oral Biol 12(12), 1615-1620

Hals E, Nernaes A (1971): Histopathology of in vitro caries developing around silver amalgam fillings. Caries Res $\underline{5(1)}$, 58-77

Hannig M, Bock H, Bott B, Hoth-Hannig W (2002): Inter-crystallite nanoretention of selfetching adhesives at enamel imaged by transmission electron microscopy. Eur J Oral 110(6), 464-470

Hattab FN, Amin WM (2001): Fluoride release from glass ionomer restorative materials and the effects of surface coating. Biomaterials 22(12), 1449-1458

Hayacibara MF, Ambrozano GM, Cury JA (2004): Simultaneous release of fluoride and aluminum from dental materials in various immersion media. Oper Dent 29(1), 16-22 Hayashi M, Wilson NH (2003): Marginal deterioration as a predictor of failure of a posterior composite. Eur J Oral Sci 111(2), 155-162

Heidemann D, Hellwig E, Hickel R, Klaiber B, Staehle H (2004): Die Bewertung direkter Komposit-Restaurationen. Zahnärztl Mitt 94(6), 650-658 
Hellwig E, Klimek J, Attin T: Einführung in die Zahnerhaltung. 3. Auflage; Urban \& Fischer Verlag, München, Jena 2003

Herrera M, Castillo A, Bravo M, Liébana J, Carrión P (2000): Antibacterial activity of resin adhesives, glass ionomer and resin-modified glass ionomer cements and a compomer in contact with dentin caries samples. Oper Dent 25(4), 265-269

Hickel R, Dasch W, Janda R, Tyas M, Anusavice K (1998): New direct restorative materials. FDI Commission Project. Int Dent J 48(1), 3-16

Higuchi WI, Valvani SC, Hefferren JJ (1974): The kinetics and mechanisms of reactions of human tooth enamel in buffered solutions of high fluoride concentrations. Arch Oral Biol 19(9), 737-746

Ho TF, Smales RJ, Fang DT (1999): A 2-year clinical study of two glass ionomer cements used in the atraumatic restorative treatment (ART) technique. Community Dent Oral Epidemiol 27(3), 195-201

Hosoda H, Yamada T, Inokoshi S (1990): SEM and elemental analysis of composite resins. J Prosthet Dent 64(4), 669-676

Hotta M, Li Y, Sekine I (2001): Mineralization in bovine dentin adjacent to glass-ionomer restorations. J Dent 29(3), 211-215

Irie M, Suzuki K (2002): Effects of delayed polishing on gap formation of cervical restorations. Oper Dent 27(1), 59-65

Irie M, Tjandrawinata R, Suzuki K (2003): Effect of delayed polishing periods on interfacial gap formation of Class V restorations. Oper Dent 28(5), 552-559

Kalsbeek H, Verrips GH (1994): Consumption of sweet snacks and caries experience of primary school children. Caries Res 28(6), 477-483

Karantakis P, Helvatjoglou-Antoniades M, Theodoridou-Pahini S, Papadogiannis Y (2000): Fluoride release from three glass ionomers, a compomer, and a composite resin in water, artificial saliva, and lactic acid. Oper Dent 25(1), 20-25

Kawai K, Tantbirojn D, Kamalawat AS, Hasegawa T, Retief DH (1998): In vitro enamel and cementum fluoride uptake from three fluoride-containing composites. Caries Res $\underline{32(6)}$, 463469

Khan AM, Suzuki H, Nomura Y, Taira M, Wakasa K, Shintani H, Yamaki M (1992):

Characterization of inorganic fillers in visible-light-cured dental composite resins. J Oral Rehabil 19(4), 361-370

Kidd EA (1976): Microleakage in relation to amalgam and composite restorations. A laboratory study. Br Dent J 141(10), 305-310 
Kidd EA (1991): The caries status of tooth-coloured restorations with marginal stain. $\mathrm{Br}$ Dent J 171(8), 241-243

Kidd EA, O'Hara JW (1990): The caries status of occlusal amalgam restorations with marginal defects. J Dent Res $\underline{69(6)}, 1275-1277$

Kidd EA, Toffenetti F, Mjör IA (1992): Secondary caries. Int Dent J 42(3), 127-138

Kidd EA, Joyston-Bechal S, Beighton D (1995): Marginal ditching and staining as a predictor of secondary caries around amalgam restorations: a clinical and microbiological study. J Dent Res $\underline{74(5)}, 1206-1211$

Kleverlaan CJ, Feilzer AJ (2005): Polymerization shrinkage and contraction stress of dental resin composites. Dent Mater 21(12), 1150-1157

Klinger HG, Wiedemann W (1985): Grenzen der Remineralisierbarkeit initialer Karies. Dtsch Zahnärztl Z 40(1), 16-22

Klinkenberg E, Bibby BG (1950): The effect of topical applications of fluorides on dental caries in young adults. J Dent Res 29(1), 4-7

Komori A, Ishikawa H (1999): The effect of delayed light exposure on bond strength: lightcured resin-reinforced glass ionomer cement vs light-cured resin. Am J Orthod Dentofacial Orthop $\underline{116(2)}$, 139-145

Kotsanos N (2001): An intraoral study of caries induced on enamel in contact with fluoridereleasing restorative materials. Caries Res 35(3), 200-204

Krämer N, Kunzelmann KH, Pollety T, Pelka M, Hickel R (1994): Langzeiterfahrungen mit Cerment-Zementfüllungen in Klasse-I/-II-Kavitäten. Dtsch ZahnärztI Z 49(11), 905-909

Krämer N, Hickel R, Müßig D (1996): Kariesprävalenz und Kieferfehlbildungen im Milchgebiß. Dtsch Zahnärztl Z 51(10), 575-578

Krämer N, García-Godoy F, Reinelt C, Frankenberger R (2006): Clinical performance of posterior compomer restorations over 4 years. Am J Dent 19(1), 61-66

Krejci I, Lutz F (1991): Marginal adaptation of Class V restorations using different restorative techniques. J Dent 19(1), 24-32

Kwon YH, Kwon TY, Ong JL, Kim KH (2002): Light-polymerized compomers: coefficient of thermal expansion and microhardness. J Prosthet Dent 88(4), 396-401

Lammers PC, Borggreven JM, Driessens FC, Van Dijk JW (1991): Influence of fluoride and carbonate on in vitro remineralization of bovine enamel. J Dent Res 70(6), 970-974

Latorre-García M, Alvarez-Gayosso C, Barceló-Santana F, Vera-Graziano R (2006): Study of shrinkage-strain and contraction rates of commercial and experimental compomers. Dent Mater 22(11), 1063-1070 
Lee SY, Dong DR, Huang HM, Shih YH (2000): Fluoride ion diffusion from a glass-ionomer cement. J Oral Rehabil 27(7), 576-586

Lees S (1968): Specific acoustic impedance of enamel and dentine. Arch Oral Biol 13(12), 1491-1500

Lennon AM, Wiegand A, Buchalla W, Attin T (2007): Approximal caries development in surfaces in contact with fluoride-releasing and non-fluoride-releasing restorative materials: an in situ study. Eur J Oral Sci 115(6), 497-501

Letzel H (1989): Survival rates and reasons for failure of posterior composite restorations in multicentre clinical trial. J Dent $\underline{17}$, Suppl 1, 10-17

Leverett DH, Adair SM, Vaughan BW, Proskin HM, Moss ME (1997): Randomized clinical trial of the effect of prenatal fluoride supplements in preventing dental caries. Caries Res $\underline{31(3)}$, 174-179

Li Y, Swartz ML, Phillips RW, Moore BK, Roberts TA (1985): Effect of filler content and size on properties of composites. J Dent Res $\underline{64(12)}$, 1396-1401

Limeback $H$ (1999): A re-examination of the pre-eruptive and post-eruptive mechanism of the anti-caries effects of fluoride: is there any anti-caries benefit from swallowing fluoride? Community Dent Oral Epidemiol 27(1), 62-71

Lin CT, Lee SY, Keh ES, Dong DR, Huang HM, Shih YH (2000): Influence of silanization and filler fraction on aged dental composites. J Oral Rehabil 27(11), 919-926

Loesche WJ, Murray RJ, Mellberg JR (1973): The effect of topical acidulated fluoride on percentage of Streptococcus mutans and Streptococcus sanguis in interproximal plaque samples. Caries Res 7(4), 283-296

Mair LH (1995): Wear patterns in two amalgams and three posterior composites after 5 years' clinical service. J Dent 23(2), 107-112

Maltz M, Oliveira EF, Fontanella V, Carminatti G (2007): Deep caries lesions after incomplete dentine caries removal: 40-month follow-up study. Caries Res $\underline{41(6)}$, 493-496

Mandari GJ, Frencken JE, Van't Hof MA (2003): Six-year success rates of occlusal amalgam and glass-ionomer restorations placed using three minimal intervention approaches. Caries Res $\underline{37(4)}$, 246-253

Manhart J, Chen HY, Mehl A, Weber K, Hickel R (2001): Marginal quality and microleakage of adhesive class $\mathrm{V}$ restorations. J Dent 29(2), 123-130

Marks LA, Weerheijm KL, van Amerongen WE, Groen HJ, Martens LC (1999): Dyract versus Tytin Class II restorations in primary molars: 36 months evaluation. Caries Res 33(5), 387-392 
Marks LA, Verbeeck RM, De Maeyer EA, Martens LC (2000): Effect of a neutral citrate solution on the fluoride release of resin-modified glass ionomer and polyacid-modified composite resin cements. Biomaterials 21(19), 2011-2016

Marshall GW, Olson LM, Lee CV (1975): SEM investigation of the variability of enamel surfaces after simulated clinical acid etching for pit and fissure sealants. J Dent Res 54(6), 1222-1231

Mathis RS, Ferracane JL (1989): Properties of a glass-ionomer/resin-composite hybrid material. Dent Mater $\underline{\text { (5) }}$, 355-358

Mayer T, Lenhard M, Pioch T (1996): Der Einfluß plastischer Füllungsmaterialien auf das Demineralisationsverhalten von Zahnschmelz. Dtsch Zahnärztl Z 51(6), 235-237

Mazzaoui SA, Burrow MF, Tyas MJ (2000): Fluoride release from glass ionomer cements and resin composites coated with a dentin adhesive. Dent Mater 16(3), 166-171

McKay FS (1952): The study of mottled enamel (dental fluorosis). J Am Dent Assoc 44(2), 133-137

Meiers JC, Miller GA (1996): Antibacterial activity of dentin bonding systems, resin-modified glass ionomers, and polyacid-modified composite resins. Oper Dent 21(6), 257-264

Mellberg JR (1992): Hard-tissue substrates for evaluation of cariogenic and anti-cariogenic activity in situ. J Dent Res $\underline{71(5)}$, 1169-1172

Mellberg JR, Loertscher KL (1974): Comparison of in vitro fluoride uptake by human and bovine enamel from acidulated phosphate-fluoride solutions. J Dent Res 53(1), 64-67

Mellberg JR, Laakso PV, Nicholson CR (1966): The acquisition and loss of fluoride by topically fluoridated human tooth enamel. Arch Oral Biol 11(12), 1213-1220

Millar BJ, Robinson PB, Inglis AT (1997): Clinical evaluation of an anterior hybrid composite resin over 8 years. Br Dent J 182(1), 26-30

Miller WD: Die Mikroorganismen der Mundhöhle. Thieme Verlag, Leipzig 1889

Mirth DB, Adderly DD, Monell-Torrens E, Amsbaugh SM, Li SH, Bowen WH (1985):

Comparison of the cariostatic effect of topically and systemically administered controlledrelease fluoride in the rat. Caries Res $\underline{19(5)}, 466-474$

Miyazaki K, Horibe T (1988): Polymerization of multifunctional methacrylates and acrylates. J Biomed Mater Res 22(11), 1011-1022

Mjör IA (2005): Clinical diagnosis of recurrent caries. J Am Dent Assoc 136(10), 1426-1433.

Mjör IA, Jokstad A (1993): Five-year study of Class II restorations in permanent teeth using amalgam, glass polyalkenoate (ionomer) cerment and resin-based composite materials. J

Dent 21(6), 338-343 
Mjör IA, Jokstad A, Qvist V (1990): Longevity of posterior restorations. Int Dent J 40(1), 11-17

Momoi Y, McCabe JF (1993): Fluoride release from light-activated glass ionomer restorative cements. Dent Mater 9(3), 151-154

Moreno EC, Zahradnik RT (1973): The pore structure of human dental enamel. Arch Oral Biol 18(8), 1063-1080

Mount GJ (1986): Longevity of glass ionomer cements. J Prosthet Dent 55(6), 682-685

Mundorff-Shrestha SA, Featherstone JD, Eisenberg AD, Cowles E, Curzon ME, Espeland MA, Shields CP (1994): Cariogenic potential of foods. II. Relationship of food composition, plaque microbial counts, and salivary parameters to caries in the rat model. Caries Res 28(2), 106115

Nakamichi I, Iwaku M, Fusayama T (1983): Bovine teeth as possible substitutes in the

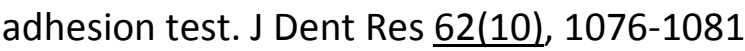

Ngo H, Earl A, Mount GJ (1986): Glass-ionomer cements: a 12-month evaluation. J Prosthet

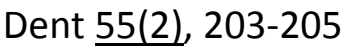

Nicholson CR, Mellberg JR (1969): Effect of natural fluoride concentration of human tooth enamel on fluoride uptake in vitro. J Dent Res $\underline{48(2)}$, 302-306

Nicholson JW, Czarnecka B. (2004): The release of ions by compomers under neutral and acidic conditions. J Oral Rehabil 31(7), 665-670

Nicolaisen S, von der Fehr FR, Lunder N, Thomsen I (2000): Performance of tunnel restorations at 3-6 years. J Dent 28(6), 383-387

Nikolaenko SA, Lohbauer U, Roggendorf M, Petschelt A, Dasch W, Frankenberger R (2004): Influence of c-factor and layering technique on microtensile bond strength to dentin. Dent Mater 20(6), 579 - 585

Oesterle $\amalg$, Shellhart WC, Belanger GK (1998): The use of bovine enamel in bonding studies. Am J Orthod Dentofacial Orthop 114(5), 514-519

$\varnothing$ gaard B (2001): $\mathrm{CaF}_{2}$ formation: cariostatic properties and factors of enhancing the effect. Caries Res $\underline{35}$, Suppl 1, 40-44

Øgaard B, Rölla G, Ruben J, Dijkman T, Arends J (1988): Microradiographic study of demineralization of shark enamel in a human caries model. Scand J Dent Res 96(3), 209-211 Opdam NJ, Roeters JJ, Kuijs R, Burgersdijk RC (1998): Necessity of bevels for box only Class II composite restorations. J Prosthet Dent 80(3), 274-279

Pallesen U, Qvist V (2003): Composite resin fillings and inlays. An 11-year evaluation. Clin Oral Investig $\underline{7(2)}, 71-79$ 
Papagiannoulis L, Kakaboura A, Eliades G (2002): In vivo vs in vitro anticariogenic behavior of glass-ionomer and resin composite restorative materials. Dent Mater $\underline{18(8)}$, 561-569

Pearce El (1983): A microradiographic and chemical comparison of in vitro systems for the simulation of incipient caries in abraded bovine enamel. J Dent Res 62(9), 969-974

Pearnchob N, Dashevsky A, Bodmeier R (2004): Improvement in the disintegration of shellaccoated soft gelatin capsules in simulated intestinal fluid. J Control Release 94(2-3), 313-321

Pereira PN, Inokoshi S, Tagami J (1998 a): In vitro secondary caries inhibition around fluoride releasing materials. J Dent 26(5-6), 505-510

Pereira PN, Inokoshi S, Yamada T, Tagami J (1998 b): Microhardness of in vitro caries inhibition zone adjacent to conventional and resin-modified glass ionomer cements. Dent Mater 14(3), 179-185

Phantumvanit P, Songpaisan Y, Pilot T, Frencken JE (1996): Atraumatic restorative treatment (ART): a three-year community field trial in Thailand--survival of one-surface restorations in the permanent dentition. J Public Health Dent 56(3), 141-145

Pieper K, Meyer G, Marienhagen B, Motsch A (1991): Eine Langzeitstudie an Amalgam und Kunststoff-Füllungen. Dtsch Zahnärztl Z 46(3), 222-225

Pilebro CE, van Dijken JW (2001): Analysis of factors affecting failure of glass cermet tunnel restorations in a multi-center study. Clin Oral Investig 5(3), 96-101

Poureslami HR, Torkzadeh M, Sefadini MR (2007): Study of changes in phosphate, calcium and fluoride ions in plaque and saliva after the administration of a fluoride mouth rinse. $J$ Indian Soc Pedod Prev Dent 25(3), 122 -125

Powis DR, Follerås T, Merson SA, Wilson AD (1982): Improved adhesion of a glass ionomer cement to dentin and enamel. J Dent Res $\underline{61(12)}, 1416-1422$

Prati C, Chersoni S, Cretti L, Montanari G (1998): Retention and marginal adaptation of a compomer placed in non-stress-bearing areas used with the total-etch technique: a 3-year retrospective study. Clin Oral Invest 2(4), $168-173$

Prati C, Nucci C, Toledano M, García-Godoy F, Breschi L, Chersoni S (2004): Microleakage and marginal hybrid layer formation of compomer restorations. Oper Dent 29(1), 35-41

Preston AJ, Mair LH, Agalamanyi EA, Higham SM (1999): Fluoride release from aesthetic dental materials. J Oral Rehabil 26(2), 123-129

Quirynen M, Marechal M, Busscher HJ, Weerkamp AH, Darius PL, van Steenberghe D (1990): The influence of surface free energy and surface roughness on early plaque formation. An in vivo study in man. J Clin Periodontol 17(3), 138-144 
Qvist V (1993): Resin restorations: leakage, bacteria, pulp. Endod Dent Traumatol 9(4), 127152

Qvist V, Laurberg L, Poulsen A, Teglers PT (1997): Longevity and cariostatic effects of everyday conventional glass-ionomer and amalgam restorations in primary teeth: three-year results. J Dent Res 76(7), 1387-1396

Qvist V, Laurberg L, Poulsen A, Teglers PT (2004): Class II restorations in primary teeth: 7year study on three resin-modified glass ionomer cements and a compomer. Eur J Oral Sci $\underline{112(2)}, 188-196$

Roulet JF (1994): Marginal integrity: clinical significance. J Dent 22, Suppl 1, 9-12

Roulet JF (1997): Benefits and disadvantages of tooth-coloured alternatives to amalgam. J Dent 25(6), 459-473

Roulet JF, Salchow B, Wald M (1991): Margin analysis of posterior composites in vivo. Dent Mater 7(1), 44-49

Rowe AH (1989): A five year study of the clinical performance of a posterior composite resin restorative material. J Dent $\underline{17}$, Suppl 1, 6-9

Sales D, Sae-Lee D, Matsuya S, Ana ID (2003): Short-term fluoride and cations release from polyacid-modified composites in a distilled water, and an acidic lactate buffer. Biomaterials $\underline{24(10)}, 1687-1696$

Samuel SM, Rubinstein C (2001): Microhardness of enamel restored with fluoride and nonfluoride releasing dental materials. Braz Dent J 12(1), 35-38

Schmidlin PR, Wolleb K, Imfeld T, Gygax M, Lussi A (2007): Influence of beveling and ultrasound application on marginal adaptation of box-only Class II (slot) resin composite restorations. Oper Dent 32(3), 291-297

Shaw AJ, Carrick T, McCabe JF (1998): Fluoride release from glass-ionomer and compomer restorative materials: 6-month data. J Dent 26(4), 355-359

Sheorey DS, Shastri AS, Dorle AK (1991): Effect of variables on the preparation of shellac microcapsules by solvent evaporation technique: Part 1. Int J Pharm 68(1-3), 19-23

Silveira de Araújo C, Incerti da Silva T, Ogliari FA, Meireles SS, Piva E, Demarco FF (2006): Microleakage of seven adhesive systems in enamel and dentin. J Contemp Dent Pract $\underline{7(5)}$, 26-33

Smales RJ (1977): Composite resin restorations: a clinical assessment of two materials. J Dent $\underline{5(4)}, 319-326$

Smales RJ, Gerke DC (1992): Clinical evaluation of four anterior composite resins over five years. Dent Mater 8(4), 246-251 
Smales RJ, Gerke DC, White IL (1990): Clinical evaluation of occlusal glass ionomer, resin, and amalgam restorations. J Dent 18(5), 243-249

Small IC, Watson TF, Chadwick AV, Sidhu SK (1998): Water sorption in resin-modified glassionomer cements: an in vitro comparison with other materials. Biomaterials 19(6), 545-550

Stearns RI (1971): Incorporation of fluoride by human enamel. II. An exothermic chemical process. J Dent Res 50(6), 1575-1579

Suzuki S, Suzuki SH, Cox CF (1996): Evaluating the antagonistic wear of restorative materials when placed against human enamel. J Am Dent Assoc 127(1), 74-80

Svanberg M (1992): Class II amalgam restorations, glass-ionomer tunnel restorations, and caries development on adjacent tooth surfaces: a 3-year clinical study. Caries Res 26(4),_315318

Svanberg M, Mjör IA, Orstavik D (1990): Mutans streptococci in plaque from margins of amalgam, composite, and glass-ionomer restorations. J Dent Res 69(3), 861-864

Swift EJ Jr, Wilder AD Jr, May KN Jr, Waddell SL (1997): Shear bond strengths of one-bottle dentin adhesives using multiple applications. Oper Dent 22(5), 194-199

Takagi S, Liao H, Chow LC (2000): Effect of tooth-bound fluoride on enamel demineralization/remineralization in vitro. Caries Res 34(4), 281-288

Tam LE, Pilliar RM (1994): Fracture surface characterization of dentin-bonded interfacial fracture toughness specimens. J Dent Res $\underline{73(3)}$, 607-619

Tam LE, Chan GP, Yim D (1997): In vitro caries inhibition effects by conventional and resinmodified glass-ionomer restorations. Oper Dent 22(1), 4-14

Tay WM, Braden M (1988): Fluoride ion diffusion from polyalkenoate (glass-ionomer) cements. Biomaterials $\underline{9(5)}$, 454-456

Temin SC, Csuros Z, Mellberg JR (1989): Fluoride uptake from a composite restorative by enamel. Dent Mater $\underline{5(1)}, 64-65$

Ten Cate JM (1990): In vitro studies on the effects of fluoride on de- and remineralization. J Dent Res $\underline{69}$, Spec Iss, 614-619

Ten Cate JM, van Duinen RN (1995): Hypermineralization of dentinal lesions adjacent to glass-ionomer cement restorations. J Dent Res $\underline{74(6)}, 1266-1271$

Tyas MJ (2000): Three-year clinical evaluation of a polyacid-modified resin composite (Dyract). Oper Dent 25(3), 152-154

Van Dijken JW (1999): Longevity of new hybrid restorative materials in class III cavities. J Dent Res 107 (3), 215-219 
Van Dijken JW, Kieri C, Carlén M (1999): Longevity of extensive class II open-sandwich restorations with a resin-modified glass-ionomer cement. J Dent Res $\underline{78(7)}, 1319-1325$

Van Loveren C (1990): The antimicrobial action of fluoride and its role in caries inhibition. J Dent Res $\underline{69}$, Spec No, 676-681

Venkateswarlu P (1990): Evaluation of analytical methods for fluorine in biological and related materials. J Dent Res $\underline{69}$, Spec Iss, 514-521

Verbeeck RM, De Maeyer EA, Marks LA, De Moor RJ, De Witte AM, Trimpeneers LM (1998): Fluoride release process of (resin-modified) glass-ionomer cements versus (polyacidmodified) composite resins. Biomaterials 19(6), 509-519

Vercruysse CW, De Maeyer EA, Verbeeck RM (2001): Fluoride release of polyacid-modified composite resins with and without bonding agents. Dent Mater 17(4), 354-358

Wahab FK, Shaini FJ, Morgano SM (2003): The effect of thermocycling on microleakage of several commercially available composite Class V restorations in vitro. J Prosthet Dent 90(2), 168-174

Wassell RW, McCabe JF, Walls AW (1992): Subsurface deformation associated with hardness measurements of composites. Dent Mater $\underline{8(4)}, 218-223$

Watson PS, Pontefract HA, Devine DA, Shore RC, Nattress BR, Kirkham J, Robinson (2005): Penetration of fluoride into natural plaque biofilms. J Dent Res $\underline{84(5)}, 451-455$

Wefel JS, Harless JD (1981): The effect of topical fluoride agents on fluoride uptake and surface morphology. J Dent Res $\underline{60(11)}$, 1842-1848

Weidmann SM, Weatherell JA, Hamm SM (1967): Variations of enamel density in sections of human teeth. Arch Oral Biol 12(1), 85-97

Weinmann W, Thalacker C, Guggenberger R (2005): Siloranes in dental composites. Dent Mater $\underline{21(1)}, 68-74$

Welbury RR, Walls AW, Murray JJ, McCabe JF (1991): The 5-year results of a clinical trial comparing a glass polyalkenoate (ionomer) cement restoration with an amalgam restoration. Br Dent J 170(12), 177-181

Welbury RR, Shaw AJ, Murray JJ, Gordon PH, McCabe JF (2000): Clinical evaluation of paired compomer and glass ionomer restorations in primary molars: final results after 42 months. Br Dent J 189(2), 93-97

Wesenberg G, Hals E (1980): The structure of experimental in vitro lesions around glass ionomer cement restorations in human teeth. J Oral Rehabil 7(2), 175-184

White DJ, Nancollas GH (1990): Physical and chemical considerations of the role of firmly and loosely bound fluoride in caries prevention. J Dent Res $\underline{69}$, Spec Iss, 587-594 
Whitford GM, Schuster GS, Pashley DH, Venkateswarlu P (1977): Fluoride uptake by Streptococcus mutans 6715. Infect Immun 18(3), 680-687

Wilder AD Jr, May KN Jr, Bayne SC, Taylor DF, Leinfelder KF (1999): Seventeen-year clinical study of ultraviolet-cured posterior composite Class I and II restorations. J Esthet Dent 11(3), 135-142

Williams JA, Billington RW, Pearson GJ (1999): The influence of sample dimensions on fluoride ion release from a glass ionomer restorative cement. Biomaterials 20(14), 13271237

Williams JA, Billington RW, Pearson GJ (2001): A long term study of fluoride release from metal-containing conventional and resin-modified glass-ionomer cements. J Oral Rehabil 28(1), $41-47$

Wilson AD, Kent BE (1972): A new translucent cement for dentistry. The glass ionomer cement. Br Dent J 132(4), 133-135

Witzel MF, Ballester RY, Meira JB, Lima RG, Braga RR (2007): Composite shrinkage stress as a function of specimen dimensions and compliance of the testing system. Dent Mater 23(2), 204-210

Xie J, Powers JM, McGuckin RS (1993): In vitro bond strength of two adhesives to enamel and dentin under normal and contaminated conditions. Dent Mater 9(5), 295-259

Yamamoto H, Iwami Y, Unezaki T, Tomii Y, Tuchitani Y (2000): Fluoride uptake around cavity walls; two-dimensional mapping by electron probe microanalysis. Oper Dent 25(5), 104-112

Yamamoto H, Iwami Y, Unezaki T, Tomii Y, Ebisu S (2001): Fluoride uptake in human teeth from fluoride-releasing restorative material in vivo and in vitro: two-dimensional mapping by EPMA-WDX. Caries Res 35(2), 111-115

Yaman SD, Er O, Yetmez M, Karabay GA (2004): In vitro inhibition of caries-like lesions with fluoride-releasing materials. J Oral Sci $\underline{46(1)}$, 45-50

Yamauti M, Giovannini JFBG, Caixeta RB, Soares LF, Palmieri HEL, Fagundes OR (2009): Fluoride release profile from different dental restorative materials using ion-selektive electrode. Dent Mater 25(5), e25

Yamazaki H, Margolis HC (2008): Enhanced enamel remineralization under acidic conditions in vitro. J Dent Res 87(6), 569-574

Yost KG, van Demark PJ (1978): Growth inhibition of Streptococcus mutans and Leuconostoc mesenteroides by sodium fluoride and ionic tin. Appl Environ Microbiol 35(5), 920-924

Young AM, Rafeeka SA, Howlett JA (2004): FTIR investigation of monomer polymerisation and polyacid neutralisation kinetics and mechanisms in various aesthetic dental restorative materials. Biomaterials 25(5), 823-833 
Zainuddin N, Karpukhina N, Hill RG, Law RV (2009): A long-term study on the setting reaction of glass ionomer cements by ${ }^{27}$ Al MAS-NMR spectroscopy. Dent Mater 25(3), 290-295

Zanata RL, Navarro MF, Barbosa SH, Lauris JR, Franco EB (2003): Clinical evaluation of three restorative materials applied in a minimal intervention caries treatment approach. J Public Health Dent 63(4), 221-226

Ziraps A, Honkala E (2002): Clinical trial of a new glass ionomer for an atraumatic restorative treatment technique in class I restorations placed in Latvian school children. Med Princ Pract 11, Suppl 1, 44-47 


\section{Liste der verwendeten Geräte und Materialien}

\subsection{Geräte und Werkzeuge}

- Adapta Tiefziehsystem - Bego Goldschlägerei Wilh. Herbst GmbH \& Co. KG, Bremen

- Bohrschablone, Sonderanfertigung, wissenschaftliche Werkstätten, Universitätsklinikum Göttingen

- Brutschrank Venticell - Fa. Medcenter Einrichtungen MMM Group, Gräfelfing

- Degulux soft-start, UV-Polymerisationslampe - Dentsply De Trey GmbH, Konstanz

- DIN 7200 genormtes Henkellocheisen Masterline, $\varnothing 6$ mm

- Schneider + Klein Metallwaren GmbH \& Co. KG, Stuttgart

- EXAKT Trennschleifsystem - Apparate GmbH \& Co KG, Norderstedt

- Feinwaage „R $160 P^{\prime \prime}$ - Sartorius AG, Göttingen

- Fluoridelektrode „Combination ISE Fluoride with solid state Membrane“

- Fa. Mettler Toledo, Schweiz

- Garant ${ }^{\circledR}$ Diamant-Zylinderschleifstift D 126, Kopf $\varnothing 5$ mm, abgerundete Kanten

- Hoffmann GmbH, München

- Gilson Pipetman ${ }^{\circledR}$ P, Mikroliterpipetten $10 \mu \mathrm{l}, 100 \mu \mathrm{l}, 200 \mu \mathrm{l}$ und $1000 \mu \mathrm{l}$

- Gilson SAS, Villiers-le-Bel, Frankreich

- Microprocessor pH/Ion Meter pMX 3000 - Fa. WTW, Weilheim

- Mischer Vortex Genie 2 - Fa. Bender \& Hobein, Schweiz

- MOTIC SMZ-168 Zoom Stereomikroskop \& Moticam 1000 USB 2.0 Hochauflösende

Digitalkamera - Beyersdörfer GmbH, Mandelbachtal

- pH-Meter 761 Calimatic - Fa. Knick, Berlin

- Schott Kaltlichtquelle KL 1500 - Schott AG, Mainz

- Standbohrmaschine Metabo T6 electronic - Metabowerke GmbH, Nürtingen

- Universalanmischgerät Silamat - Fa. Vivadent - Schaan, Liechtenstein

- Zeiss Stemi SV 11 Biokularauflichtmikroskop - Carl Zeiss Jena GmbH, Jena

- Zentrifuge MC 6 für PCR-Reaktionsgefäße - Sarstedt AG \& Co.KG, Nümbrecht 


\subsection{Chemikalien und Reagenzien}

- Blattgelatine Typ A, weiß (kollagenes Eiweiß aus Schweineschwarten)

- Gelita Deutschland GmbH, Eberbach

- Fluoridstandardlösung $10 \mathrm{~g} / \mathrm{l}$ Fluorid als NaF - Fa. WTW, Weilheim

- Natriumchlorid (NaCl) - Merck AG, Darmstadt

- Natronlauge $(\mathrm{NaOH}) 1 \mathrm{~mol} / \mathrm{l}$ - Merck AG, Darmstadt

- Salzsäure $(\mathrm{HCl}) 1 \mathrm{~mol} / \mathrm{l}$ - Merck AG, Darmstadt

- Schellack - Eberhard Faber GmbH, Staedler Group, Neumarkt

- Thymol - Fa. Synopharm, Barsbüttel

- TISAB-III-Lösung (Total Ionic Strength Adjustment Buffer) - Merck AG, Darmstadt

\subsection{Verbrauchsmaterialien}

- Absorbent Cotton Pellets No.3 - Produits Dentaires SA, Vevey, Schweiz

- Adaptafolien 0,6 mm - Bego Goldschlägerei Wilh. Herbst GmbH \& Co. KG, Bremen

- Apply-Tips - Hager \& Werken GmbH \& Co KG, Duisburg

- Cocoa Butter for ionomer filling - GC Corporation, Tokyo, Japan

- Dyract ${ }^{\circledR}$ eXtra Kompomer Füllungsmaterial, Farbe A2, Lot 0612000270

-Dentsply De Trey GmbH, Konstanz

- ep TIPS, 2-200 $\mu$ l und 50-1000 $\mu$ I Pipettenspitzen - Eppendorf GmbH, Hamburg

- Ketac ${ }^{\mathrm{TM}}$ Conditioner, 10\%iges Polyacrylsäuregel zur Dentinvorbehandlung

- 3M ESPE AG Dental Products, Seefeld

- Ketac ${ }^{\mathrm{TM}}$ Fil Plus Aplicap ${ }^{\mathrm{TM}}$ Glasionomerzement, Farbe A4, Lot 286420

- 3M ESPE AG Dental Products, Seefeld

- Laborröhrchen, 50 ml - Greiner Bio-One GmbH, Frickenhausen

- Neo Tips Präzisionspipettenspitzen 0,1-10 $\mu \mathrm{l}$

- Neo Lab Migge Laborbedarf-Vertriebs GmbH, Heidelberg

- Parafilm „M“, Labor Film - American Can Company, Greenwich, Connecticut, USA

- PCR-Softubes 0,2 ml, Reaktionsgefäße - Biozym Scientific GmbH, Hess. Oldendorf

- Prime\&Bond ${ }^{\circledR} \mathrm{NT}$, Schmelz-/Dentinadhäsiv - Dentsply De Trey GmbH, Konstanz 
- Safe-Lock Tubes, Reaktionsgefäße, Größe $2 \mathrm{ml}$ und 1,5 ml - Eppendorf AG, Hamburg

- SiC-Naßschleifpapier WS Flex 800, 1200 \& 4000

- Hermes Schleifmittel GmbH \& Co. KG, Hamburg

- Spectrum ${ }^{\circledR}$ Komposit Füllungsmaterial, Farbe B2 - Dentsply De Trey GmbH, Konstanz

- Surgident Periphery Wax - Fa. Heraeus Kulzer GmbH, Hanau

- Tesa ${ }^{\circledR}$-Film - Tesa AG, Hamburg

- Thermoplastic Impression Compound - Fa. Kerr Italia, Scafati Salerno, Italien

- Ultra Etch ${ }^{\circledR}, 35 \%$ iges Phosphorsäuregel

- Ultradent Products Inc., South Jordan, Utah, USA 


\section{Danksagung}

Mein Dank gilt Herrn Prof. Dr. med. dent. Thomas Attin für die Überlassung dieses spannenden Themas. Ich danke Frau Dr. Annette Wiegand für die geduldigen Korrekturen der Doktorarbeit und die Unterstützung während der Anfertigung der Doktorarbeit. Ich danke Herrn Klaus Becker für die Erstellung des Programms für die Umrechnung der Fluoridionenkonzentrationen. Mein Dank gilt ebenfalls den Mitarbeitern des Instituts für Statistik der Universität Göttingen, insbesondere Dr. Klaus Jung, für die Hilfe bei der statistischen Auswertung der Messdaten. 